
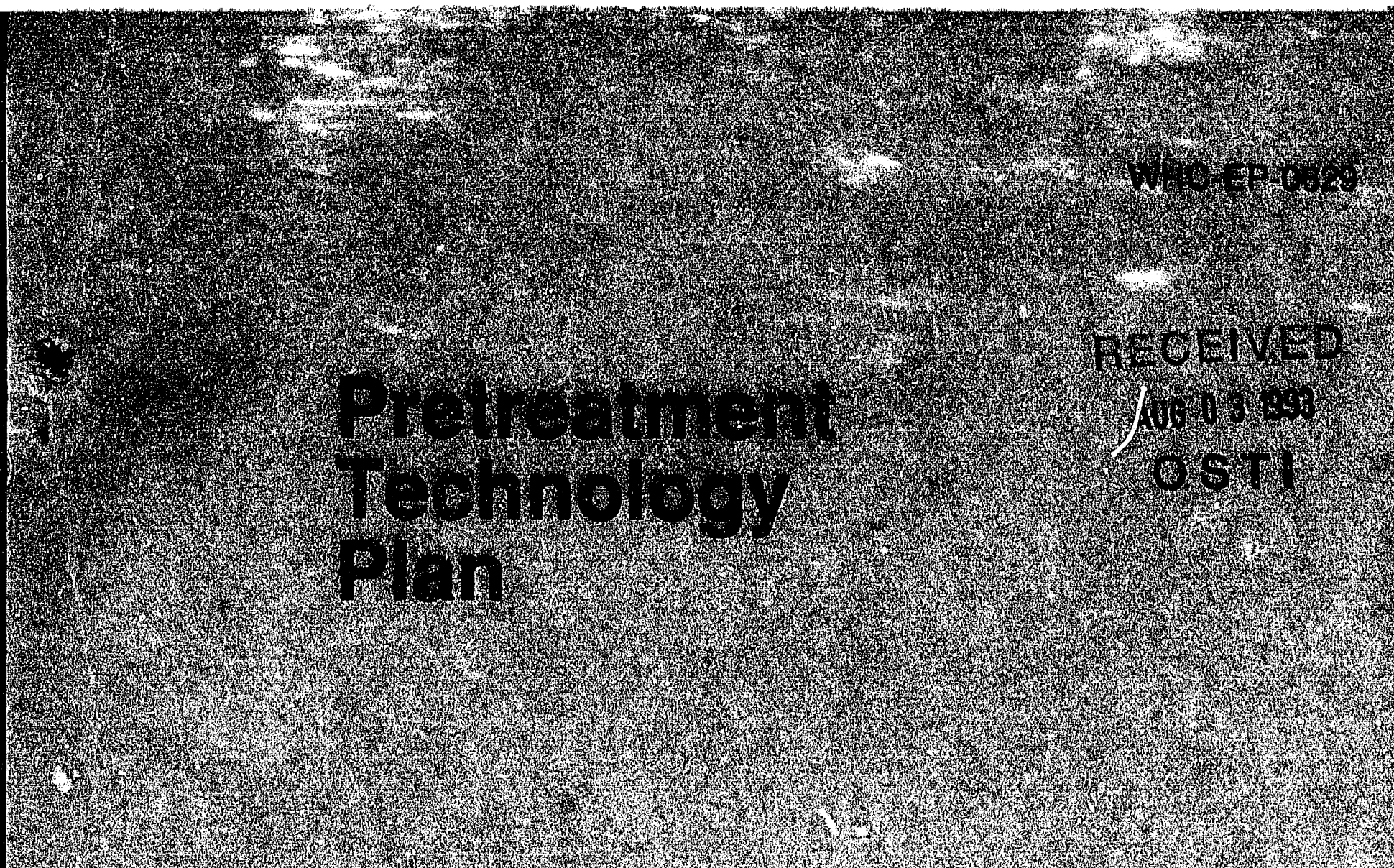

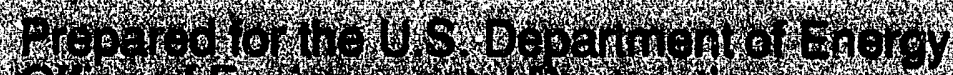

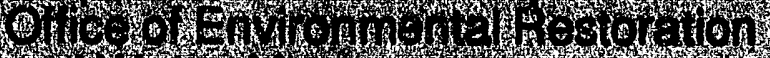

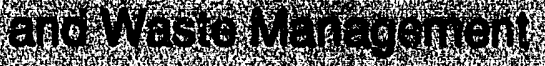

(1)






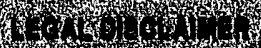

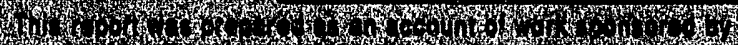

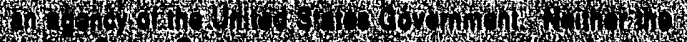

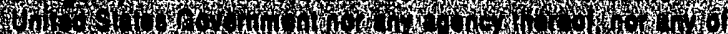

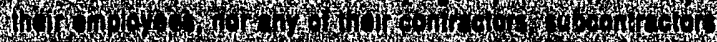

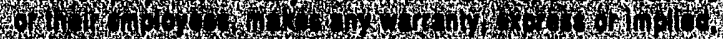

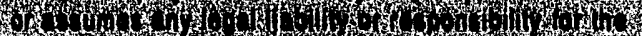

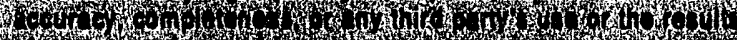

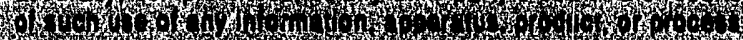

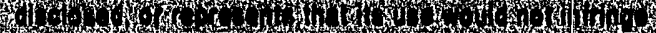

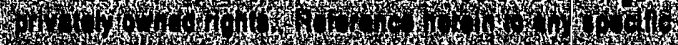

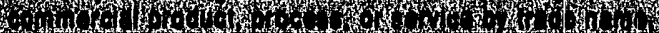

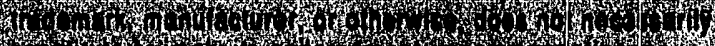
8010 H

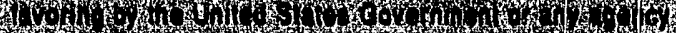
7.

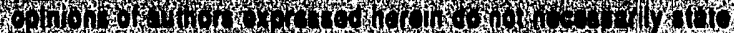

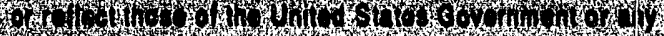
to

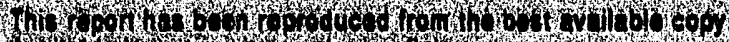

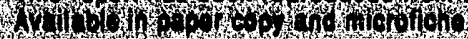

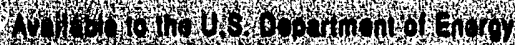

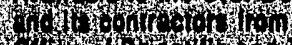


4. 0 .

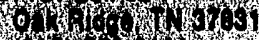

(6) 3106

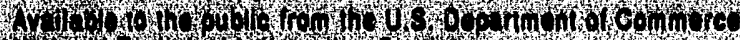
7i

10.

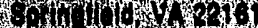
$100 \mathrm{z}, 2 \%$

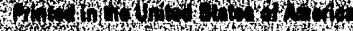
6. 


\section{Pretreatment Technology Plan}

\section{S. A. Barker}

Westinghouse Hanford Company

C. K. Thornhill

L. K. Holton

Pacific Northwest Laboratory

Date Published

March 1993

Prepared for the U.S. Department of Energy Office of Environmental Restoration and Waste Management

\footnotetext{
(W) Westinghouse

P.O. Box 1970

Hantord Compamy Richland, Washington 99352

Hanford Operations and Engineering Contractor for the

U.S. Department of Energy under Contract DE-AC06-87RL10930
} 





WHC-EP-0629

Document Title:

Prepared by:

Prepared by:

Prepared by:

Approved by:
PRETREATMENT TECHNOLOGY PLAN

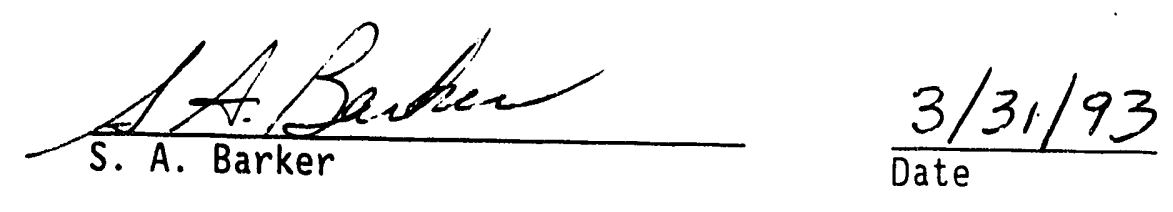

$\frac{3 / 31 / 93}{\text { Date }}$

$\frac{\text { CKT for ZK/tolton, } / 1}{\text { L.K. Horton, Jr. }} \frac{3 / 31 / 93}{\text { Date }}$

Sol X. Appel

$\frac{7130 / 9.3}{\text { Date }}$ 
WHC-EP-0629

This page intentionally left blank. 
WHC-EP-0629

\section{ACKNOWLEDGEMENTS}

The authors of this report would like to acknowledge the efforts and contributions of the following authors and support personnel. Without their contributions, this report could not have been produced. The additional contributors include L. R. Bunnell (PNL), C. D. Carlson (PNL), M. J. Danielson (PNL), K. Eager, E. O. Jones (PNL), M. J. Klem, D. E. Kurath (PNL), B. C. Landeene, G. J. Lumetta (PNL), G. T. MacLean, C. D. Meng, R. M. Orme, M. E. Payne, and L. J. Silva (PNL). 
WHC-EP-0629

This page intentionally left blank. 
FORWARD

The Pretreatment Technology Plan has been prepared to present the technology development work required for the Tank Waste Remediation System (TWRS) Program to meet Hanford Federal Facility Agroment and Consent Order (Tri-Party Agreement) milestones. Specificall;, this program supports the December 1999 startup of the Hanford Waste Vitrification Plant (HWVP) by supplying sludge-washed solids for feed to the facility. Following the startup of the HWVP, pretreatment operations are supported that provide continuous operations of the facility. Additional processing capabilities -either a central facility or distributed compact facilities - - will be brought onl ine in the time period between 2005 and 2015. In addition, process technology will be developed to support efforts to reduce radionuclide concentrations in aqueous streams being immobilized in the low-level waste form.

The development of technology as presented in this report assumes that research and process development activities are not constrained by budgetary and resource (i.e., staffing and facility) limitations. This strategy also presents extensive efforts at the parallel development of redundant processes through the early phases of the program. This developmeni of redundant processes is being performed to reduce program risk due to the early development status of the processes being proposed. As the program progresses and the process technology matures, decision points are presented that reduce the number of processes being carried forward.

Currently, the TWRS program activities are being re-evaluated and reprioritized. Consequently, substantial changes are being made to the TWRS strategy. Originally, this Pretreatment Technology Plan would directly support the TWRS Integrated Technology Plan. However, because of proposed changes in TWRS Program strategy (as a result of direction from the TWRS leadership council) and the required release date of this document, the changes that are being made to the Pretreatment technology planing to support the new proposed TWRS integrated program are not reflected in this release of the Pretreatment Technology Plan. Once the TWRS Program strategy has been developed and agreed to by the parties interested in the environmental restoration of the Hanford Site, this document will be updated and re-released. It is expected that this document will be revised on an annual basis to reflect current program objectives, plans, and status.

Costs pertaining to this program are not presented in this document. Due to the proposed substantial changes to the Pretreatment Program, costs currently developed do not reflect the revised strategy. Projected costs relating to the Pretreatment Technology Program will be published in the Integrated Technology Plan, and in the TWRS Multi-Year Program Plan later this fiscal year. In addition, costs pertaining to pretreatment technology will be published in future revisions of this document. 
WHC-EP-0629

This page intentionally left blank.

viii 
WHC-EP-0629

\section{CONTENTS}

1.0 INTRODUCTION . . . . . . . . . . . . . . . . . 1-1

1.1 BACKGROUND ......................... . . . $1-1$

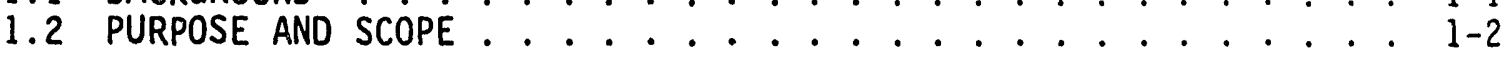

2.0 PRETREATMENT ELEMENT DESCRIPTION .............. 2-1

2.1 NEEDS AND OBJECTIVES ..................... 2-1

2.2 STRATEGY . . . . . . . . . . . . . . 2-1

2.3 PROGRAM ELEMENT FUNCTIONS ............ . . . 2-8

2.4 CURRENT TECHNOLOGY DEVELOPMENT ACTIVITIES . . . . . . . 2-12

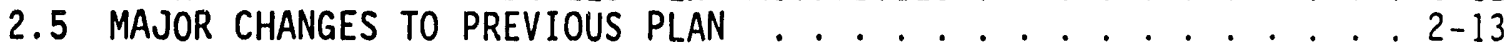

2.6 LIFETIME BUDGET ESTIMATES .................. . . . . . . . . . . .

2.7 PROGRAM ELEMENT MASTER SCHEDULE . . . . . . . . . 2-13

2.7.1 PROGRAM ASSUMPTIONS AND CONSTRAINTS AFFECTING PRETREATMENT TECHNOLOGY DEVELOPMENT . . . . . . . 2-13

3.0 TECHNOLOGY PLANNING RESULTS ................. . . . . . . . . .

3.1 REFERENCE SYSTEM TECHNOLOGY DEVELOPMENT . . . . . . . . . 3-1

3.1.1 Description of the Reference System ......... 3-1

3.1.2 Prioritized Description of Uncertainties and Vulnerabilities Associated with

Reference System . . . . . . . . . . . 3-1

3.1.3 Prioritized Functional Needs ............ . 3-5

3.1.4 Prioritized Technology Development Activities in Response to Functional Needs

3.1.5 Recommended Technology Development Activities .... 3-5

3.1.6 Technology Development Enhancements ........ 3-5

3.2 ALTERNATIVE SYSTEM DEVELOPMENT . . . . . . . . . 3-12

3.2.1 Description of Alternative System/Strategy . . . . . 3-12

3.2.2 Uncertainties and Risks Associated with Alternate System ........... 3-15

3.2.3 Pretreatment Technology Development Activities . . . . 3-15

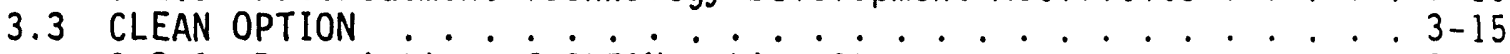

3.3.1 Description of CLEAN Option/Strategy . . . . . . 3-15

3.3.2 Uncertainties and Risks Associated with CLEAN . . . . 3-17

3.3.3 Prioritized Functional Needs . . . . . . . . . . . . . . 3-17

3.3.4 Prioritized Technology Development Activities . . . . 3-17

4.0 TECHNOLOGY PROGRAM DESCRIPTION ............... . . . . .

4.1 TECHNOLOGY PROGRAM DESCRIPTIONS . . . . . . . . . . . . . 4-1

4.1.1 Reference Technology.............. . . 4-1

4.1.2 Pretreatment System Enhancements . . . . . . . . 4-22

4.1.3 Technology Alternatives ............. . . 4-35

4.1 .4 CLEAN . . . . . . . . . . . . . . . . .

4.2 CROSSCUTTING OR TECHNOLOGY DEVELOPMENT SUPPORT ACTIVITIES . . 4-42

4.2 .1 Corrosion Support .............. 4-42

4.2 .2 Pilot-Plant Strategy ........... . . 4-46

4.2.3 Systems. Engineering Studies ... . . . . . . . 4-50

4.2.4 Thermodynamic Modeling of Waste Tank Constituents . . 4-51 
WHC-EP-0629

\section{CONTENTS (continued)}

4.3 SCHEDULE

4.3.1 PROGRAM ASSUMPTIONS AND CONSTRAINTS

AFFECTING PRETREATMENT TECHNOLOGY



4.5 TIME PHASED BUDGET ESTIMATES

4.5 TIME-PHASED BUDGET ESTIMATES . . . . . . . . . . . . . . . . . . . . . . 4 4-58

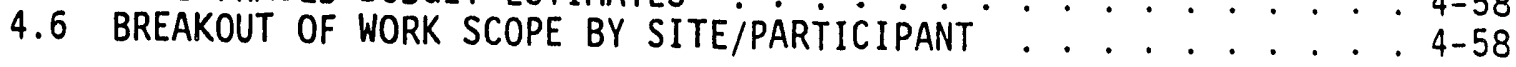

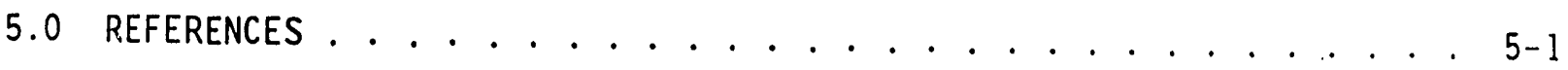

\section{APPENDIXES}

A PRETREATMENT MASTER SCHEdULE................... . . . APP A-l 
WHC-EP-0629

\section{LIST OF FIGURES}

2-1 Functional Flow Diagram for TWRS-Developed

Pretreatment Technology Option .............. . 2-4

2-2 Functional Flow Diagram for TWRS Draft

Reference Pretreatment Option ............ 2-5

2-3 Functional Flow Diagram for TWRS Extended

Pretreatment with Recycle (CLEAN) Option . . . . . . . . . . 2-6 
WHC-EP-0629

\section{LIST OF TABLES}

2-1 Fiscal Year 1993 Pretreatment Technology Development Activities . . 2-12

3-1 Prioritized Technology Development Activities--

Reference Pretreatment System ............... . 3-6

3-3 Prioritized Technology Development Activities--

Pretreatment System Enhancements .............. . 3-11

4-1 Sludge Washing Milestones .................. . 4-4

4-2 Ion Exchange Technology Schedule ............... . 4-7

4-3 Organic/Ferrocyanide Destruction Milestones .......... . 4-10

4-4 Selective Leaching Milestones ................. . 4-13

4-5 Blending Milestones................... . 4-14

4-6 Sludge Dissolution Milestones ................ . 4-16

4-7 TRU Removal Milestones ................... 4-20

4-8 Strontium Removal Milestones ................. . 4-22

4-9 Alternate TRU Removal Milestones .............. . 4-25

4-10 Strontium and TRU Removal on Basic Side . . . . . . . . . . . . 4-27

4-11 Cesium Removal (Acid Side) Milestones............. . 4-28

4-12 Nitrate Removal Milestones .................. . 4-29

4-13 Iodine Removal Milestones ................. . 4-31

4-14 Technetium Removal Milestones................ . 4-33

4-15 Low-Level Waste Organic Destruction Milestones . . . . . . . . 4-34

4-16 Milestones for SREX Process Development . . . . . . . . . . 4-36

4-17 Sludge Leaching Milestones . . . . . . . . . . . . . . 4-37

4-18 Calcine/Leach Milestones ................. . . 4-39

4-19 Clean Option Technical Issues . . . . . . . . . . . . . . 4-40

4-20 CLEAN Option Functional Needs . . . . . . . . . . . . . . . 4-41

4-21 Long-Term Milestones for Corrosion Support . . . . . . . . . . . 4-43 
WHC-EP-0629

LIST OF TABLES (continued) 4-22 Summary of Technical Information Needs for Pretreatment
Process Testing

4-23 Thermodynamic Modeling Milestones .............. . 4-52

4-24 Ongoing Pretreatment Technology Activities Other

than the Hanford Site or Funded by EM-50 . . . . . . . . . . . . . 4-59 


\section{LIST OF TERMS}




WHC-EP-0629

\section{LIST OF TERMS (continued)}

$\begin{array}{ll}\text { WFQ } & \text { waste form qualification } \\ \text { WHC } & \text { Westinghouse Hanford Company } \\ \text { WOL } & \text { wedge-opening loading } \\ \text { WSCP } & \text { water soluble chelating polymers }\end{array}$




\section{WHC-EP-0629}

This page intentionally left blank. 


\subsection{INTRODUCTION}

\subsection{BACKGROUND}

The U.S. Department of Energy (DOE) established the Tank Waste Remediation System (TWRS) to safely manage and dispose of the radioactive wastes (current and future) stored in double-shell tanks (DST) and single-shell tanks (SST) at the Hanford Site. TWRS is composed of six major program elements, including Pretreatment, which is the subject of this technology plan. Before TWRS was formed, pretreatment development was based on the Record of Decision (ROD) (DOE 1988) from the Hanford Defense Waste-Environmental Impact Statement (HDW-EIS) (DOE 1987), which only addressed DST wastes. At that time needs were identified for dissolving soluble salts through sludge washing, removing cesium by ion exchange, and extracting transuranics (TRU) based on solvent extraction (SX) processes. These, plus many other alternative processes, are now being evaluated for application to TWRS as part of the rebaselining development effort associated with the disposal of both the DSTS and SSTs.

A national technology workshop was held in June 1992 as part of the TWRS technology planning efforts. During this workshop, a pretreatment technology working group (TWG) met to identify, evaluate, and prioritize candidate technologies in a systematic manner, as was done by each of the other program elements. This process, the workshop participants, and the results are summarized in the Proceedings from the workshop. TWRS National Technology Workshop. Nine pretreatment systems were presented to the TWG, which had previously been evaluated on the basis of cost, schedule compatibility, technical performance, Environmental Safety and Health (ES\&H), and institutional acceptance. The TWG identified functional needs, which are specific capabilities required to implement a pretreatment system, and evaluated on the basis of centrality to the system, uncertainty reduction, urgency, and enhancement potential. Then, known technologies were identified for each functional need and evaluated on the basis of needs met, technical feasibility, schedule compatibility, and cost.

This plan summarizes the results of the workshop and other working group meetings as follows.

- The objectives for tank waste pretreatment processes were identified.

- Pretreatment systems to satisfy the objectives were evaluated.

- The functional needs for each system were determined.

- Technologies for each of the functional needs were prioritized.

This plan also presents a strategy for implementing the technology development activities required to support the pretreatment of Hanford site tank wastes. This plan, and similar plans for each of the other program elements, will be summarized in the TWRS integrated technology plan (ITP). 


\subsection{PURPOSE AND SCOPE}

This technology plan presents a strategy for the identification, evaluation, and development of technologies for the pretreatment of wastes stored in underground storage tanks at the Hanford Site. This strategy includes deployment of facilities and process development schedules to support the other program elements. This document also presents schedule information for alternative pretreatment systems: (1) the reference pretreatment technology development system (2) an enhanced pretreatment technology development system, and (3) alternative pretreatment technology development systems. These system alternatives are discussed in section 2.2. 
WHC-EP-0629

\subsection{PRETREATMENT ELEMENT DESCRIPTION}

\subsection{NEEDS AND OBJECTIVES}

The mission for the TWRS is to provide treatment, storage, and disposal of waste in a safe, cost-effective, and environmentally sound manner. As an element of TWRS, waste pretreatment is needed to pretreat tank wastes, to resolve tank safety issues, and to separate wastes into high-level and low-level fractions for subsequent immobilization and disposal. The following are specific objectives.

- Investigate and develop approaches to destroy organics and ferrocyanides in tank wastes so the wastes can be safely stored until facilities are available to retrieve and process them for disptisal. Organics, ferrocyanides, hydrogen generation, and high heat have been identified as critical safety issues associated with storage of waste in tanks. This is the highest priority objective for pretreatment.

- Pretreat the wastes to separate the low-level and high-level fractions while al so reducing the number of canisters of high-level waste (HLW) generated.

- Remove chemical and radiochemical constituents from the low-level waste (LLW) to meet the LLW form feed requirements. The 1 imits for radionuclides and hazardous chemicals in $L L W$ have not yet been definitively established and could vary between waste types.

- Support development and demonstration of vitrification technology through provision of representative HLW feeds to the Hanford Waste Vitrification Plant (HWVP) bench-scale melter.

- Design and develop pretreatment processes that accomplish the above objectives in a manner that minimizes risk of non-compliance with environmental regulations.

\subsection{STRATEGY}

Several program options are being evaluated for disposal of the tank wastes to establish the preferred program. These options include pretreatment processes ranging from minimal separations of the $H L W$ and $L L W$ to advanced separation processes that dramatically reduce the volume of HLW and LLW produced and/or reduce the chemical toxicity of the LLW. Each of the options described below addresses one or more pretreatment objectives.

- Developed (or Minimum) Pretreatment Technology System. This option incorporates sludge washing and cesium ion exchange to remove the bulk of the nonradioactive elements soluble ir, a basic solution from most radioactive elements, which are insoluble in basic solution. 
Destruction of organics and ferrocyanides to resolve related tank safety issues is also included. This option incorporates blending of waste streams to minimize the volume of HLW and the number of unique feed types to the HWVP. Sludge washing, cesium ion exchange, organic/ferrocyanide destruction, and blending are included in all tank waste pretreatment options.

This option produces approximately $38,000 \mathrm{HLW}$ canisters $(0.6 \mathrm{~m}$ [2 ft] diameter by $3.05 \mathrm{~m}[10 \mathrm{ft}]$ long) and 180 grout vaults.

This option has the following advantages.

- In-tank sludge washing generates little secondary waste.

- This option can be deployed early with less technical uncertainty.

This option has the following disadvantages.

- The volume of HLW will exceed the amount that can be vitrified within the current design life of the HWVP.

- Transportation and repository disposal costs are higher than costs for other options (although the total life-cycle cost may be lower).

- Draft Reference Pretreatment system. This option includes the minimum pretreatment technologies and adds sludge dissolution followed by TRU and strontium removal. These processes are based on acid dissolution of the metal hydroxide sludge followed by TRU and strontium extraction. This increases the LLW fraction while reducing the volume of HLW waste. Several process options are candidates to provide these more aggressive separations, although a development program is needed to investigate and select the appropriate processes. This option would be deployed in phases to resolve tank safety issues as a priority and to bring mature technologies online in the near term, while required technology development activities are completed.

This option produces approximately 11,000 HLW canisters and 270 grout vaults.

This option has the following advantages.

- This option reduces the volume of vitrified HLW to an amount which can be vitrified within the current HWVP design life.

- This option dramatically reduces the repository disposal costs compared with the Minimum Pretreatment option. 
This option has the following disadvantages.

- The proposed separations processes have increased technical uncertainties compared to the Minimum Pretreatment System.

- This proposed option slightly increases radionuclides in LLW for onsite disposal.

- Capital and operating costs are higher than for the Minimum Technology Pretreatment System.

- Extensive Pretreatment with Material. Recycle (CLEAN). The CLEAN option uses technology requiring extensive research and development to provide minimum volumes of HLW and LLW by destroying and/or separating many of the components not treated by the first two options. Sludge dissolution, organic destruction, and advanced radionuclide extraction are the basic processes. Extensive chemical recovery and recycling are added to avoid generating additional chemical waste to the LLW stream.

This option produces approximately 1,000 to 2,000 HLW canisters and 100 to 150 grout vaults.

This option has the following advantages.

- This option sends the smallest volume of HLW to the repository by extensive extraction and concentration of radionuclides and removal of nonradioactive constituents in the waste.

- The LLW fraction may be low enough in radionuclides and hazardous material that current grout vault barriers and containment can be reduced or el iminated.

This option has the following disadvantages.

- Many of the processes will require substantial technical development and currently have high technical uncertainties because of their limited state of development.

- This option may be very complex to operate because of the size and number of new processes involved.

- Process development and facility costs are not well defined, but are expected to be higher than any of the other options.

Figures 2-1, 2-2, and 2-3 provide functional flow diagrams of the three pretreatment options described above. These span the anticipated range of alternatives being considered in the development of the overall TWRS baseline. The baseline TWRS strategy is anticipated to be selected from one of the three options, or will be a hybrid based on these options. 
Figure 2-1. Functional Flow Diagram for TWRS-Developed Pretreatment Technology Option.

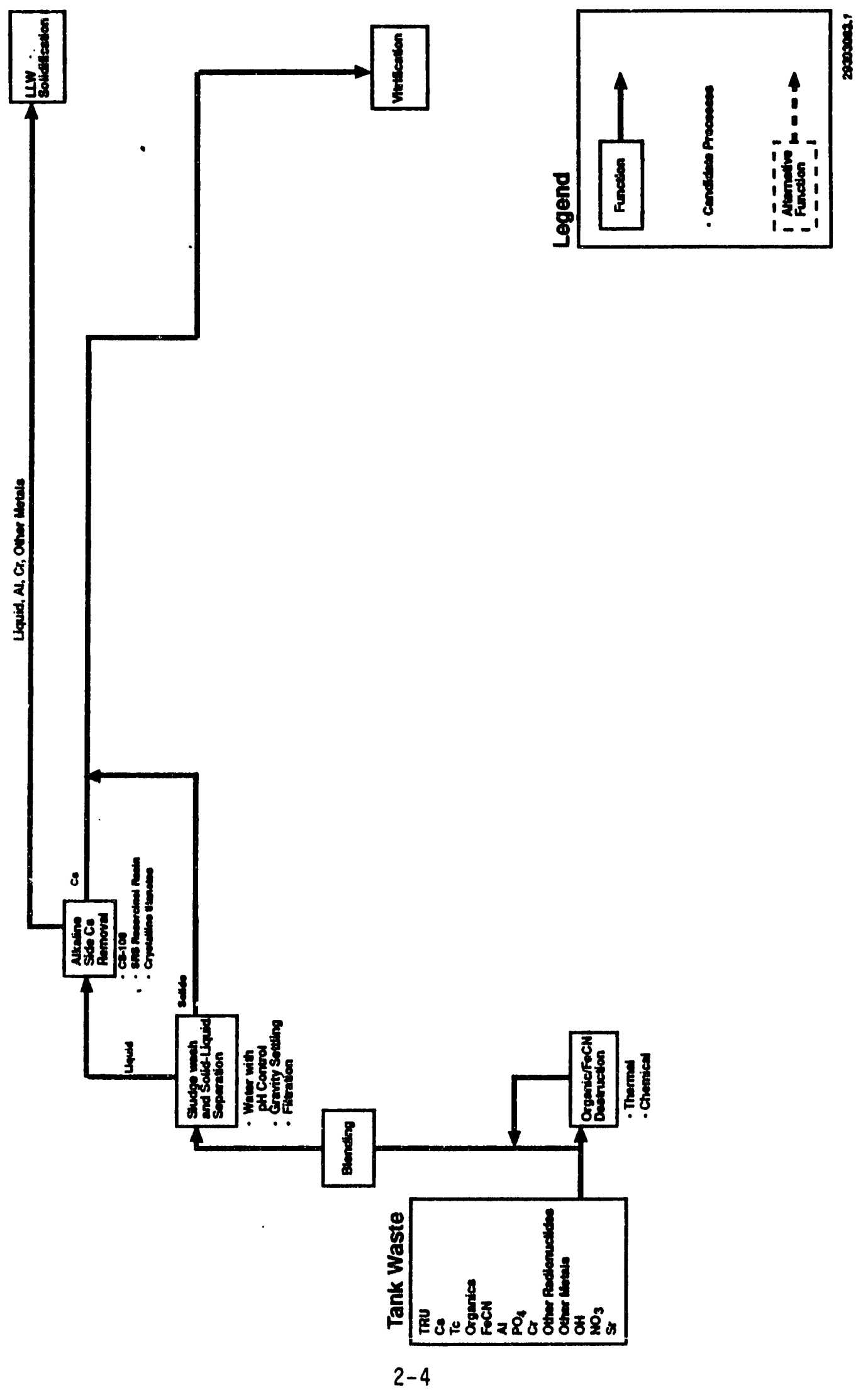


Figure 2-2. Functional Flow Diagram for TWRS Draft Reference Pretreatment Option.

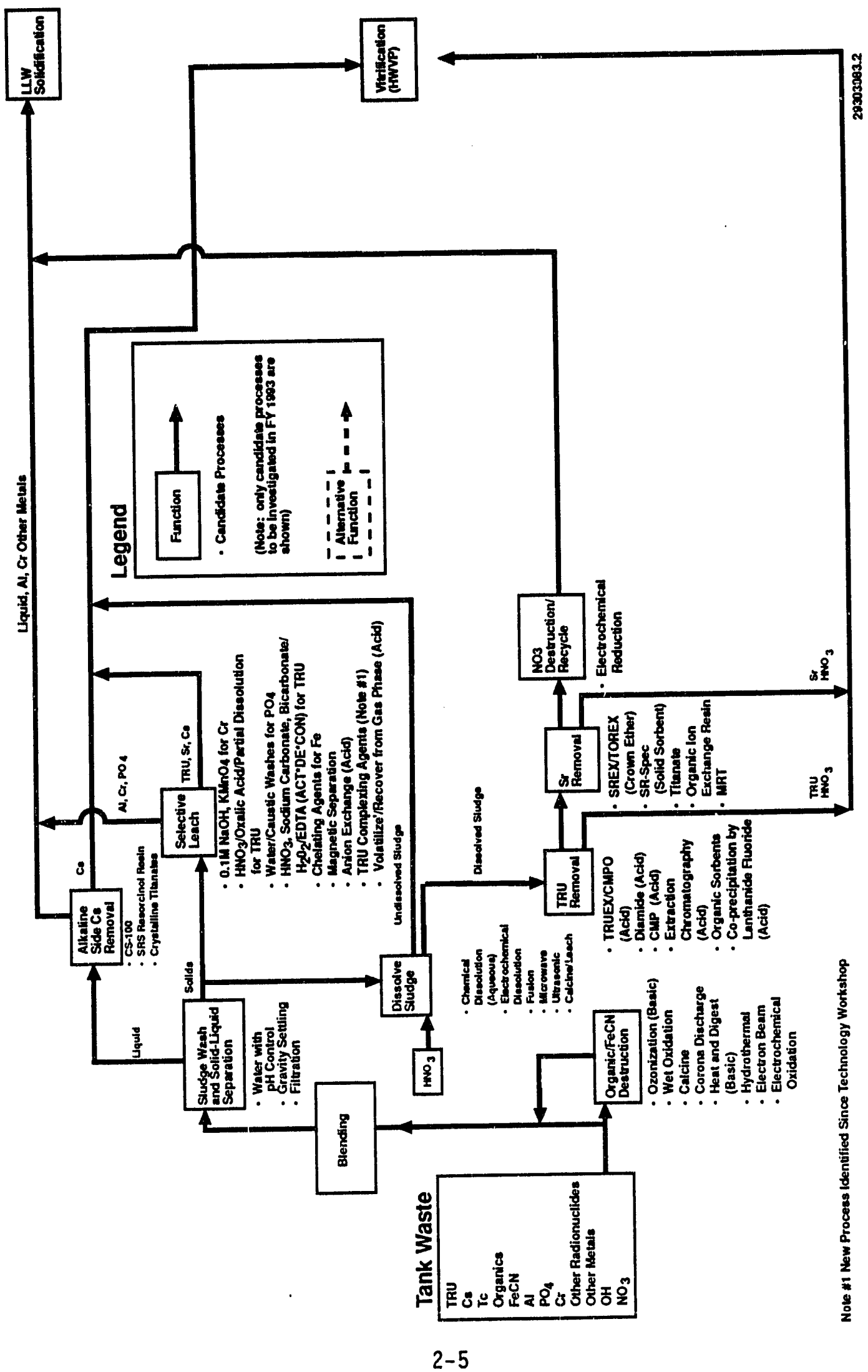


Figure 2-3. Functional Flow Diagram for TWRS Extended Pretreatment with Recycle (CLEAN) Option.

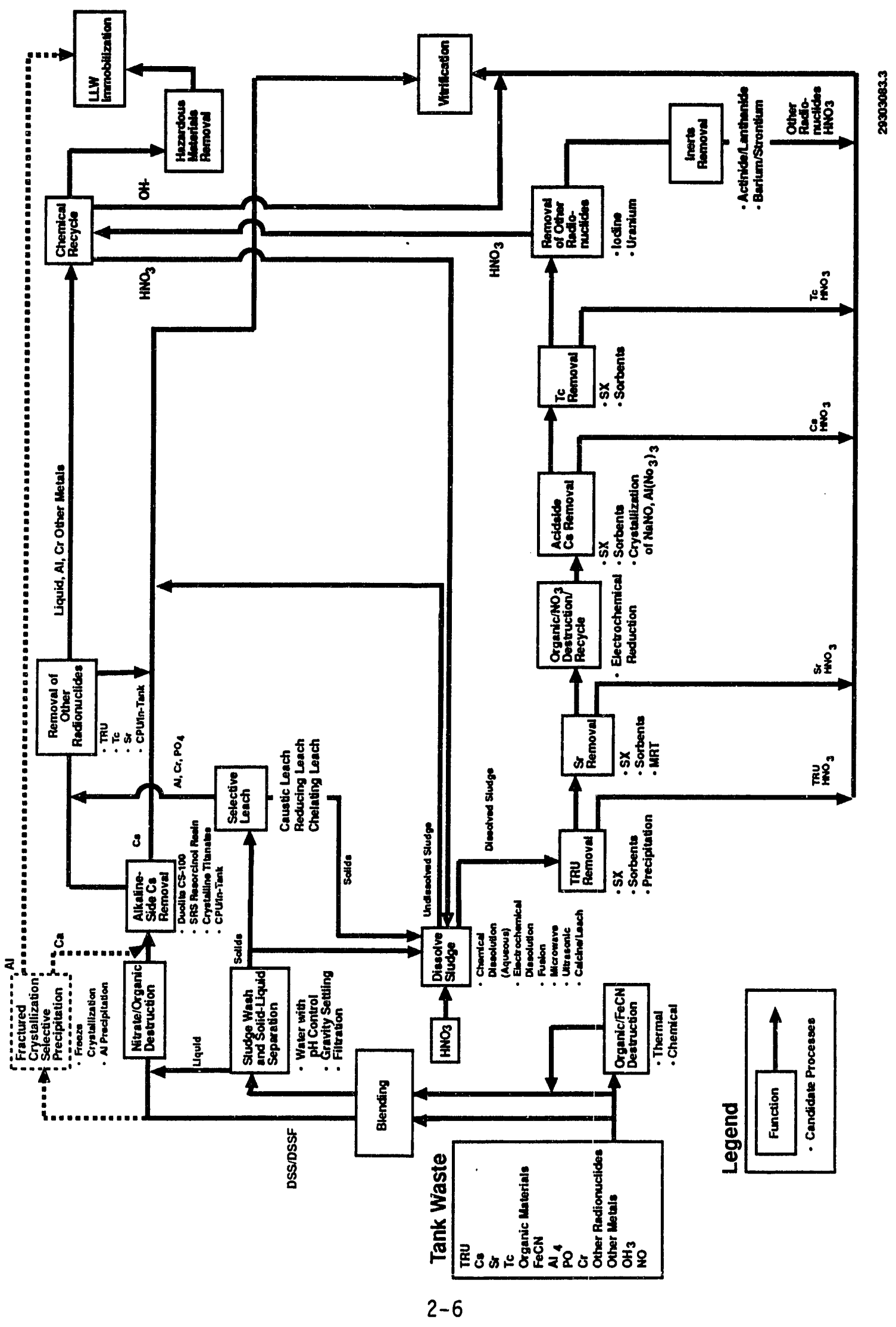


The TWRS pretreatment strategy also includes possible deployment of several different facility options, which will be indicated in the discussion of the functional needs and/or the system descriptions in Section 3.0. Basically, these options include the following.

- In-Tank Processing. Some pretreatment operations will be conducted in new or existing DSTs, thus minimizing the extent of the need for new operating facilities. This would require new equipment to support the processing and could require waste retrieval and transfer between tanks.

- Compact Processing Unit (CPU). CPUs are modular systems targeted to accomplish a single function and would be located in the vicinity of the tank (or tank farm) being remediated. This concept is currently being evaluated for the removal of cesium from double-shell slurry/double-shell slurry feed (DSS/DSSF) feed to the grout facility. However, other CPUs could be deployed as standalone production facilities if the CPU concept proves feasible and offers cost and/or schedule advantages over the reference approach. CPUs have significantly smaller production capacities than other facilities; thus, they could also be operated as the pilot-plant demonstration of processes subsequently targeted for the IPM or for a new pretreatment facility where production rates will be significantiy higher.

Large, Centralized Pretreatment Facilities. Many processes, because of their complexity and/or needs to treat large volumes, will have to be deployed in new, centralized treatment facilities. Two types of Central Facilities are being considered for deployment:

- Initial Pretreatment Module (IPM). Initial pretreatment targeted at resolving tank safety issues (i.e., organic/ferrocyanide destruction) may be conducted in a new niodular facility, which could be deployed on a faster ichedule than a new radiochemical processing facility (i.e., a canyon-type facility). Decisions may be made to include other process funcitions, such as cesium ion exchange, in the IPM.

- New Pretreatment Facility (NPF). Processes will be deployed in a new pretreatment facility when (1) significant development work is required before deployment and/or (2) the processes are not suitable for operations in a module facility because of their complexity. Tinis would be the last pretreatment facility to be deployed and would require the greatest capital expenditure. The scope depends on the pretreatment processes selected and the feasibility of the other processing options. 


\subsection{PROGRAM ELEMENT FUNCTIONS}

The Pretreatment TWG identified the following list of functions. The extent to which any or all of these functions are deployed depends on the final pretreatment system selected.

- Blending. Blending deals with the physical combination of solids, liquids, and slurries. By physically combining materials from multiple tanks, several benefits potentially can be achieved; (1) pretreatment process feed can be made more homogeneous by mixing wastes with similar contents, but with variations in component concentrations; (2) pretreatment feed can be made available sooner by allowing slow SST-retrieval processes to work on several tanks simultaneously; and (3) HWVP feeds can be made more homogeneous and with better glass-making characteristics. The major impetus for this approach would allow higher waste loading in glass by minimizing the impacts of glass-formulation-limiting impurities, such as chromium in Plutonium Finishing Plant (PFP) waste and zirconium in neutralized cladding removal waste (NCRW). Blending would take place within the tank farm facilities.

- Sludge Wash. Sludge washing involves removing water-soluble compounds (e.g., cesium, sodium compounds, potassium compounds) from the waste by successive mixing and decanting of tank sludges with water or inhibited water (water with sodium hydroxide and sodium nitrate added based on tank farm operating procedures for corrosion contro1). This process can be used as the sole treatment for sludges or as a precursor to additional pretreatment processing. The water-soluble components constitute up to 60 percent of the waste solids in the tanks. If required, the decanted liquids are further treated (e.g., for the removal of soluble ${ }^{137} \mathrm{Cs}$ ), but ultimately the bulk of the water-soluble components wili end up in the low-activity waste form (i.e., grout). Sludge washing could take place in-tank or in a standalone processing facility.

- Solid/Liquid Separation. Solid/liquid separation deals with the physical separation of a liquid phase from a solid phase. Because of the importance of this operation and the technical issues associated with the wide variety of wastes at the Hanford Site, this has been identified as a separate function. Operations included in this function are settling/decanting, filtration, centrifugation, and flocculation. The solid/liquid separation operations would take place in-tank and also in a separate processing facility.

- Organic Destruction. Organic destruction involves the breakdown of organic compounds for the reduction of hydrogen-generating properties and the preparation of feed for grout. Reduction of in-tank hydrogen generation will involve the near-term destruction of a significant percentage of the organic compounds currently found in the waste. The requirements for the destruction of organic components for preparation of grout feed are expected to be even more extensive and complete. As a result, two processes are expected: a near-term, moderately efficient process for hydrogen generation resolution (safety issue), and a long-term, highly 
effective process for almost total destruction of organics in grout feed (a performance issue). Organic components in the waste tanks include cesium complexants, process solvent diluents (e.g., normal paraffinic hydrocarbons), cleaning and decontamination solutions, and the normal decomposition products from these materials. Organic destruction may take place in-tank or in a pretreatment module (IPM and/or CPU), depending on the needed degree of destruction and the process selected. Organic destruction is not needed for pretreatment of feed to HWVP. The long-term destruction of organics to meet grout specifications may take place in a new pretreatment facility.

- Cesium $\left.{ }^{137} \mathrm{Cs}\right)$ Removal. Cesium removal is the function dealing with the separation and collection of cesium frcm liquified streams to be fed to grout. Cesium removal processes could occur in-tank or in a pretreatment module (CPU, IPM, and/or new facility). For technology selection, this function is further broken down to cesium recovery from basic streams, which is part of all pretreatment scenarios, and cesium recovery from acid streams (a pretreatment enhancement).

- Strontium $\left({ }^{90} \mathrm{Sr}\right)$ Removal. Strontium removal is the function dealing with the separation and collection of strontium from waste solids. Strontium is not highly soluble in water or caustic solutions and will primarily be only in solution in acid streams within the pretreatment facility. Based on the expected acidic streams involved, strontium concentration and removal would only occur in a pretreatment facility or within a tank farm constructed of suitably corrosion-resistant materials. The solids that will be treated for strontium removal are also being processed for other radionuclide removal, and their processing residues will ultimately be disposed of in grout. For strontium recovery to meet the requirements of CLEAN and/or the Class A limit in grout, strontium recovery from the supernate will also be required. For technology selection, strontium removal is also broken down into recovery from acid streams and recovery from basic streams.

- Technetium ( ${ }^{99} \mathrm{Tc}$ ) Removal. Technetium is presumed to exist in waste streams on the Hanford Site in the form of pertechnate $\left(\mathrm{TCO}_{4}^{-}\right)$, a relatively mobile component in grout. This radionuclide is judged to be a significant contributor to doses for individuals in performance assessments. Therefore, a process for removing this component from grout feeds may be required. This removal would occur in the CPU, the IPM or a new facility. This function is also broken down to technetium removal from acid streams and technetium removal from basic streams for technology selection.

- Sludge Dissolution. Acid dissolution involves dissolving waste solids in an acid (such as nitric acid) as an integral part of pretreatment. To minimize the mass of material fed to the HWVP, it will be necessary to use processes that require solids to be dissolved in an aqueous stream for separations to be performed. This function will also include a solid/liquid separation function to remove undissolved solids from the acid stream. Acid dissolution would occur within a new pretreatment facility. 
- Transuranic (TRU) Removal. Removal of TRUs involves the separation of long-lived radionuclides from grout feeds. These processes will typically separate TRU components from acidic solutions. Products from this function will be (1) a low-activity stream containing the bulk of the dissolved solids, which will be neutralized and fed to the grout facility; and (2) a stream containing TRUs, which will be fed to the HWVP. TRU removal processes significantly reduce the mass of certain feeds to the HWVP. For TRU recovery to meet the requirements of CLEAN and/or to meet the Class A 7 imit in grout, TRU recovery from the supernate will also be required. Thus, this function also includes evaluation of technologies for TRU removal from complexed, alkaline solutions. Because of the chemical nature of these processes, they would occur within a pretreatment facility.

- Selective Leaching. Selective leaching processes are a group of intermediate-term processes that are designed to remove minor components from the bulk solids. Depending on the process involved, selective leaching may be applied to HWVP or grout treatment facility feeds. Examples of components selectively leached from grout feeds include americium and plutonium. HWVP feeds would be selectively leached to remove components that greatly affect waste formulation of the glass such as phosphates, sulfates, and chromium.

- Bulk Leaching. Bulk leaching is a group of intermediate-term processes that are designed to remove major components from the bulk solids. It is expected that bulk leaching processes will be used to reduce the mass of HWVP feeds. HWVP feeds would be bulk leached to remove components that can be easily separated from the radionuclide-contaminated waste and that greatly affect the mass of waste fed to HWVP. Examples of components to be tested for applicability of bulk leaching from HWVP feeds include aluminum, phosphate, bismuth, zirconium, and iron. It is expected that alkaline bulk leaching processes would occur as in-tank processes.

- Ferrocyanide $\left(\mathrm{Fe}(\mathrm{CN})_{4}\right)$ Destruction. Ferrocyanides are reactive agents that, in sufficient quantities, are classified as safety concerns in the SSTs. Oxidation processes are being investigated to break down the ferrocyanide molecules into nonhazardous materials before final waste disposal. Ferrocyanide destruction processes would be conducted in the IPM.

- Nitrate/Nitrite Destruction. Nitrate and nitrite destruction can increase the environmental acceptability of the grout disposal form although destroying the nitrates in the existing waste has little benefit (because grout would still be limited by sodium). However, significant savings are associated with destroying nitrates from the nitric acid that is added for dissolution before neutralization. 
- Calcination. Calcination is a process where waste solids and liquids are introduced into a high-temperature furnace (calciner). The temperature of the vessel is sufficiently high that liquids are evaporated and solid materials are reacted to a fused or oxide state. Organic materials are broken down mostly to carbon dioxide and water. Nitrates and nitrites will be converted to nitrogen oxides and then scrubbed from the offgas. Calcination of waste streams would be performed in a pretreatment facility.

- Iodine Removal. If the concentration of ${ }^{129} \mathrm{I}$ is found to be high enough, either an offgas treatment step in HWVP or a pretreatment step may be necessary. The intent of this functional need is to remove and isolate the iodine for disposal in some other waste form. This removal and preparation of a new waste form would be done in a new pretreatment facility.

- Chemical Recycle. The wastes contain large quantities of nonradioactive chemicals. In addition, many of the pretreatment systems identified may use large quantities of chemicals. To minimize the waste that requires disposal and to minimize the use of additional chemicals, it will probably be advisable to separate these chemicals from various wastes streams and recycle them. This separation and recycle is the intended scope of this functional need. This function will only be deployed in the CLEAN or extensive-pretreatment-with-recycle option. Thus, this would be performed in a new pretreatment facility.

- Removal of Radionuclides to Class A. This functional need is to remove radionuclides (that are not specifically identified as separate functional needs) from the waste so that the LLW can meet a Class A category (e.g., $\left.{ }^{65} \mathrm{Ni}\right)$. These radionuclides would be disposed in the glass matrix. Again, this function is associated with the CLEAN option and would be deployed in a new pretreatment facility.

- Removal of Heavy Metals. In the small probability that heavy metals are not acceptable in grout or some other LLW form, this functional need was identified to remove the heavy metals and isolate them for some other disposal form. This function is a component of CLEAN and would occur in a new pretreatment facility.

- Recovery of Noble Metals. If the noble metal concentrations are found to be high enough, several problems may exist within the HWVP process. The first potential problem is the generation of hydrogen during the feed preparation steps. The second involves the precipitation of metals in the melter. This function relates to a way for pretreatment to address this concern, should it be necessary. Noble metals would be removed from the glass feed and converted for reuse or disposed of in grout. If required, this function would be deployed in a new pretreatment facility as part of the CLEAN option. 


\subsection{CURRENT TECHNOLOGY DEVELOPMENT ACTIVITIES}

Pretreatment activities currently being funded include technologies common to all TWRS strategies (i.e., developed pretreatment technologies), advanced separation techniques, pilot-plant facilities, and technical integration activities. Technologies common to all TWRS strategies that can be deployed in the short term include sludge washing organic/ferrocyanide destruction and cesium ion exchange. Advanced separation technologies currently being evaluated include techniques for separating TRU, cesium, and strontium from the bulk of the nonradioactive inorganic constituents in the sludge. An ongoing study to examine pilot-plant needs and potential locations will be completed in the first half of fiscal year (FY) 1993. Finally, work is being conducted to cover technical integration of the program, including preparation of this plan, conducting technology workshops and technical exchanges, and supporting development of baseline documents for TWRS and Pretreatment management. Table 2-1 summarizes the specific technologies being evaluated.

Table 2-1. Fiscal Year 1993 Pretreatment Technology Development Activities.

\begin{tabular}{|l|l|}
\hline \multicolumn{1}{|c|}{ Functional need } & \multicolumn{1}{|c|}{ Technology } \\
\hline Organic/ferrocyanide destruction & $\begin{array}{l}\text { Wet oxidation (1) } \\
\text { Calcination (1) } \\
\text { Ozonation (1) } \\
\text { Steam reforming (1) } \\
\text { Heat and digest (2) } \\
\text { Corona discharge (2) } \\
\text { Electrochemical oxidation (2) } \\
\text { Hydrothermal (1) } \\
\text { Electron beam (2) }\end{array}$ \\
\hline Alkaline-side cesium removal & $\begin{array}{l}\text { CS-loo/SRS Resorcinol ion exchange } \\
\text { Crystalline titanates }\end{array}$ \\
\hline $\begin{array}{l}\text { Sludge wash and solid/liquid } \\
\text { separations }\end{array}$ & $\begin{array}{l}\text { Gravity settling } \\
\text { Water with pH control }\end{array}$ \\
\hline Selective leach & 0.l M sodium hydroxide, KMnO \\
\hline Sodium and aluminum removal & $\begin{array}{l}\text { Aluminum precipitation } \\
\text { Fractional crystallization }\end{array}$ \\
\hline Dissolve sludge & $\begin{array}{l}\text { Chemical dissolution } \\
\text { Calcine/leach }\end{array}$ \\
\hline Transuranic removal & $\begin{array}{l}\text { Transuranic extraction/CMPO (acid) } \\
\text { Alternate transuranic removal }\end{array}$ \\
\hline Acid-side cesium removal & Evaluate processes \\
\hline Strontium removal & Evaluate processes \\
\hline Technetium removal & Evaluate processes \\
\hline
\end{tabular}

CMPO = octyl (phenyl) $-\mathrm{N}, \mathrm{N}$-di isobutylcarbamoyl-methylphosphine oxide

(1) To be deployed in the Initial Pretreatment Module to resolve safety issues

(2) Possible long-term enhancements to meet grout feed requirements. 


\subsection{MAJOR CHANGES TO PREVIOUS PLAN}

This is Revision 0 of the TWRS Pretreatment Technology Development Plan. This plan will be updated annually.

\subsection{LIFETIME BUDGET ESTIMATES}

Budget estimates have not been included in this document. At this time, extensive revisions are being proposed to the TWRS strategy in response to the TWRS Program leadership council. These revisions may significantly affect the pretreatment technology development strategy, time frame, and costs. Until the TWRS program strategy is accepted by a11 interested parties; Including DOE, U.S. Environmental Protection Agency (EPA), the State of Washington, the State of Oregon, the Yakima Indian Nation, and other interested parties; the costs for the pretreatment technology development program are subject to change.

Projected costs relating to the pretreatment technology program will be published in the Integrated Technology Plan (DOE-RL 1993) and in the TWRS Multi-Year Program Plan. In addition, costs pertaining to pretreatment technology will be published in future revisions of this document.

\subsection{PROGRAM ELEMENT MASTER SCHEDULE}

Appendix A presents a summary-level pretreatment master schedule. The schedule is a Tri-Party Agreement-compliant schedule and assumes that resource and budget requirements are unconstrained. Included in the schedule are activities which are not included in the technology plan. These additional activities represent expected HWVP activities, pretreatment engineering activities, and pretreatment facility and operations activities. The additional activities are presented to illustrate the time frame in which process design information will be required to support project design and construction activities.

\subsubsection{PROGRAM ASSUMPTIONS AND CONSTRAINTS AFFECTING PRETREATMENT TECHNOLOGY DEVELOPMENT}

The following is a summary list of assumptions and constraints used in developing the waste pretreatment work scope. Additional detailed assumptions associated with specific tasks may have al so been used. Additional key assumptions and constraints are expected in the new TWRS strategy which will impact the planned work scope.

- The HWVP will begin hot operations in December 1999*.

\footnotetext{
*Assumption likely to change based on proposed TWRS new technical strategy.
} 
- Advanced separation processes (i.e., processes beyond cesium ion exchange and sludge washing) are required to minimize the number of glass canisters produced.

- The available characterization and Tracks Radioactive Components (TRAC) data provide an adequate planning base for pretreatment processes. New sample data shall be available to support development and implementation of pretreatment processes.

- Tank space is available to support pretreatment operations in accordance with the annual waste volume projections.

- In-tank sludge washing and the IPM will provide sufficient feed for at least 6 to 15 years of operation of HWVP and the Grout Facility.

- All SST waste will be retrieved for processing and disposal.

- There will be no change in the U.S. Nuclear Regulatory Commission position on high-level waste.

- Tri-Party Agreement milestones will not be accelerated.

- The TWRS-EIS and ROD provide sufficient National Environmental Policy Act of 1969 (NEPA) documentation coverage for in-tank processing of DST wastes. The TWRS-EIS and resulting ROD shall provide NEPA documentation coverage for the second pretreatment module, and subsequent pretreatment facilities, if required. The TWRS-EIS ROD shall not delay detailed design for the second pretreatment module (SPM).

- The first priority of Pretreatment is safety remediation.

- Ten to 17 tanks require safety remediation through IPM.

- Tanks 106-C and 105-C will have early retrieval.

- No additional tank waste radionuclide removal will be required to complete the first 14 grout campaigns.

- Waste form qualification feeds must be available 2 years before HWVP hot startup.

- Pretreatment logic covers multiple pretreatment options, up to the "Clean" option, excluding specific elements of sludge processing associated with the "Clean" option.

"Assumption likely to change based on proposed TWRS new technical strategy. 
- The following inputs from Characterization go to all laboratory studies in pretreatment. (This is not shown in pretreatment logic because it would mask underlying ties).

- Characterization of core samples

- Liquid and solid samples from tank farm coring activities.

- Requirements Analysis Activity for each process has inputs from the following:

- Characterization

- Retrieval

-- dilution amount

-- tank sequence

- HWVP waste feed specifications

- Grout feed specifications.

- All pretreatment laboratory testing and pilot plant operations are tied to grout formulation and testing. The following items list input from Grout and the response from Pretreatment respectively.

- Grout feed specifications

- Pretreatment process capabilities and expected product compositions.

- Retrieval will supply small-scale solids samples (25 to 50 L) to all bench-scale activities.

- Retrieval will supply pilot-scale solids samples (1,135 L [300 gal]) to all pilot-scale activities.

- The Grout Facility will fill 4 vaults per year.

- The HWVP characteristics report is produced out of Pretreatment Technical Administration (Integration).

- Solvent extraction processes contractor equipment development is included under the cold solvent extraction pilot plant. The contactors equipment includes the following:

- Centrifugal contactors

- Mixer settlers

- Pulsed columns.

- Outer years of engineering analyses of solvent extraction tests of FYXX core samples feed SPM operations.

- One alternate process, with multiple functions, will be carried forward with detailed continuous testing.

- Intermediate process screening studies include technical evaluation and laboratory testing. 
- Sludge wash pilot plant can be used for intermediate process testing. Minor modifications may be needed.

- The SPM operating strategy includes the following:

- Feed variability

- Blending of pretreatment feed and products from acid side/SPM processes (i.e., TRU stream form TRUEX).

- Clean option screening studies of polishing processes includes technetium, strontium, iodine, TRU, etc.

- Sodium LLW form (to reduce vaults) should be investigated. Leave this issue to LLW group via integration team.

- Requirements for organic destruction to meet LLW disposal specifications will be more stringent than requirements for organic destruction (by IPM) to resolve safety issues.

- The required hot startup date for IPM is December 1999.

- To meet schedule requirements, design and construction of the IPM is anticipated to occur in two phases. Phase l construction is scheduled to start before Phase 2 design will have progressed sufficiently to support finalization of the Preliminary Safety Analysis Report (PSAR) and environmental permit applications. It is assumed that a limited scope safety analysis will be sufficient for authorization of Phase 1 construction, to be followed by preparation of a comprehensive PSAR in full compliance with DOE orders, based on Phase 2 detailed design. The comprehensive PSAR will be approved by DOE before the start of Phase 2 construction. Similarly, it is assumed that the regulatory agencies will allow Phase l construction to proceed before submittal of environmental permit applications that will necessarily contain Phase 2 detailed design information.

- The first feed to the IPM will be from tank 101-SY.

- The primary function of the IPM will be to resolve any remaining safety issues after mitigation actions are complete.

- Nitrate/nitrite destruction, although desirable, has been specifically excluded from IPM criteria. 


\subsection{TECHNOLOGY PLANNING RESULTS}

\subsection{REFERENCE SYSTEM TECHNOLOGY DEVELOPMENT}

\subsubsection{Description of the Reference System}

The reference system for pretreatment uses a three-phased approach for implementing technology over the duration of TWRS, moving from minimal pretreatment in Phase 1 toward an aggressive separation of radionuclides from the bulk chemical constituents in Phase 3. The first phase includes those technologies common to most pretreatment scenarios that can be deployed early. Early deployment is possible because the technologies currently exist; they require minimal development work to be available; or they address a high-priority safety issue. These are sludge washing, cesium ion exchange (basic), and organic/ferrocyanide destruction. These processes are to be conducted within existing and new DSTs, CPUs, and/or the IPM.

The second phase would deploy leaching of the sludge either for bulk leaching of chemical constituents or selective leaching of radioactive constituents to reduce the volume of sludge requiring vitrification. Blending of wastes would also be conducted in Phase 2 to minimize the number of unique feed types, thus reducing the concentration of certain chemical constituents in the waste and reducing the total volume of vitrified waste. This phase would be deployed as an in-tank process or in the IPM.

The final phase adds sludge dissolution followed by TRU and strontium extraction to convert most of the washed sludge to LLW. These additional processes would require a new pretreatment facility.

\subsubsection{Prioritized Description of Uncertainties and Vulnerabilities Associated with Reference System}

The pretreatment program element faces significant uncertainties that are applicable to all options, any one of which could significantly affect its success. A major uncertainty is that pretreatment performance specifications are unknown in terms of target volumes of glass and grout to be produced. The volume of glass produced (especially under the Phase 1 approach) may result in enormous repository disposal costs and/or it may exceed the current HWVP design life. The pretreatment scope is uncertain in terms of the number of tanks that will require pretreatment, the sequence of tanks to be retrieved and treated, and the degree of pretreatment that will be mandated for particular constituents (e.g., radionuclides, nitrates, iodine, chrome, heavy metals, noble metals, tritium, organics). In addition, changes that occur in other program elements (i.e., possible selection of an alternative LLW form) can have tremendous impacts on the specific pretreatment processes that are needed and their performance requirements. Thus, the strategy for pretreatment is to proceed with development of those technologies that are likely to be needed to support the technical strategy agreed upon by the TWRS Program and the regulators. 
3.1.2.1 Technical. The TWG identified general technical uncertainties during the TWRS Workshop associated with the draft reference system (and enhancements). These include the following issues.

- The applicability of intermediate processing is uncertain.

- The compatibility of tank storage material with pretreated wastes is unknown.

- The flexibility of the pretreatment system processes and equipment to different waste streams is unknown.

- The reliability of the pretreatment system processes and equipment needs to be determined.

- The Phase 2 and 3 technologies have largely not been developed beyond laboratory bench scale and the processes are complex.

- The extent of secondary waste generation (volume, type, and composition) needs to be determined.

In addition, specific uncertainties or vulnerabilities are associated with each functional need. These uncertainties are listed below.

Phase 1

- Sludge Washing and Liquid/Solids Separation. To be highly effective, sludge washing must be accompanied by effective liquid-solids separation. This function washes the sludge with "inhibited" water (hydroxide and nitrite added for corrosion control) and removes liquids and soluble solids trapped in the sludge. The more liquids remaining with the solids, the less complete is the segregation of the soluble and nonsoluble constituents. Sludge washing would be conducted within the tanks. Technical uncertainties include (1) the effectiveness of suspending and contacting all the sludge within the tanks, (2) the impact of thermal currents (from hot sludges), (3) the solubilities of the tank waste constituent, (4) the dynamic forces exerted on the tanks during operations, (5) optimization of washing efficiency for each waste type, (6) possibility of uncontrolled venting, effect of operation on tank corrosion, and (7) the formation of colloids and/or froths.

- Removal of Cesium. Although much is known about cesium ion exchange from basic solutions, more information is needed on (1) the best ion exchange medium to use with the particular system; and (2) the best process arrangement to use to ensure minimum secondary waste.

- Organic Destruction. The organic constituents in feed to the LLW (grout) facility need to be destroyed to produce a satisfactory grout. For the HLW vitrification facility (HW!??), the organics will be destroyed by the melting process. For some of the tanks currently being scrutinized for safety concerns, organics may need to be destroyed in the near term for continued safe storage. 
However, the scope of the organic destruction requirements to resolve safety issues or to provide acceptable grout feed is currently not well understood. In addition, the technologies that can accomplish the eventual objectives are not well developed.

- Ferrocyanide Destruction. These potentially reactive constituents in a number of the waste tanks, which in sufficient quantities are classified as safety concerns, may need to be destroyed in the IPM. the ferrocyanide molys processes are being considered to break down waste disposal. The destruction are not well

\section{Phase 2}

- Blending. This function, which connotes the mixing of the contents of two or more tanks, offers several benefits. The primary benefits are more homogeneous pretreatment process feed and more uniform feed to the HWVP, which may result in better glass-making characteristics. Availability of tanks to maximize blending and the extent to which blending can be accomplished are uncertain.

- Sludge Leaching (Selective and Bulk). Both selective and bulk leaching are envisioned to take place in the tanks as part of including radioactive Selective leaching removes minor components, are cesium, technetium, constituents, from the bulk solids. Examples would be removed and sent to the HwVP whilom, and chromium. These to the LLW. Bulk leaching removes solids, such as aluminum, removes major constituents from the bulk These would be removed from These processes have been developed the HWVP and be sent to the LLW. approach were successful, it could to a limited extent. If this Phase 3 pretreatment needs. How conceivably eliminate some of the significant development effort.

Phase 3

- Sludge Dissolution. Because of the complex mixtures that make up the sludges, predicting which reagent will be required to dissolve the solids is very difficult. Reagents that cannot be contained in conventional construction materials must be avoided.

- Removal of Transuranics. TRU waste forms will normally be in the sludge and removed from the acidic steam after sludge dissolution The options for accomplishing this have only been demonstrated in
bench-top laboratory studies.

- Removal of Strontium. Strontium, which normally will be in the sludge, must be effectively separated from a very complex matrix of constituents. The options for accomplishing this have only been demonstrated in bench-top laboratory studies. 
3.1.2.2 Programmatic. The following list of programmatic uncertainties and vulnerabilities was developed during the TWRS National Workshop. Most of these uncertainties apply to all of the pretreatment system options.

\section{- Technical}

- The development duration of technologies is unknown and may be problematic.

- Deployment duration is often unknown or may be problematic.

- The timing of pretreatment relative to the baseline HWVP schedule may be impractical.

- The pretreatment product specifications are unknown.

- The pretreatment performance specifications are unknown.

- New safety issues may arise.

- A different low-level waste form could drastically change the strategy.

- The knowledge base and experience to support investments may be inadequate.

- Non-Technical

- The potential for insufficient budget allocations to support capital expenditures, operating expenses, and development costs.

- The potential for changes in program direction.

- Program milestone slippages and/or changes adversely affect planning.

- TWRS strategy changes (end state may change).

3.1.2.3 Regulatory. At this time no specific regulatory issues are associated with pretreatment, per se. However, any regulatory issues associated with grout, glass, or any other final waste form could significantly affect the pretreatment processes selected or the performance criteria for specific processes. There will probably be regulatory issues associated with the operation of the pretreatment processes selected for final deployment. 


\subsubsection{Prioritized Functional Needs}

The reference system functional needs are prioritized as follows and match the three phases of deployment.

- Convert/Remove Organics/Ferrocyanide. This is the highest-priority need because it is required to resolve tank safety issues in the near term.

- Sludge Washing, Solid/Liquid Separation, and Cesium Ion-Exchange. This is the next priority, because these functions are common to all pretreatment scenarios; thus, the need for available proven technology is high.

- Blending and Selective Leaching. These Phase 2 functions are the next to be deployed because of the need to reduce the volume of HLW gererated by Phase 1 operations. Also, these processes would not rer,uire a new pretreatment facility.

- Sludge Dissolution, Transuranic Removal and Strontium Removal. These technologies need more extensive development and would require a new pretreatment facilit to be deployed. Thus, they will be the last processes to be deployed. However, these technologies are needed to redure the volume of HLW.

\subsubsection{Prioritized Technology Development Activities in Response to Functional Needs}

Table 3-1 presents a list of technologies in response to functional needs for the reference system. These technologies were identified and then prioritized by the TWG during the National Workshop.

\subsubsection{Recommended Technology Development Activities}

Table 3-2 summarizes the recommended pretreatment technology development activities for the reference system, with the possible impact of not funding
the activities.

\subsubsection{Technology Development Enhancements}

3.1.6.1 Technology Development Enhancements. Pretreatment system enhancements include functions that reduce the volume of and improve the environmental acceptability of the LLW form (grout). This set of technologies also includes evaluating alternative technologies to the reference technologies to reduce the volume and composition of secondary wastes produced. The technical basis for some of these functions has not yet been determined; therefore, these functions are not prioritized but are presented as a set of additional technologies that could be deployed. 
Table 3-1. Prioritized Technology Development Activities-Reference Pretreatment System.

\begin{tabular}{|c|c|c|}
\hline Functional need & Technol ogy & Prisity \\
\hline Organic destruction (1) & $\begin{array}{l}\text { Calcine/fusion } \\
\text { Steam reforming } \\
\text { Heat and digest } \\
\text { Ozonization (basic) } \\
\text { Hydrogen peroxide (acid) } \\
\text { Hydrothermal } \\
\text { Electrochemical oxidation } \\
\text { Electron beam }\end{array}$ & $\begin{array}{l}1 \\
1 \\
2 \\
3 \\
4 \\
5 \\
6 \\
7\end{array}$ \\
\hline Ferrocyanide destruction & $\begin{array}{l}\text { Calcine } \\
\text { Steam reforming } \\
\text { Ozonation } \\
\text { Hydrothermal } \\
\text { Electrochemical oxidation } \\
\text { Electron beam }\end{array}$ & $\begin{array}{l}1 \\
1 \\
2 \\
3 \\
4 \\
5\end{array}$ \\
\hline sludge wash & Water with pH control & N/A \\
\hline Solid/liquid separation & $\begin{array}{l}\text { Gravity settling } \\
\text { Centrifuge } \\
\text { Filtration }\end{array}$ & $\begin{array}{l}1 \\
1 \\
1\end{array}$ \\
\hline Cesium removal & $\begin{array}{l}\text { Cesium-100 } \\
\text { SRS Resorcinol Resin } \\
\text { Crystallization } \\
\text { Crystall ine ti tanates } \\
\text { Inorganic ion exchange } \\
\text { microspheres } \\
\text { IONSIV IE-95/96 } \\
\text { Ferrocyanide } \\
\text { Phosphomolybdate } \\
\text { Zirconium phosphate } \\
\text { pillared clay } \\
\end{array}$ & $\begin{array}{l}1 \\
1 \\
1 \\
1 \\
2 \\
3 \\
3 \\
4 \\
4\end{array}$ \\
\hline Selective leaching & \multicolumn{2}{|c|}{ NEEDS IDENTIFICATION OF COMPONENTS TO BE REMOVED } \\
\hline sludge dissolution & $\begin{array}{l}\text { High shear } \\
\text { Chemical dissolution } \\
\text { Microwave } \\
\text { Ultrasonic } \\
\text { Fusion } \\
\text { Electrochemical dissolution }\end{array}$ & $\begin{array}{l}1 \\
1 \\
2 \\
2 \\
2 \\
2\end{array}$ \\
\hline Transuranic removal & $\begin{array}{l}\text { Transuranic extraction/CMPO } \\
\text { CMP } \\
\text { DIDPA } \\
\text { Diamide } \\
\text { Extraction chromatography } \\
\text { Organic sorbents }\end{array}$ & $\begin{array}{l}1 \\
2 \\
3 \\
3 \\
3 \\
3\end{array}$ \\
\hline Strontium removal & $\begin{array}{l}\text { SREX TREX } \\
\text { Stror,-ium-spec } \\
\text { Titanate } \\
\text { Organic ion extraction resin }\end{array}$ & $\begin{array}{l}1 \\
2 \\
3 \\
4\end{array}$ \\
\hline
\end{tabular}

CMPO = octyl (phenyl)-N,N-di i sobutyl carbamoyl-methylphosph ine oxide

CMP $=$ dihexyl-N, $N$-diethyl carbamoylmethyl phosphonate

SREX = strontium extraction

SRS = Savannah River site feeds.

(1) Prioritization reflects need to resolve safety issues versus need to prepare acceptable grout 
Table 3-2. Pretreatment Technology Development Activities - Reference System. (3 sheets)

\begin{tabular}{|c|c|c|c|c|}
\hline 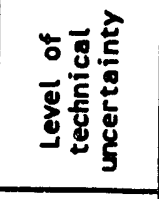 & 호 & 훙 & \begin{tabular}{|l} 
息 \\
\end{tabular} & $\begin{array}{l}\mathbf{5} \\
\stackrel{1}{x} \\
\end{array}$ \\
\hline 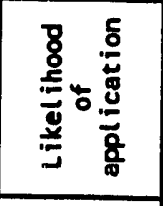 & 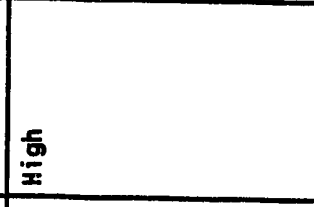 & \begin{tabular}{|l} 
竞 \\
\end{tabular} & 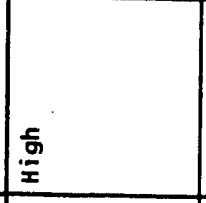 & \begin{tabular}{|l}
$\mathbf{5}$ \\
$\frac{5}{\mathbf{z}}$ \\
\end{tabular} \\
\hline 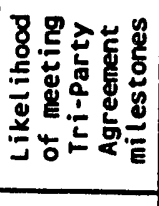 & $\begin{array}{l}\text {. } \\
\end{array}$ & \begin{tabular}{|l}
$\tilde{5}$ \\
\\
\end{tabular} & $\leqslant$ & $\frac{\Sigma}{z}$ \\
\hline 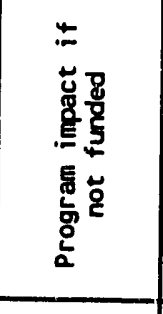 & 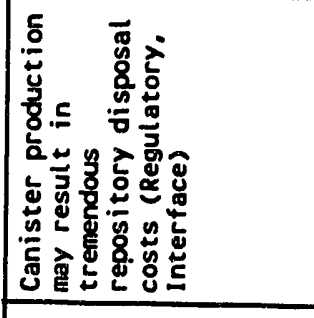 & 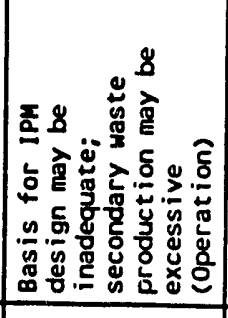 & 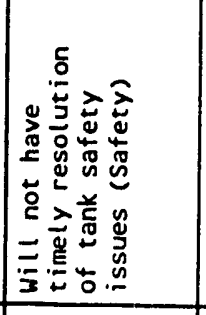 &  \\
\hline 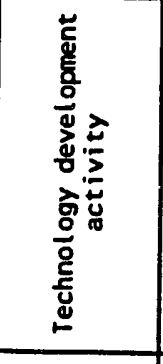 & 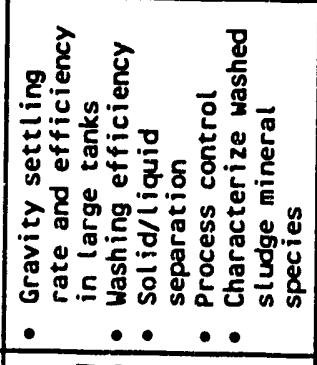 & 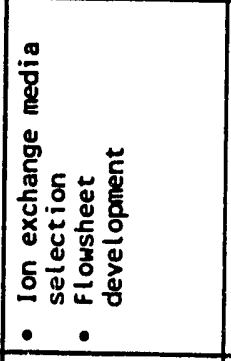 & 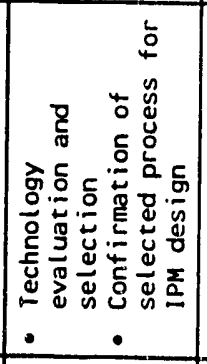 & 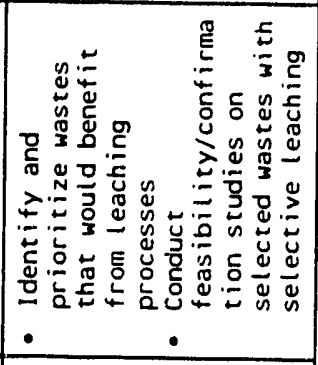 \\
\hline 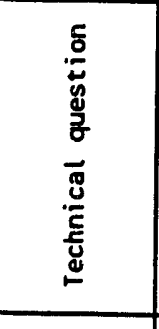 & 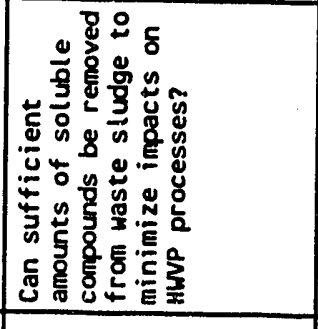 &  & 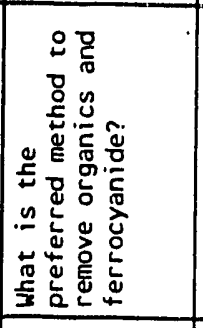 & 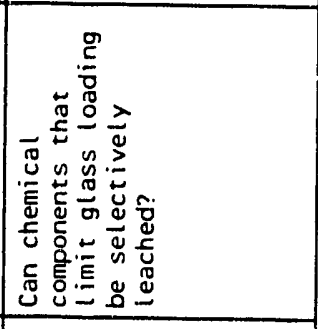 \\
\hline 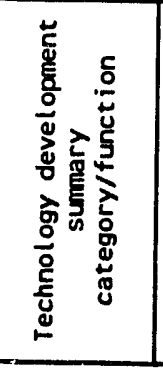 & 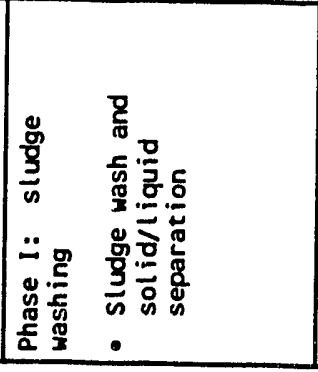 & 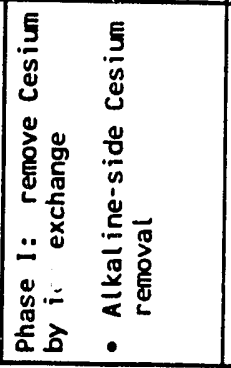 & 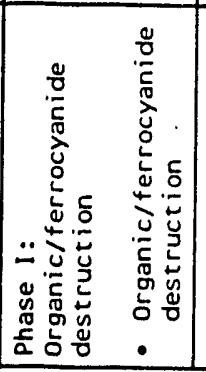 & 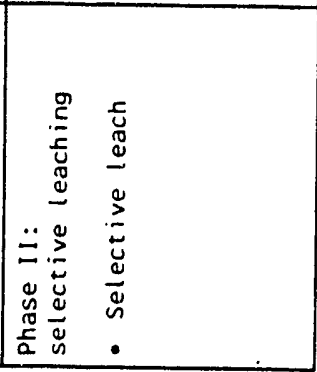 \\
\hline
\end{tabular}


Table 3-2. Pretreatment Technology Development Activities - Reference System. (3 sheets)

\begin{tabular}{|c|c|c|c|}
\hline 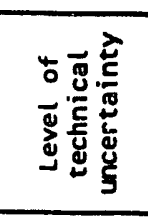 & 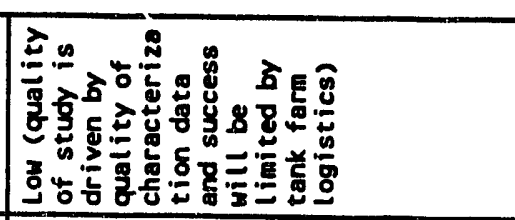 & $\mid$\begin{tabular}{l}
$\mathbf{5}$ \\
\hdashline \\
\end{tabular} & 竞 \\
\hline 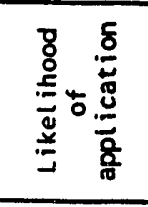 & 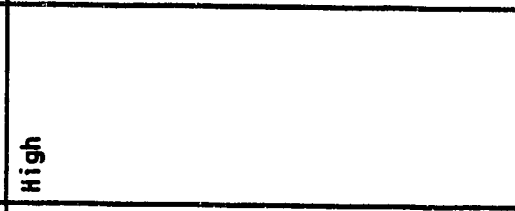 & \begin{tabular}{|l|}
$\mathbf{6}$ \\
$\mathbf{x}$ \\
\end{tabular} & 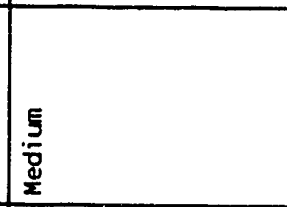 \\
\hline 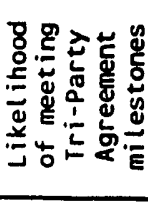 & \begin{tabular}{|l}
$\frac{5}{\underline{\underline{m}}}$ \\
\end{tabular} & $\underline{\mathbf{z}}$ & $\frac{\pi}{2}$ \\
\hline 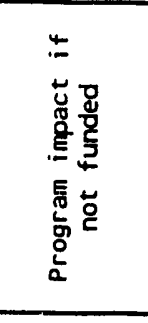 & 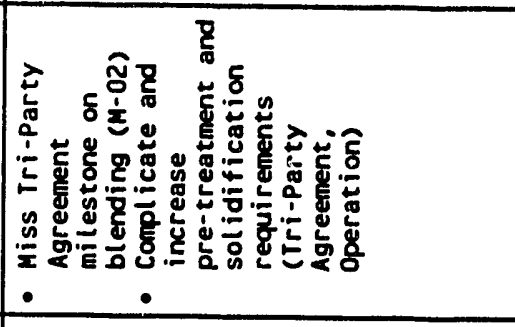 & 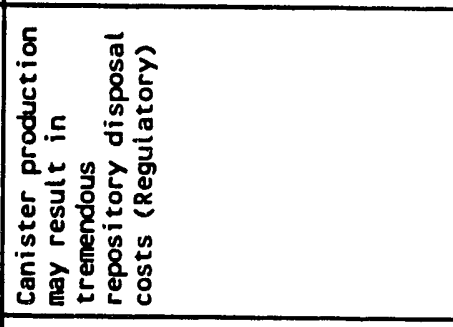 & 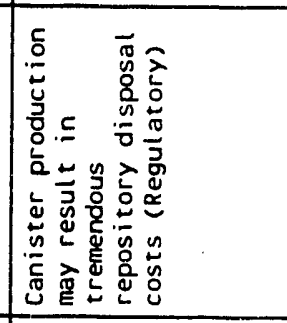 \\
\hline 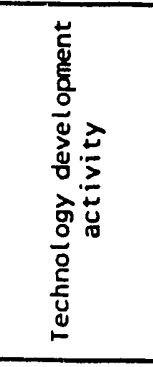 & 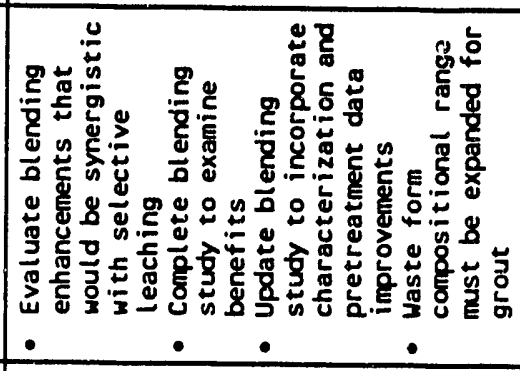 & 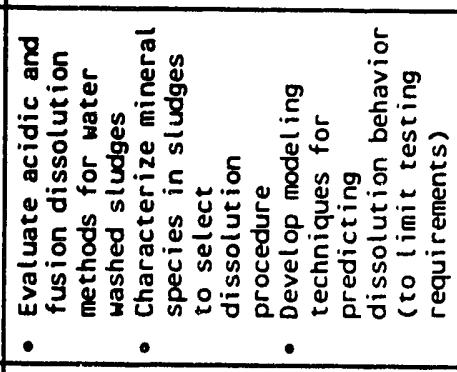 & 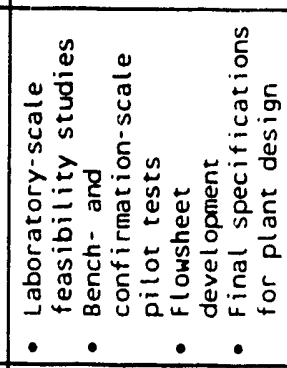 \\
\hline 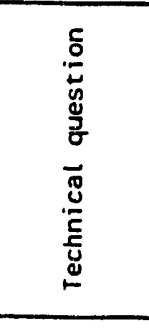 & 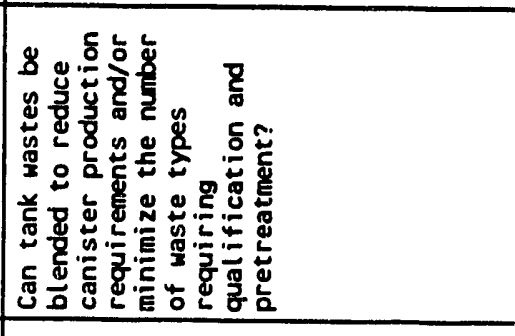 & 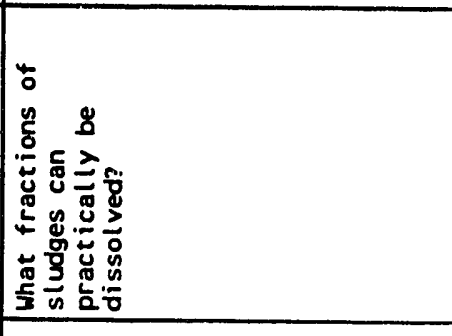 & 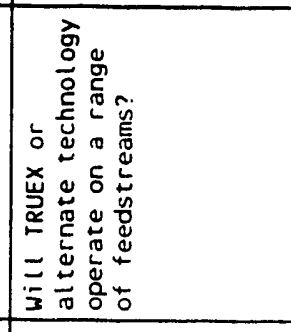 \\
\hline 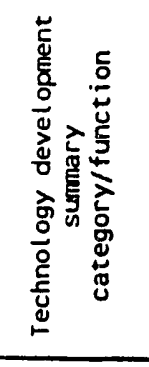 & 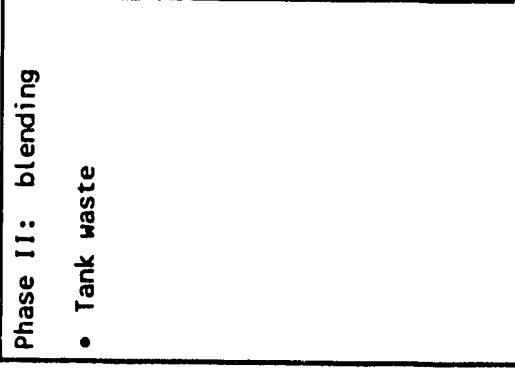 & 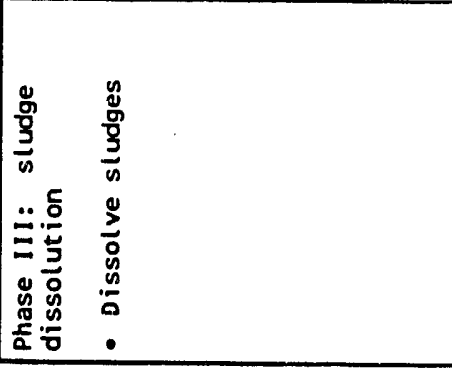 & 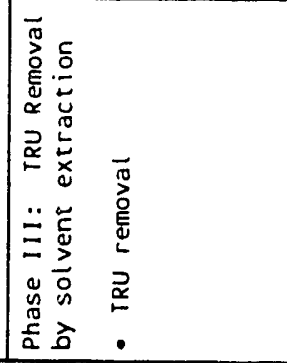 \\
\hline
\end{tabular}


WHC-EP-0629

Table 3-2. Pretreatment Technology Development Activities - Reference System. (3 sheets)

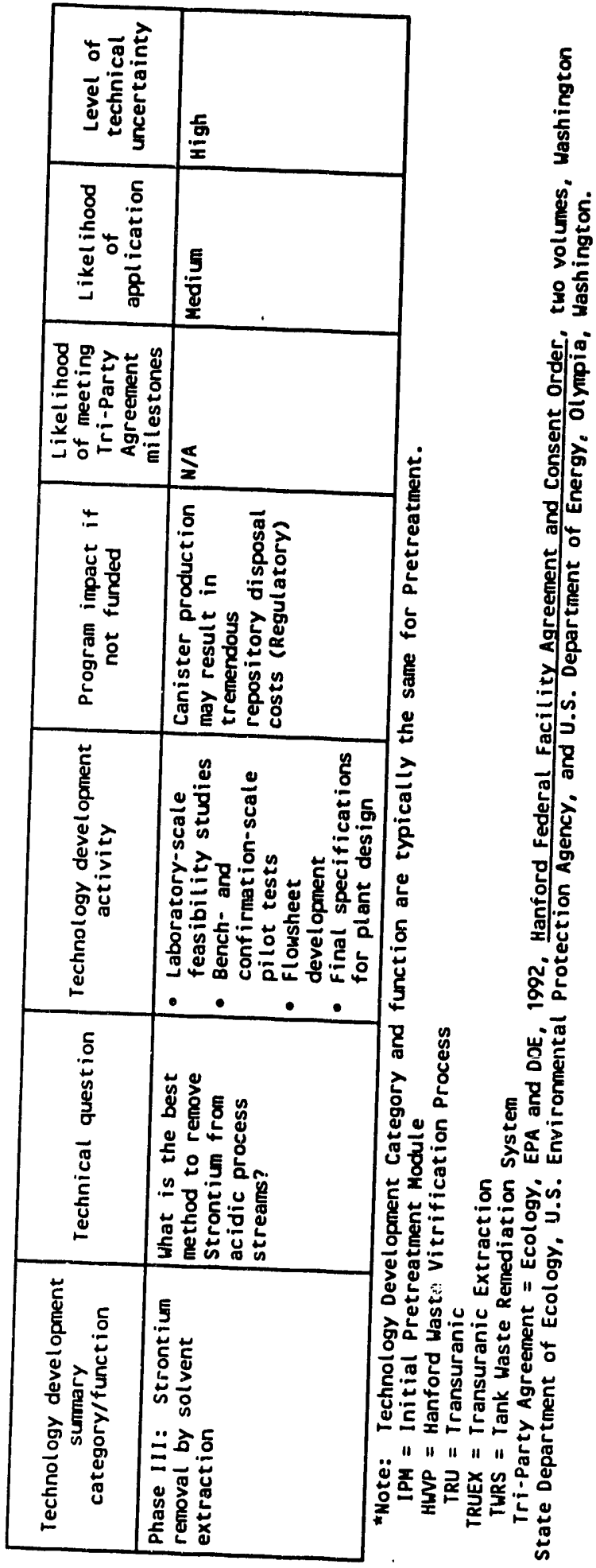


WHC-EP-0629

3.1.6.2 Functional Needs for Enhancements. Pretreatment system enhancement functions are discussed below, along with their uncertainties and vulnerabilities.

- Removal of Transuranic Radionuclides. Solvent extraction is the reference process for partitioning TRU radionuclides from dissolved sludges. Currently, transuranic extraction (TRUEX) is the preferred solvent extraction process, based on the present understanding of available process options. This separation will substantially reduce the volume of vitrified waste. However, other extractants are being investigated as alternatives to the TRUEX process should technology development efforts identify problems in deploying TRUEX at the Hanford Site. The technology requires development.

- Pretreatment Polishing Steps. Pretreatment polishing steps could be added to the long-term pretreatment strategy. Those unit operations include the removal of ${ }^{90} \mathrm{Sr}$ and TRU contamination from alkaline solutions using solid sorbents, such as silicotitanates. The technology development approach for those pretreatment systems will be similar to the cesium ion exchange technology development work discussed earlier.

- Nitrate Destruction/Recycle. The recovery and reuse of nitric acid from pretreatment processes can significantly reduce the volume of grout produced and is an integral part of the maximum pretreatment (CLEAN) option. Nitrate destruction may also be required to improve the environmental acceptability of the LLW form, i.e., grout. The optimal technology must be developed.

- Iodine Removal. Environmental acceptability of the LLW disposal form may require the removal of radioiodine $\left({ }^{129} \mathrm{I}\right)$ because of its perceived mobility in grout and in groundwater. If a high-temperature LLW waste form is ultimately adapted, the volatilization of iodine may make its separation straightforward. Alternative approaches need to be evaluated.

- Technetium Removal. Technetium removal is envisioned in the maximum pretreatment option to further reduce the radionuclide content in the grout. An alkaline-side process has been tested on a bench scale. Acid-side processes have been to a limited extent, but the technology needs to be developed further.

- Cesium Removal (Acidic Stream). The waste sludges could contain 30 to 80 percent of the cesium after sludge washing. Dissolution of these sludges to extract the TRU will dissolve the cesium into acidic solutions. Although certain candidate technologies look promising for acid-side cesium removal, they may produce too much glass or require a very narrow operating range. This is a critical area where innovative technology is needed, for both the reference and the CLEAN option. 
3.1.6.3 Prioritized Technology Development Activities in Response to

Functional Needs. Table 3-3 presents the prioritized list of technologies by functional needs for the technology enhancements. These technologies were identified and then prioritized by the TSG during the National Workshop.

Table 3-3. Prioritized Technology Development Activities-Pretreatment System Enhancements.

\begin{tabular}{|c|c|c|}
\hline Functional need & Technology & Priority \\
\hline $\begin{array}{l}\text { TRU removal } \\
\text { (a) ternatives to TRUEX) }\end{array}$ & $\begin{array}{l}\text { CMP } \\
\text { DIDPA } \\
\text { AIky Diamides } \\
\text { Extraction chromatography } \\
\text { Organic sorbents }\end{array}$ & $\begin{array}{l}2 \\
3 \\
3 \\
3 \\
3\end{array}$ \\
\hline $\begin{array}{l}{ }^{90} \mathrm{Sr} \text { and TRU removal on } \\
\text { basic side } \\
\text { (polishing) }\end{array}$ & $\begin{array}{l}\text { Titanate } \\
\text { Organic ion exchange } \\
\text { Crystallization }\end{array}$ & $\begin{array}{l}1 \\
1 \\
1\end{array}$ \\
\hline Remove/convert nitrates & $\begin{array}{l}\text { Calcine/incineration } \\
\text { Organo-chemical denitration } \\
\text { Fluidized bed calcination } \\
\text { Molten salt } \\
\text { Aluminum reduction } \\
\text { Electrochemical reduction }\end{array}$ & $\begin{array}{l}1 \\
1 \\
1 \\
1 \\
2 \\
2\end{array}$ \\
\hline Iodide removal (basic) & $\begin{array}{l}\text { Anion exchange } \\
\text { Crystallization }\end{array}$ & 1 \\
\hline $\begin{array}{l}\text { Iodide/Iodine removal } \\
\text { (acid) }\end{array}$ & $\begin{array}{l}\text { Solvent extraction } \\
\text { Anion exchange } \\
\text { Volatilize, recover from gas } \\
\text { phase }\end{array}$ & $\begin{array}{l}1 \\
1 \\
2\end{array}$ \\
\hline $\begin{array}{l}\text { Technetium removal } \\
\text { (basic) }\end{array}$ & $\begin{array}{l}\text { Crystallization } \\
\text { SREX sludge treatment } \\
\text { Organic IX } \\
\text { quaternary amines } \\
\text { Electrolytic anion exchange }\end{array}$ & $\begin{array}{l}1 \\
1 \\
2 \\
2 \\
3\end{array}$ \\
\hline $\begin{array}{l}\text { Technetium removal } \\
\text { (acid) }\end{array}$ & $\begin{array}{l}\text { TRUEX/SREX } \\
\text { Organic ion exchange } \\
\text { Tertiary amines } \\
\text { Aliquot-336 Imp Zeolites }\end{array}$ & $\begin{array}{l}1 \\
2 \\
2 \\
3\end{array}$ \\
\hline Cesium removal (acid) & RESEARCH NEEDED & \\
\hline LLW organic destruction & Same as reference tech. & \\
\hline
\end{tabular}

CMP = dihexyl-N,N-diethylcarbamoylmethyl phosphonate

$L L W=$ Low-level waste.

SREX = Strontium extraction.

$T R U=$ Transuranic.

TRUEX = Transuranic extraction. 
WHC-EP-0629

3.1.6.4 Recommended Technology Development Activities. Table 3-4 summarizes the recommended technology development activities for pretreatment system enhancements.

\subsection{ALTERNATIVE SYSTEM DEVELOPMENT}

Alternative pretreatment systems are also identified and recommended for evaluation if (1) the reference system is not selected for deployment because of the costs associated with development, demonstration, and implementation of the necessary technologies or (2) because the time to develop the technologies is not compatible with the overall remediation schedule for the Hanford Site. Further, pretreatment alternatives are required because of the uncertainties associated with the LLW form and definition of constituent limits in that form, as well as uncertainties in sufficiently reducing the volume of sludge to permit Hanford Site $H L W$ to be vitrified in a reasonable time.

\subsubsection{Description of Alternative System/Strategy}

For the purposes of this technology plan, the pretreatment alternatives focus on simpler pretreatment processes because the reference, enhancements to the reference, and the CLEAN strategy all employ more extensive pretreatment processes. These extensive pretreatments are targeted to reduce the volume of HLW and improve the acceptability of the LLW form. However, this will come at the expense of long and costly technology development efforts.

Five alternative pretreatment systems were identified during the TWRS National Technology Workshop. With the exception of calcination, these alternatives assume that organic destruction would be completed in the IPM. Each is recommended for further feasibility studies.

- Bulk Treatmen Using Precipitation Technology. This pretreatment approach uses precipitation and carrier precipitation technologies to remove radioactive contaminations from tank wastes. A wide range of precipitates has been identified for removing cesium, strontium, technetium, and TRU contamination from acidic and alkaline waste streams. The technology base suggests that precipitation processes could be engineered to complete the pretreatment mission $i$ the separation efficiency could be maintained high enough. Preliminary laboratory or flowsheet studies are needed to establish technical feasibility.

- Bulk Treatment Using Chromatography. This pretreatment approach uses ion-exchange and extraction chromatography to decontaminate tank wastes. Both alkaline and acidic side processes will be considered in this evaluation.

- Bulk Treatment Using Leaching and Ion-Exchange Process. This pretreatment approach uses technology that can be applied to the bulk leaching of major chemical components including sodium, 
Table 3-4. Pretreatment Technology Development Activities - Enhanced Systems. (2 sheets)

\begin{tabular}{|c|c|c|c|c|}
\hline 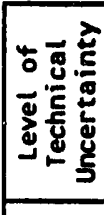 & 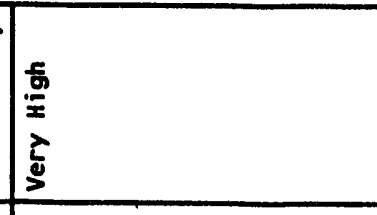 & \begin{tabular}{|l}
$\underline{\underline{D}}$ \\
\end{tabular} & \begin{tabular}{|l|}
$\mathbf{5}$ \\
$\underline{\underline{\mathbf{z}}}$ \\
\end{tabular} & 童 \\
\hline & 章 & 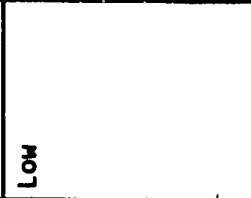 & $\mid \begin{array}{l}\frac{E}{5} \\
\frac{5}{5} \\
\frac{z}{5}\end{array}$ & $\stackrel{z}{a}$ \\
\hline$\frac{0}{2}=$ & 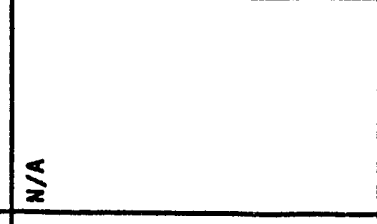 & $\underline{\mathbf{z}}$ & $\frac{s}{z}$ &  \\
\hline 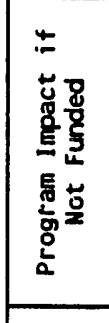 & 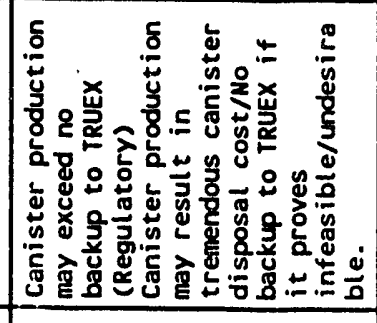 & 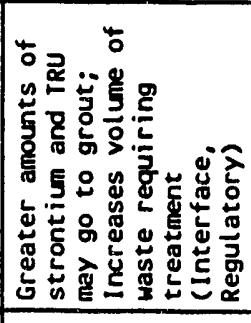 & 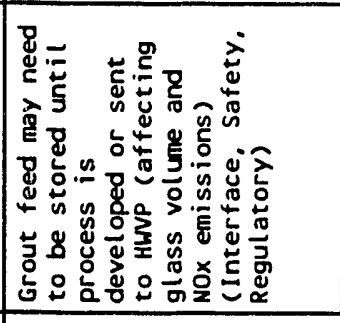 & 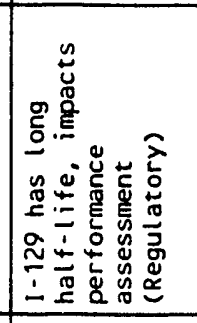 \\
\hline 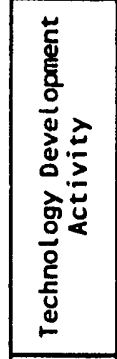 & 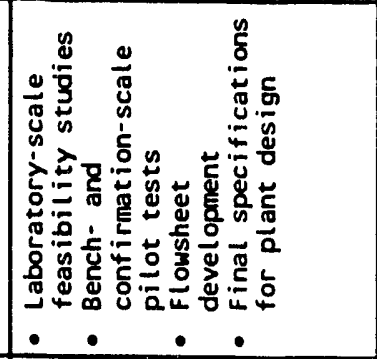 & 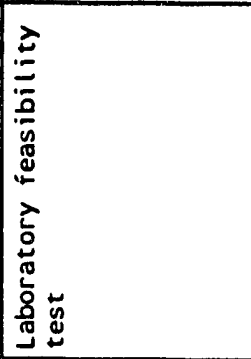 & 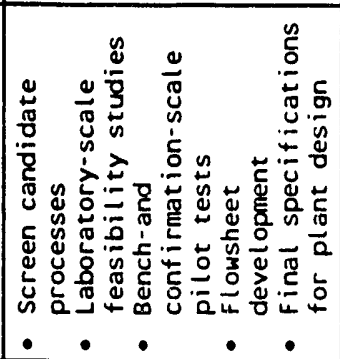 & 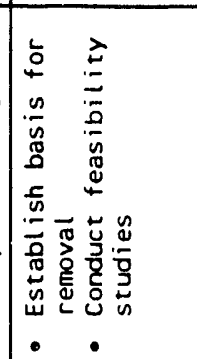 \\
\hline 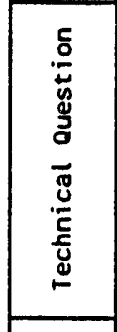 & 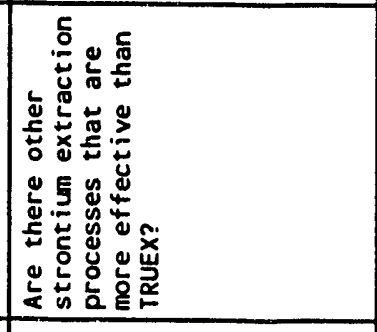 & 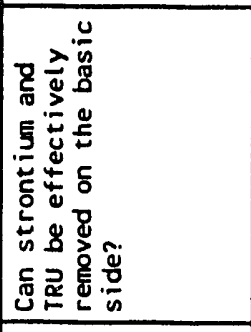 & 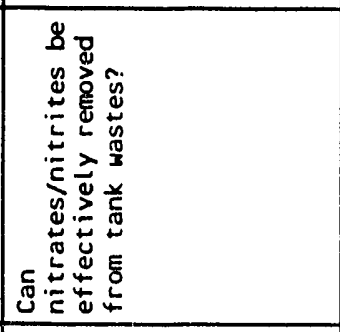 & 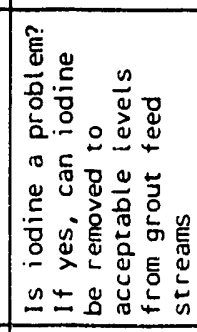 \\
\hline 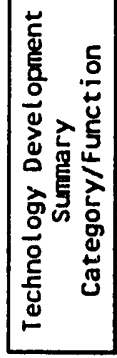 & 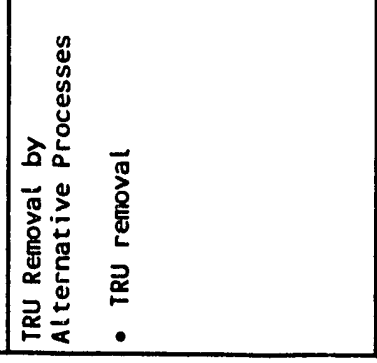 & 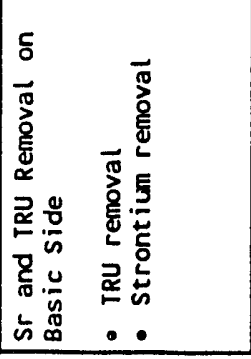 & 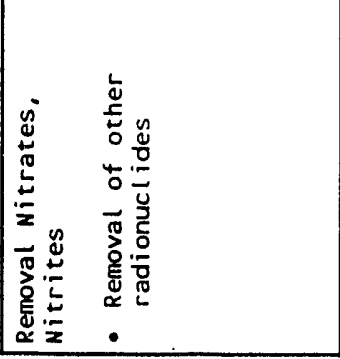 & 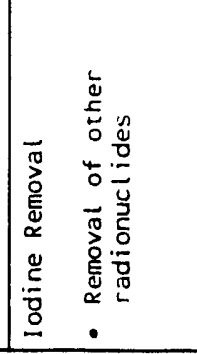 \\
\hline
\end{tabular}


Table 3-2. Pretreatment Technology Development Activities - Reference System. (2 sheets)

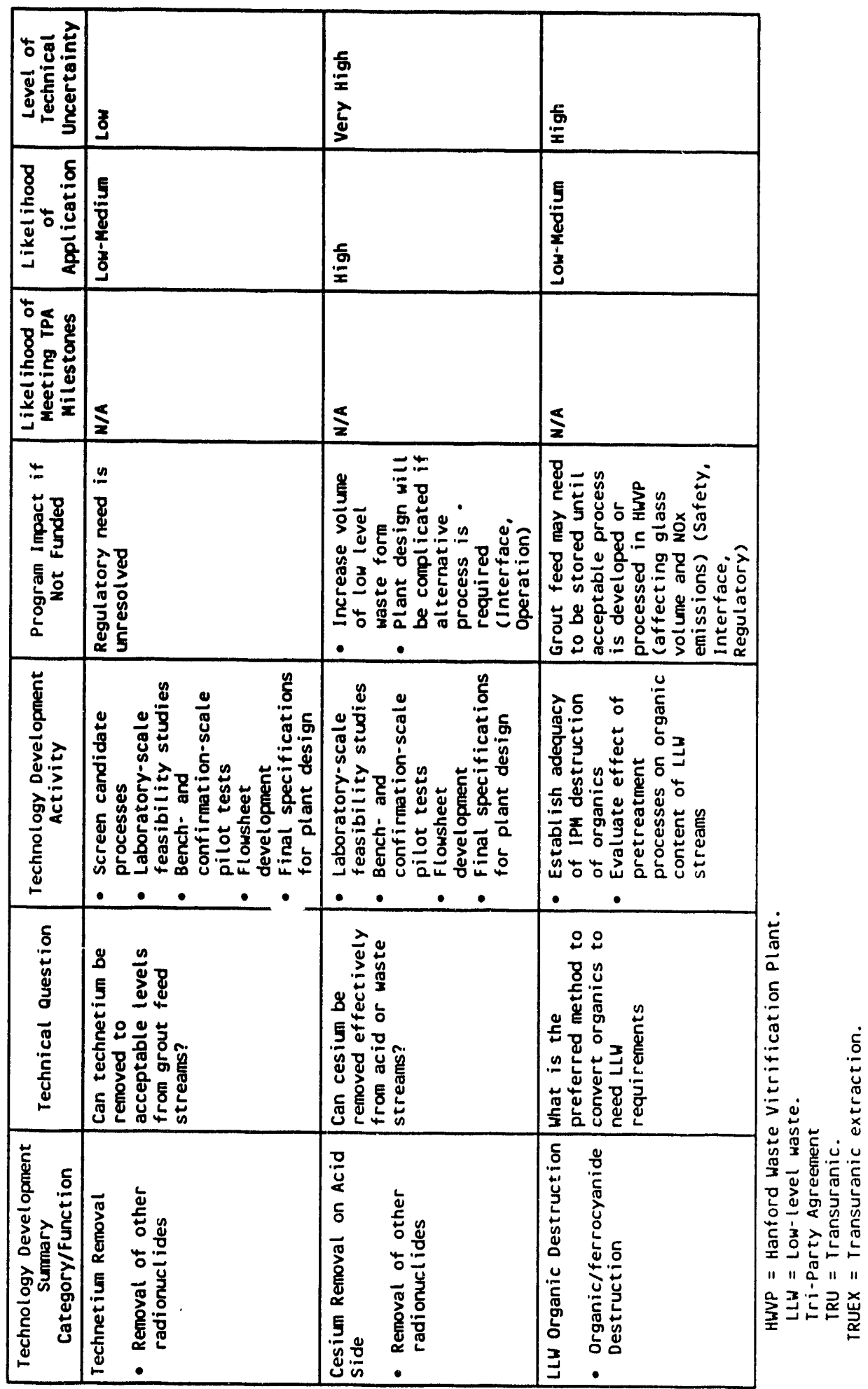


phosphorus, bismuth, aluminum, iron, and minor constituents (strontium, cesium) to reduce the volume of the HLW form. Leach solutions will be decontaminated using ion-exchange, and the sludges will be converted to a HLW form.

Alternatively, the sludge will be decontaminated by leaching radionuclides. The decontaminated sludge would be converted to a LLW form while the leach solution is handled as HLW.

- Calcine and Bulk Leaching. For this pretreatment approach, the entire volume of waste is calcined to destroy nitrate/nitrite and organics present in the waste. The resultant calcine product is contacted with a variety of chemical reagents to remove radioactive or chemical contaminants (as required).

- Sludge Washing Only. This pretreatment alternative involves sludge washing tank waste and decontamination of the supernatants and wash solutions with ion-exchange. Blending of tank wastes will be heavily relied on to reduce the HLW vitrification requirements. This alternative represents a minimum of technology development for pretreatment compared to the other pretreatment systems.

\subsubsection{Uncertainties and Pisks Associated with Alternate System}

Most of the technical and programmatic risks associated with the reference system also apply to the alternatives. The risk of generating excessive HLW for vitrification is greater with these options than with the reference or enhancements. Some of the technologies for reducing the volume of HLW are not well defined and will require extensive technology development efforts.

\subsubsection{Pretreatment Technology Development Activities}

Table 3-5 summarizes the recommended technology development activities for alternative systems.

\subsection{CLEAN OPTION}

\subsubsection{Description of CLEAN Option/Strategy}

The CLEAN option is a pretreatment option that applies aggressive pretreatment of the tank waste, as detailed in Section 4.1 .4 
WHC-EP-0629

Table 3-5. Pretreatment Technology Development Activities - Alternative Systems

\begin{tabular}{|c|c|c|}
\hline 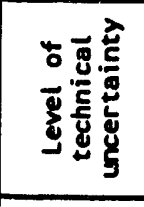 & $\mid \begin{array}{l}\mathbf{5} \\
\mathbf{I}\end{array}$ & $\frac{5}{i}$ \\
\hline 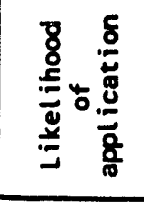 & $\underline{z}$ & $\frac{s}{z}$ \\
\hline 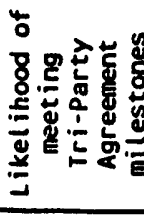 & $\leqslant$ & $\leq \frac{1}{2}$ \\
\hline 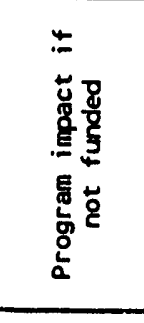 & 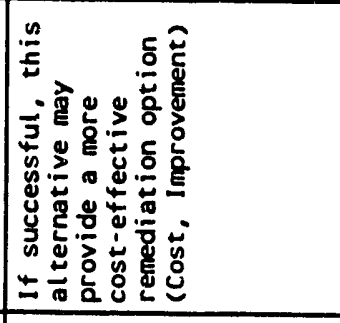 & 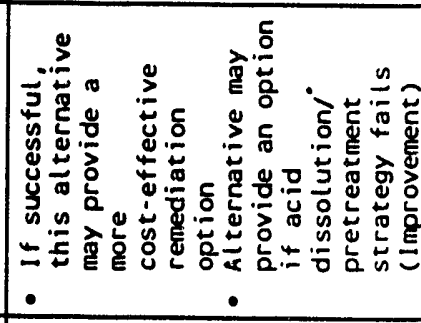 \\
\hline 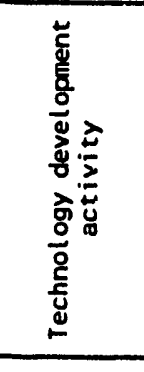 & 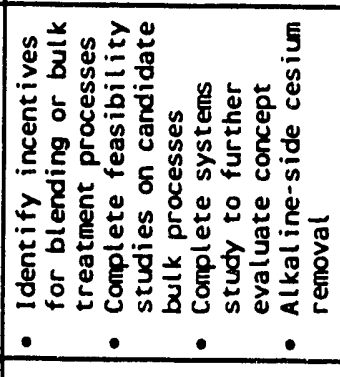 & 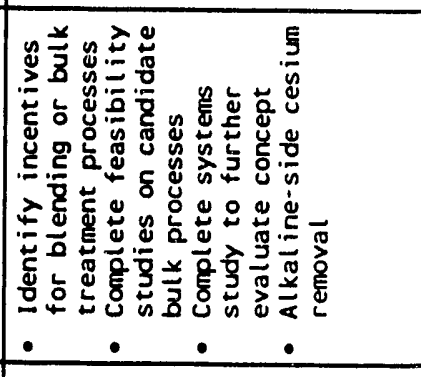 \\
\hline 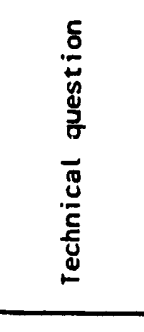 & 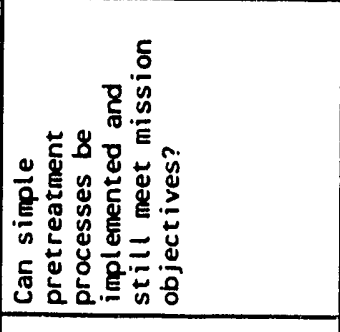 & 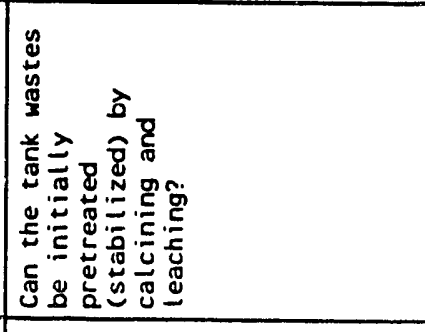 \\
\hline 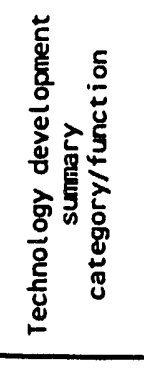 & 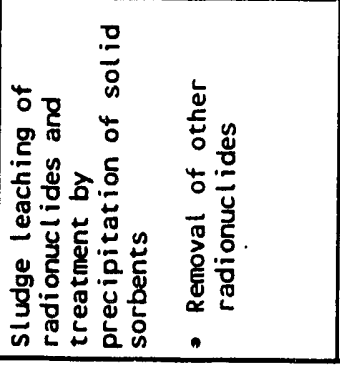 & 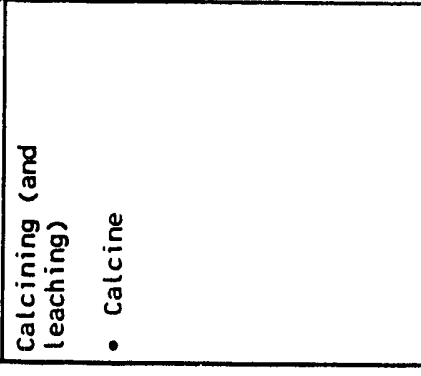 \\
\hline
\end{tabular}




\subsubsection{Uncertainties and Risks Associated with CLEAN}

In addition to the uncertainties and vulnerabilities associated with the reference and enhanced systems (whose functions are also included in CLEAN), there is uncertainty that the additional functions of the CLEAN pretreatment concept can be developed, demonstrated, and deployed in a timely manner. The costs of developing all of the CLEAN technologies are expected to be the highest of any option, and the schedule will be the longest for remediating the Hanford Site tank wastes.

\subsubsection{Prioritized Functional Needs}

The additional functions required to implement CLEAN include chemical recycle, removal of radionuclides to Class $A$, removal of heavy metals, and recovery of noble metals. These functions are described in Section 2.3. They have not been prioritized because of the limited development of the CLEAN option.

\subsubsection{Prioritized Technology Development Activities}

The TWRS TWG did not rank technologies associated with the CLEAN option as most of the functional needs require additional research to ident ify and prioritize technologies. Also, the full scope of CLEAN has not been fully formulated at this time. 
$W H C-E P-0629$

This page intentionally left blank. 
WHC-EP-0629

\subsection{TECHNOLOGY PROGRAM DESCRIPTION}

\subsection{TEEHNOLOGY PROGRAM DESCRIPTIOISS}

Section 3.0 summarized the pretreatment functional needs and, where applicable, the prioritized technology responses to those needs for the reference pretreatment system, for enhancements to the reference, and for alternatives. As a result of these functional needs and technology responses, a technology development program has been identified. Presented in this section are the planned activities by functional need for each of the pretreatmer.t system, including scope, deliverables, and schedules.

\subsubsection{Reference Technology}

The reference pretreatment system is the three-phased technology deployment strategy presented in Section 3.1. The first phase consists of organic/ferrocyanide destruction to mitigate tank safety concerns, sludge washing, and cesium ion exchange. The second phase adds tank blending and selective leaching of the slidge. The third and final phase adds sludge dissolution and TRU and strontium extraction. The technology development prugram for each of these functions is summarized below.

\subsubsection{Sludge Washing.}

Statement of Issue. Sludge washing is the minimal pretreatment that can be done on any tank sludge. It is expected that sludge washing will be performed on the sludge from each Hanford Site tank, except for complexant concentrate waste sludges. Sludge washing is defined as mixing the sludge with raw or inhibited water (dilute sodium hydroxide and sodium nitrate added), then separating the undissolved solids from the wash liquor.

The primary benefit of sludge washing will be a reduction in the volume of $\mathrm{HLW}$. Sludge washing will remove the soluble components (e.g., $\mathrm{NaNO}_{3}$, $\mathrm{NaNO}_{2}$, and sodium hydroxide) from the sludge. Included in the soluble portion of the sludge and saltcake is a large fraction of the ${ }^{137} \mathrm{Cs}$. Necessary information to be determined includes the disposition of various radionuclides in the washed solids and the wash liquor phase. This information will be used to determine what additional processing will be needed to dispose of the liquids as a low ? evel waste and what additional processing will be needed to minimize glass canister production in the HWVP.

Additional processing concerns to be addressed include, evaluation of solid-liquid separation, measurement of natural settling rates, evaluation of safety issues, such as the effect of turning the air lift circulators off on heat generation in the ageing waste tanks.

The washed sludge could be handled in one of three ways.

- It could be vitrified.

- It could be subjected to some form of intermediate processing (e.g., aluminum leaching, r romium, leaching, and TRU leaching). 
- It could be dissolved in acid and subjected to an advanced pretreatment process (e.g., TRU extraction and strontium extraction).

The option chosen will depend on the final program strategy.

A secondary benefit of sludge washing is the removal of nitrite ion. The presence of nitrite ion in the sludge would lead to $\mathrm{NO}_{x}$ generation when the sludge is dissolved in acid or when heated in the vitrification process. The removal of nitrite by sludge washing would eliminate $\mathrm{NO}_{x}$ generation during those processing steps. Also, removal of carbonate ion by sludge washing would eliminate foaming associated with the release of $\mathrm{CO}_{2}$ during acid dissolution.

Scope. Sludge washing studies will be conducted on actual tank sludge samples over a period of seven years. The objective of these studies will be to determine the effect of sludge washing on the composition of the sludge. The composition of each washed sludge (e.g., radionuclides, chromium, aluminum, iron, bismuth, and phosphorus contents) will be determined, as will the composition of the wash solutions. These data will be used to make decisions as to further processing of the sludges, i.e., direct vitrification, intermediate processes, or advanced pretreatment.

The tank sludges investigated in any given fiscal year will be obtained from tank core samples taken in the previous year. For example, sludges from tanks core-sampled in FY 1992 will be investigated in FY 1993. The sludge washing studies will be coordinated with sludge leaching and sludge dissolution studies to get the maximum amount of information from a given sludge sample.

Additional work scope included under sludge washing involves the development and testing needs for performing sludge wash operations. Equipment to be tested/developed includes interface monitoring equipment for evaluation of settling progress, and an online TRU monitor for continuous monitoring of the alpha activity within the supernate liquors. Additionally, methods of improving solids settling by controlling crystallization will be investigated.

A test will also be performed on tank 10l-AZ to verify that air lift circulators can be turned off without causing a steam bump in the solids. The information from this test will be used to verify aging waste tank heat build-up models.

Finally, a pilot-scale facility will be constructed and operated to produce $150-\mathrm{kg}$ samples of washed sludges for HWVP waste form qualification feed. This facility will then be operated for the duration of the tank waste remediation program. 
Status. In previous years, testing of individual sludges has been performed to determine separation factors for the various components. This testing has been limited to the small (approximately 2-gm) samples of tanks previously cored. This information is very limited and continued testing of this material is warranted. Additional testing of small samples has been performed in conjunction with acid-dissolution studies. These tests also included monitoring of solids settling rates and the effect of dilute sodium hydroxide on the settling rates.

Previously, a device to continuously measure the concentration of transuranic materials in the sludge liquor has constructed and tested. A full-scale TRU monitor has also been constructed and operated to determine the proper internal configuration for good liquid and solids flow. Final testing is to be performed in conjunction with large-scale sludge washing operations to test a full-size TRU monitor with aging waste material (NCAW).

Remaining Tasks. The following tasks are needed to bring this technology to completion.

- Complete development of the TRU monitor, especially with respect to materials of construction, and testing of the full-size device with actual waste.

- Perform extensive testing of all tanks to determine sludge 'wash parameters, such as component separation and solids settling rates.

- Perform characterization of mineral phases in washed solids.

- Develop a computer model to predict component separations.

- Complete testing of instrumentation for monitoring sludge settling.

- Perform tank 101-AZ settling-bump test

- Resolve concerns about pitting corrosion during and after sludge washing.

- Construct and operate a pilot-scale sludge wash facility to produce feed samples for waste form qualification.

Schedule Requirements/Milestone Table. The key milestones associated with the development of the sludge washing process are listed in Table 4-1. The milestones shown are those that can be clearly defined at this point in time. Additional milestones will most likely be added in the future.

\subsubsection{Cesium Removal by Ion Exchange.}

Statement of Issue. The separation of alkaline supernatants, washing of HLW sludges, and retrieval of tank wastes will generate liquid containing radioactive cesium $\left({ }^{137} \mathrm{Cs}\right)$. Before disposal in grout, these liquid wastes will be treated at the IPM by ion exchange to remove a majority of the cesium. In previous screening studies, various ion exchange media were tested for their capacity to recover cesium. Extensive studies to characterize the 
Table 4-1. Sludge Washing Milestones.

\begin{tabular}{|c|c|l|}
\hline Milestone & $\begin{array}{c}\text { Completion } \\
\text { date }\end{array}$ & \multicolumn{1}{|c|}{ Milestone description } \\
\hline 1 & $09 / 99$ & $\begin{array}{l}\text { Complete sludge wash laboratory testing of all } \\
\text { Core samples. }\end{array}$ \\
\hline 2 & $09 / 93$ & $\begin{array}{l}\text { Complete preparation of a cont inuous sludge } \\
\text { washing flowsheet for neutral ized cladding } \\
\text { removal waste. }\end{array}$ \\
\hline 3 & $09 / 94$ & $\begin{array}{l}\text { Complete tank 105-C sludge washing flowsheet } \\
\text { based on laboratory data. }\end{array}$ \\
\hline 4 & $09 / 94$ & $\begin{array}{l}\text { Complete in-tank operational test of in-tank } \\
\text { washing instrumentation. }\end{array}$ \\
\hline 5 & $09 / 95$ & $\begin{array}{l}\text { Complete tank 10l-Az sludge wash flowsheet based } \\
\text { on computer model. }\end{array}$ \\
\hline 6 & $09 / 96$ & $\begin{array}{l}\text { Complete testing of corrosion probe in first } \\
\text { selected double-shell tank. }\end{array}$ \\
\hline 7 & $01 / 96$ & $\begin{array}{l}\text { Complete corrosion evaluation for neutral ized } \\
\text { cladding removal waste. }\end{array}$ \\
\hline 8 & $01 / 98$ & $\begin{array}{l}\text { Complete transuranic monitor test in conjunction } \\
\text { with tank lol-Az sludge washing operations. }\end{array}$ \\
\hline 9 & $01 / 98$ & $\begin{array}{l}\text { Start up sludge washing pilot plant for waste } \\
\text { form qualification in new hot pilot facility. }\end{array}$ \\
\hline
\end{tabular}

equilibrium behavior of selected ion exchange media over a wide range of conditions have also been completed. The remainder of the ion-exchange technology program entails defining, verifying, and recommending an ion-exchange process for the IPM through laboratory-scale column studies, ion-exchange resin stability studies, and pilot-plant process demonstrations.

The concentration of 1 iquid wastes processed through the IPM ion-exchange system will vary. Some feeds could conceivably be full-strength supernatant liquors decanted directly from the tanks; other feeds will be wash waters that could vary widely in concentration. Variations also will occur in the relative concentration of cesium and significant constituents ( $\mathrm{Na}, \mathrm{K}, \mathrm{Rb}, \mathrm{OH})$ from one type of waste to the next. These and other independent variables that affect the performance of ion-exchange columns need to be characterized to support the design and subsequent operation of the ion-exchange system.

Scope. Batch equilibrium studies initiated during FY 1992 will be concluded during FY 1993 to provide a comprehensive reference of equilibrium behavior for the ion-exchange media under consideration. This task is designated design basis experiment (Phase 0 ). As the IPM project progresses and additional design basis information requirements are ident ified, it is anticipated that further Design Basis Experiments (Phase 1, Phase 2, etc.) will be completed. For example, during FY 1994 Phase 1 is planned to verify 
the baseline IPM flowsheet on a bench scale. In FY 1995, it is anticipated that project design, safety, and regulatory documents will have identified issues requiring resolution through laboratory studies.

The studies being conducted during FY 1993 include a bench-scale column-loading study to define the breakthrough behavior of selected ion-exchange resins with emphasis on the operation of a multiple-column system and establishing the "maximum" volumetric throughput for the subject resins. In conjunction with the loading studies, there will also be experiments to optimize and verify the conditions for elution and regeneration of the columns. A study of the effects of radiation on two resins produced by Boulder Scientific Co. (resorcinol-formaldehyde polymer) and the Rohm and Haas Co. (CS-100) will also be completed. This study will examine the degradation of resin performance, the gas releases during irradiation, the water soluble organic degradation products, the corrosive effects during irradiation, and a comparison of results for irradiation that occur under static and flowing
conditions.

In addition to the above laboratory- and bench-scale work, preparations for an ion-exchange pilot plant will be initiated in FY 1993. This will include a task to document the objectives of a pilot plant and an assessment of pilot-plant facilities that are available within the DOE complex. By the end of FY 1993 a decision will be made on the course of action (e.g., pilot plant at Pacific Northwest Laboratory (PNL) versus Savannah River Technical Center (SRTC) and documentation of the functions and requirements for the pilot plant. Pilot-plant design, procurement and installation activities will be completed by the end of Calendar Year (CY) 1994, and pilot-plant testing and reporting will be reported by the end of $\mathrm{CY} 1995$.

The final activities within the scope of the ion-exchange development program will include development of a preliminary conceptual flowsheet for IPM ion exchange at the end of $\mathrm{CY} 1993$, a conceptual flowsheet at the end of $\mathrm{CY}$ 1994, and a final flowsheet April 30, 1996. Each flowsheet update will incorporate the results of laboratory-scale and pilot-plant results, as well as changes in IPM process philosophy.

Simultaneously with the cesium ion exchange development activities, the first CPU is being designed and procured to complete cesium ion exchange on tank supernatant. The CPU is scheduled to be deployed in the tank farms several years before IPM is ready for radioactive operations. Current plans are to use resorcinol resin developed at the Savannah River Site.

Status. In previous years, screening studies were conducted to identify ion exchangers for use in B Plant for the pretreatment of neutralized current acid waste (NCAW) supernatant and wash waters. The selection criteria were a high capacity for cesium in the presence of a high concentration of sodium, and reasonable stability in a harsh radioactive and chemical environment. Those screening studies narrowed the choices to a Rohm and Haas phenolic resin (CS-100 and an SRTC-developed resorcinol resin).

During FY 1992, an extensive test program was started to quantify the equilibrium behavior of the above resins. These tests established the equilibrium capacity of the resins under a wide range of concentrations and over the temperature range that would be encountered during processing. For 
the sake of comparison, identical tests with an inorganic exchanger (IE-96) were completed at the same time. However, IE-96 is the ion exchanger in use at the West Valley Demonstration Project. IE-96 is not in contention for use at the IPM because it is not stable in Hanford Site highly alkal ine waste solutions.

Approximately 500 experiments were completed with CS-100 and the resorcinol resin. The primary conclusions of the FY 1992 work were that: (1) the ion-exchange capacity of CS-100 and IE-96 doubles over the temperature range from 40 to $10^{\circ} \mathrm{C}$, while the capacity of the resorcinol resin improves only slightly; (2) the resins' capacity for cesium correlates with the total sodium and equilibrium sodium-to-cesium ratio (i.e., capacity in simulated NCAW and simulated complexant concentrate (CC) were found to be the same, implying that generic ion-exchange data can be applied to a broad range of waste types); and (3) that the capacity of the exchangers has the following order: resorcinol > IE-96 > CS-100, although the difference in capacity diminishes as the sodium/cesium ratio diminishes. The interference effects from potassium and rubidium were only partially characterized in these experiments.

Remaining Tasks. The following tasks are needed to bring this technology activity to completion.

- Conduct design basis experiments to provide comprehensive ion exchanger equilibrium data, verify the design basis flowsheet, and provide other project design-basis information as the IPM project evolves.

- Conduct column-loading and elution studies.

- Conduct radiation and chemical stability testing.

- Evaluate pilot-plant objectives.

- Design, procure, install, and operate a pilot plant.

- Update periodic IPM flowsheets to support the project design.

Schedule Requirements/Milestone Table. Table 4-2 is an ion-exchange technology schedule that is unconstrained by IPM project deadiines. The milestones lead to IPM flowsheet documents that support the project.

\subsubsection{Organic/Ferrocyanide Destruction}

Statement of Issue. The following classes of tanks at the Hanford Site are considered to have the highest safety risks.

- Explosive gas (H2) generating tanks

- Organic tanks

- Ferrocyanide tanks. 
Table 4-2. Ion Exchange Technology Schedule.

\begin{tabular}{|c|c|c|}
\hline Milestone & Completion date & Milestone description \\
\hline 1 & $04 / 93$ & Report on comprehensive equilibrium study \\
\hline 2 & $09 / 93$ & Design basis test plan (Phase 1) \\
\hline 3 & $03 / 94$ & Design basis test report (Phase 1) \\
\hline 4 & $07 / 93$ & Report on column-loading and elution study \\
\hline 5 & $08 / 93$ & Report on resin radiation/chemical stability \\
\hline 6 & $06 / 93$ & $\begin{array}{l}\text { Report on pilot-plant functions and } \\
\text { requirements }\end{array}$ \\
\hline 7 & $12 / 93$ & $\begin{array}{l}\text { Pilot-plant test description and } \\
\text { specifications }\end{array}$ \\
\hline 8 & $09 / 93$ & $\begin{array}{l}\text { Draft IPM ion-exchange preliminary conceptual } \\
\text { flowsheet }\end{array}$ \\
\hline 9 & $12 / 93$ & $\begin{array}{l}\text { IPM ion-exchange preliminary conceptual } \\
\text { flowsheet }\end{array}$ \\
\hline 10 & $09 / 94$ & $\begin{array}{l}\text { Optimization test report for cesium ion } \\
\text { exchange }\end{array}$ \\
\hline 11 & $09 / 94$ & Complete resin procurement \\
\hline 12 & $04 / 94$ & Compiete pilot-plant design \\
\hline 13 & $09 / 94$ & Complete pilot-plant procurement \\
\hline 14 & $12 / 94$ & Complete pilot-plant installation \\
\hline 15 & $12 / 94$ & IPM ion-exchange conceptual flowsheet \\
\hline 16 & $12 / 95$ & Design basis test report (Phase 2) \\
\hline 17 & $12 / 95$ & Complete pilot-plant test report \\
\hline 18 & $03 / 96$ & IPM ion-exchange final flowsheet \\
\hline
\end{tabular}

$I P M=$ Initial Pretreatment Module. 
Problems associated with these types of tanks could be lessened dramatically if the organic or ferrocyanide constituents of the waste could be destroyed or removed. Near-term processing to accomplish this destruction or removal may be needed to ensure continued safe storage of these wastes until final disposal process operations can be initiated. However, the scope of the organic destruction requirement currently is not well understood, nor are the technologies that can accomplish the eventual objectives well developed. Thus, the objective of this task is to evaluate and develop organic destruction technologies to be incorporated into the IPM or, possibly, into a standalone CPU. Also, ensuring that the organic destruction process selected meets the current grout feed specification of $1,500 \mathrm{ppm}$ organic carbon is a technical concern. Unless destroyed before grouting, organic complexants may greatly facilitate unacceptable transport of radionuclides or toxic metal leached from the grouted waste to the environment. Certain organic compounds may also be listed as hazardous constituents.

Scope. This work includes tasks to be performed by Westinghouse Hanford Company (WHC), PNL and outside vendors working through WHC and PNL. Laboratory studies will be conducted on selected technologies to provide data necessary to narrow technology choices. The tasks include establishing testing standards, and performing preliminary laboratory tests using synthetic wastes (based on the contents of an organic and a ferrocyanide watch list tank), and preliminary laboratory tests with actual wastes (from both an organic and a ferrocyanide watch list tank). Based on the results of these studies, a pilot plant will be designed and built for one or more of the selected technologies. Engineering evaluations of the data from the laboratory tests and operating the pilot plant will be completed to support decisions on the final technology and the design, fabrication, and operation of a radioactive pilot facility. Operation of the hot pilot plant on actual Hanford Site tank waste will support IPM goals by providing data for operation and full-scale IPM design that cannot be obtained by tests of waste simulants. Data will be collected and compared to batch and cold pilot plant data in the areas of chemical kinetics, element phase distribution, offgas composition, destruction efficiencies, and safety.

A separate composition variability study is being conducted by Grout Technology. The available grout formulas and validated core sample data will be used to develop a formulation for grouting treated wastes. This study will determine effects that treating simulated and actual watch list tank waste will have on grout quality.

Status. A technology plan was developed and implemented in Fy 1993. Some preliminary laboratory work has been performed. However, laboratory testing with ferrocyanide waste cannot begin until a suitable analys is method is available. Ozonation tests were performed on a simulant of waste from tank 241-SY-101 in FY 92. Test plans have been completed for conducting ozone tests using actual 241-SY-101 wastes in FY 93. Batch wet oxidation tests were conducted using an organic waste simulant. A bench-scale continuous low-temperature wet oxidation reactor is being fabricated. Some laboratory calcination work using actual waste has been completed. A calcination plasma arc demonstration using synthetic waste also was completed. Laboratory organic destruction tests were performed on synthetic wastes using an electrochemical cell. Other laboratory testing is to be completed in FY 1993. 
The concept for the cold pilot plant is being developed. A safety evaluation was completed and a detailed design for the ozone process was initiated. Preliminary flowsheets for the ozone, low-temperature wet oxidation, and calcination technologies are being prepared and finalized in FY 1993. An independent peer review of the IPM Engineering study recommended hot-pilot-plant testing of the destruction technology to confirm early findings. An IPM technology plan was developed for FY 1993 to include grout testing of treated waste and to establish a baseline for the destruction technologies. The plan includes grout testing of ozone-treated simulated and actual waste from tank 241-SY-101. Additional grout tests may be performed in FY 1993 on 241-SY-101 waste simulants after treating the simulant using the calcination and low-temperature hydrothermal processes. issue.

Remaining Tasks. Completion of the following tasks will close this

- Develop destruction testing standards and laboratory analys is methods.

- Perform preliminary laboratory tests on synthetic and actual organic and fer rocyanide wastes from watch list tanks

- Complete ozone cold pilot plant and test with waste simulants; procure or identify an offsite cold pilot plant for conducting low-temperature wet oxidation tests using simulants; complete design of calcination reactor, and complete tests using waste simulants.

- Complete preliminary and revised flowsheets for the ozone, low-temperature wet-oxidation and calcination technologies as input to design activities.

- Define requirements for the hot pilot plant facility; design, fabricate, and install equipment in a hot cell complex; and complete tests with actual wastes.

- Perform grout tests on other watch list tank waste and destruction technologies, as required. Develop formulations from the current grout technology database and recommend grout formulation changes, as required.

Schedule Requirements/Milestone Table. Table 4-3 lists the key milestones associated with organic/ferrocyanide destruction.

\subsubsection{Selective Leaching of Sludge.}

Statement of Issue. It is expected that advanced sludge pretreatment processes, such as the TRUEX process, will not be available until approximately 5 to 10 years after the startup of HWVP. Thus, there is a possibility that gaps may occur in the feedstock for HWVP before the startup of the second pretreatment module (SPM). Selective leaching processes might be implemented on certain wastes to provide continuity of feed to HWVP if a gap occurs between the feeds provided by sludge washing and the startup of the SPM. Leaching processes are not expected to reduce the HLW volume to the 
WHC-EP-0629

Table 4-3. Organic/Ferrocyanide Destruction Milestones.

\begin{tabular}{|c|c|c|}
\hline Milestone & Completion date & Milestone description \\
\hline 1 & $06 / 93$ & $\begin{array}{l}\text { Recommend preferred organic } \\
\text { processes to conceptual design } \\
\text { report }\end{array}$ \\
\hline 2 & $09 / 93$ & $\begin{array}{l}\text { Issue report on alternative } \\
\text { organic destruction } \\
\text { technologies }\end{array}$ \\
\hline 3 & $06 / 94$ & $\begin{array}{l}\text { Issue report on synthetic } \\
\text { waste laboratory tests }\end{array}$ \\
\hline 4 & $06 / 96$ & $\begin{array}{l}\text { Start grout tests of synthetic } \\
\text { and watch list tank wastes }\end{array}$ \\
\hline 5 & $9 / 93$ & $\begin{array}{l}\text { Issue preliminary report on } \\
\text { laboratory tests with tank } \\
\text { wastes }\end{array}$ \\
\hline 6 & $03 / 95$ & $\begin{array}{l}\text { Complete construction of } \\
\text { calcine pilot plant }\end{array}$ \\
\hline 7 & $01 / 95$ & $\begin{array}{l}\text { Complete construction of ozone } \\
\text { pilot plant }\end{array}$ \\
\hline 8 & $03 / 98$ & $\begin{array}{l}\text { Issue report on cold pilot } \\
\text { plant tests }\end{array}$ \\
\hline 9 & $03 / 93$ & $\begin{array}{l}\text { Complete preliminary ozone } \\
\text { flowsheet }\end{array}$ \\
\hline 10 & $09 / 93$ & $\begin{array}{l}\text { Complete preliminary calcine } \\
\text { flowsheet }\end{array}$ \\
\hline 11 & $12 / 98$ & Complete hot pilot plant tests \\
\hline
\end{tabular}

extent advanced pretreatment methods wi11, but they may be easily implemented in the IPM at a modest cost. The costs of performing such processes may be offset by the cost of having HWVP idle from lack of feed. This task will address the development of appropriate leaching technologies.

Scope. Two general types of leaching methods will be considered: (1) leaching of nonradioactive components (e.g., aluminum, silicon, chromium) from the tank sludges, and (2) leaching of TRUs from the sludges. In the first approach, the volume of HLW is reduced by dissolution of certain sludge components, while the TRUs remain in the sludge. The leached sludge would be handled as HLW. In the second approach, the HLW volume is reduced by dissolution of the TRU portion of the waste, while the bulk waste material remains undissolved. If sufficiently decontaminated, the remaining solids could be handled as LLW. The leachate could be vitrified directly or processed further to concentrate the TRUs. 
Intermediate processing studies will be ongoing through FY 2002. The scope of this work will involve: (1) identifying the tank sludges that might be amenable to pretreatment by leaching methods, (2) developing of the process chemistry needed to leach the desired components from the sludge,

(3) developing the process flowsheets for each candidate waste type, and (4) testing the leaching processes at laboratory-, bench-, and pilot-plant scales. Investigations will focus on removing aluminum and silicon by caustic leaching, removing chromium by oxidation to $\mathrm{CrO}_{4}{ }^{2-}$ or by selective leaching with complexants, leaching TRUs with dilute $\mathrm{HNO}_{3}$ (possibly in the presence of an oxidant), and leaching TRUs from alkaline tank sludges (e.g., with complexants and water-soluable chelates). For planning purposes, it is assumed that TRU leaching will be investigated for all sludges that are TRU wastes, but those wastes that have borderline TRU contamination levels (e.g., 100 to $500 \mathrm{nCi} \mathrm{TRU} / \mathrm{g}$ ) will be given priority. Aluminum and silicon leaching would be done on those tanks that contain significant quantities of these elements. Chromium leaching will only be done on wastes with significant chromium content.

Status. A method to leach aluminum, chromium, phosphorous and sulfur from PFP sludge (tank SY-102) has been demonstrated at a laboratory scale using actual PFP sludge (Lumetta et a1. 1992; Lumetta and Swanson 1993C). This method involves leaching the sludge with $0.1 \mathrm{M}$ sodium hydroxide at $100{ }^{\circ} \mathrm{C}$, then with $\mathrm{KMnO}_{4}$ at $100{ }^{\circ} \mathrm{C}$. In initial tests, this method was found to remove greater than 95 percent of the aluminum, chromium, phosphorous, and sulfur from the PFP sludge. Implementation of this process would be expected to result in the production of -500 canisters of glass for disposal of this waste, as opposed to $\sim 2,500$ canisters if only sludge washing is employed. Further laboratory testing of this method is required to ensure that the method is applicable for the entire volume of sludge in the tank. Also, laboratory tests are required to ensure that the leach solutions are non-TRU.

Leaching of alkaline-washed sludge from SST U-110 with $2 \mathrm{M} \mathrm{HNO}_{3}\left(100{ }^{\circ} \mathrm{C}\right)$ was found to dissolve the TRU content of the sludge without dissolving a large fraction of the sludge (Lumetta et al. 1993b). The initial tests suggest that most $(-75 \%)$ of the sludge from tank $U-110$ can be handled as LLW, with the resulting grout form meeting Nuclear Regulatory Commission (NRC) Class C LLW criteria. The acid leach solution could be sent to HWVP directly or processed further to concentrate the TRUs.

It is expected that as more tank wastes are investigated, other wastes will be identified that could be pretreated using leaching methods. issue:

Remaining Tasks. Completion of the following tasks will close this

- Identification of wastes that have chemical components that would benefit from selective leaching processes

- Screening study of potential reagents to oxidize chromium(III) to chromium(VI) and selection of the best oxidant

- Screening study of potential complexants for the selective leaching of chromium from alkaline tank sludges and selection of the best complexant chromium leaching agent 
- Laboratory-scale and larger scale testing of chromium-leaching agents with actual waste

- Identification of wastes that have high aluminum and silicon contents

- Laboratory-scale and larger scale testing of leaching processes for the removal of aluminum and silicon with actual waste

- Bench-scale testing of caustic leaching with actual waste

- Screening study of potential complexants for the selective leaching of TRUs from alkaline tank sludges and selection of the best complexant TRU leaching agent

- Laboratory-scale and larger scale testing of TRU-leaching agents with actual waste

- Laboratory study of the corrosion effects of higher oxidation state components

- Determination of the need to reduce chromium(VI) to chromium(III) before feeding leach liquors to grout

- Flowsheet development for selective leaching processes.

Schedule Requirements/Milestone Table. Selective sludge leaching studies will be ongoing through FY 2002. Studies will be conducted based on tank composition data to identify tank wastes that will benefit from selective component leaching. Each particular tank sludge will be evaluated as samples become available. The key milestones associated with the development of the selective leaching processes are listed in Table 4-4. The milestones shown are those that can be clearly defined at this time. Additional milestones will likely be added in the future.

\subsubsection{Blending.}

Statement of Issue. Many waste streams expected as feed to the HWVP and the Grout Treatment Facility have components that limit the waste loading. Blending of waste feed streams is being considered as a simple but effective method of increasing the waste loading in grout and glass. The basic concept is that a feed high in one component will be mixed with another feed that contains a high level of a different component, producing a blended stream with a lower concentration of both components.

Scope. Development of computer software to examine benefits of blending, which incorporates all of the tank waste compositions and explores the impact of various assumptions and constraints, will be continued. This software is being developed to access a tank waste database and interface with databases or other software containing information on pretreatment and waste disposal processes. The completed software will provide an optimum treatment strategy for a given set of constraints and will allow "what if" studies to be readily performed. Continued use of the software by systems personnel is desirable for feedback to the software development. 
Table 4-4. Selective Leaching Milestones.

\begin{tabular}{|c|c|c|}
\hline Milestone & Completion date & Milestone description \\
\hline 1 & $09 / 93$ & $\begin{array}{l}\text { Update flowsheet for intermediate } \\
\text { processing Plutonium Finishing Plant }\end{array}$ \\
\hline 2 & $09 / 94$ & $\begin{array}{l}\text { Complete laboratory-scale testing with } \\
\text { FY } 1992 \text { cores }\end{array}$ \\
\hline 3 & $09 / 94$ & $\begin{array}{l}\text { Determine what tanks sampled in FY } 1992 \\
\text { are candidates }\end{array}$ \\
\hline 4 & $09 / 95$ & $\begin{array}{l}\text { Complete laboratory-scale testing with } \\
\text { FY } 1993 \text { cores }\end{array}$ \\
\hline 5 & $09 / 95$ & $\begin{array}{l}\text { Determine what tanks sampled in FY } 1993 \\
\text { are candidates }\end{array}$ \\
\hline 6 & $09 / 96$ & $\begin{array}{l}\text { Complete laboratory-scale testing with } \\
\text { FY } 1994 \text { cores }\end{array}$ \\
\hline 7 & $09 / 97$ & $\begin{array}{l}\text { Complete laboratory-scale testing with } \\
\text { FY } 1995 \text { cores }\end{array}$ \\
\hline 8 & $09 / 98$ & $\begin{array}{l}\text { Complete laboratory-scale testing with } \\
\text { Fy } 1996 \text { cores }\end{array}$ \\
\hline 9 & $09 / 99$ & $\begin{array}{l}\text { Complete laboratory-scale testing with } \\
\text { FY } 1997 \text { cores }\end{array}$ \\
\hline 10 & $09 / 00$ & $\begin{array}{l}\text { Complete laboratory-scale testing with } \\
\text { FY } 1998 \text { cores }\end{array}$ \\
\hline 11 & $09 / 01$ & $\begin{array}{l}\text { Complete laboratory-scale testing with } \\
\text { FY } 1999 \text { cores }\end{array}$ \\
\hline
\end{tabular}

Status. An initial study was completed in FY 1993 that identified the magnitude of the benefits from blending. This study indicates that the waste loading in the grout and glass can be increased and that the number of components exceeding the grout and glass specifications can be greatly reduced but not completely eliminated. This study also identified limiting case grout components (fluorine, lead) that could result in more grout vaults than the current estimates. Blending is viewed as a supplemental strategy that should be considered as a part of all waste pretreatment systems.

The initial blending study focused on blending wastes from pretreatment with sludge wash and selective leaching and did not consider more aggressive pretreatment methods. The software that is being developed incorporates an improved model for estimating glass waste loading. It will design a specific component frit for each waste feed, which will maximize waste loading to determine an optimum blend. 


\section{Remaining Tasks.}

- Complete the waste-blending computer system to add a user interface and extend the capability to include all of the DST and SST wastes.

- Extend the system capability to include pretreatment scenarios other than sludge wash. Incorporate new tank waste composition data as they become available.

- Complete development of system architecture and basic capabilities.

- Extend computer system to handle all tank wastes and pretreatments and develop an optimized strategy for waste pretreatment.

Schedule Requirements/Milestone Table. The waste-blending task. schedule requirements and milestones are presented in Table 4-5.

Table 4-5. Blending Milestones.

\begin{tabular}{|c|c|l|}
\hline Milestone & Completion date & \multicolumn{1}{|c|}{ Milestone description } \\
\hline 1 & $03 / 93$ & $\begin{array}{l}\text { Cleared report on initial phases of the } \\
\text { blending study, Tri-Party Agreement } \\
\text { milestone }\end{array}$ \\
\hline 2 & $09 / 93$ & $\begin{array}{l}\text { Letter report summarizing incentives for } \\
\text { blending the first 20 tanks to be } \\
\text { retrieved }\end{array}$ \\
\hline 3 & $09 / 94$ & $\begin{array}{l}\text { Complete development of system } \\
\text { architecture and basic capabi lities }\end{array}$ \\
\hline 4 & $09 / 95$ & $\begin{array}{l}\text { Extend computer system to handle all tank } \\
\text { wastes and pretreatments and develop an } \\
\text { optimized strategy for waste pretreatment }\end{array}$ \\
\hline 5 & $09 / 95$ & $\begin{array}{l}\text { Expand system to include a knowledge } \\
\text { based advisor system to assist user }\end{array}$ \\
\hline
\end{tabular}

"Hanford Federal Facility Agreement and Consent Order, 1992, 2 vols, as amended, Washington State Department of Ecology, U.S. Environmental Protection Agency, and U.S. Department of Energy, Olympia, Washington. 


\subsubsection{Sludge Dissolution}

Statement of Issue. In some cases (e.g., NCAW), separated and washed DST sludges can be vitrified without further pretreatment. However, to implement the SPM separation processes (e.g., TRU extraction, strontium removal) required for other sludges (e.g., PFP, CC, or NCRW), it would be necessary to dissolve the components to be separated. The washed sludges will be treated (dissolved) to prepare an aqueous $\mathrm{HNO}_{3}$ feed for the SPM. Thus, sludge dissolution is critical to the success of the Reference and CLEAN pretreatment systems.

Scope. Sludge-dissolution studies must be done on a tank-by-tank basis using actual tank samples. Sludge simulants are not suitable for such studies because of uncertainties regarding the specific species present in the wastes. A systematic study of sludge dissolution will be conducted at a laboratory scale; these tests will be ongoing through FY 2000. The tank sludges investigated in any given fiscal year will be obtained from tank core samples taken in the previous year. For example, sludges from tanks core sampled in FY 1992 will be investigated in FY 1993. The results from the laboratory-scale dissolution tests will be used to plan scale-up. The sludge dissolution tests will be an integral part of the bench-and pilot-plant scale solvent extraction tests (Section 4.1.1.7).

Status. Sludge-dissolution laboratory studies have been conducted on (NCRW) sludge (Lumetta and Swanson 1993b), on PFP sludge (Lumetta and Swanson 1993C), and on sludges from SSTs B-110 and U-110 (Lumetta et a1. 1993b). In all cases except tank U-110, good dissolution of the sludge solid's was achieved using $\mathrm{HNO}_{3}$ and $\mathrm{HNO}_{3} / \mathrm{HF}$ solutions. Washing the NCRW solids exiensively with water removes the flouride ion, which is necessary for dissolucion of the large amounts of zirconium present in NCRW solids. The results from these preliminary sludge dissolution studies were very promising. Candidate reagents and procedures for making all the various types of SST sludge soluable have been addressed by Schultz and Kupfer (1991). However, laboratory studies are needed on many more tank sludges to gain confidence that the wastes to be treated in the SPM can be dissolved for processing. issue:

Remaining Tasks. Completior of the following tasks will close this

- Develop a comprehensive dissolution plan for laboratory-scale s'squential tests with actual water-washed sludges. The goal of this plan should be to determine practical dissolution schemes that can be applied on a plant scale. This plan should address the following:

- Nature, hierarchy, volume, and composition of reagents to be employed with each sludge type

- Details (e.g., time, temperature) of each sequential dissolution step

- Analytical procedures to measure the degree of dissolution accomplished with each reagent. 
- Based on the results of the laboratory tests, complete the following:

- Bench-scale dissolution tests

- Pilot-scale dissolution tests.

Schedule Requirements/Milestone Table. Sludge dissolution studies will be conducted on each particular tank sludge as samples become available. The key milestones associated with the development of the sludge dissolution processes are listed in Table 4-6. The milestones shown are those that can be clearly defined at this time. Additional milestones will likely be added in the future.

Table 4-6. Sludge Dissolution Milestones.

\begin{tabular}{|c|c|l|}
\hline Milestone & Completion date & \multicolumn{1}{|c|}{ Milestone description } \\
\hline 1 & $09 / 94$ & $\begin{array}{l}\text { Complete laboratory-scale testing with } \\
\text { FY } 1992 \text { and FY 1993 cores }\end{array}$ \\
\hline 2 & $09 / 95$ & $\begin{array}{l}\text { Complete laboratory-scale testing with } \\
\text { FY } 1994 \text { cores }\end{array}$ \\
\hline 3 & $09 / 96$ & $\begin{array}{l}\text { Complete laboratory-scale testing with } \\
\text { FY 1995 cores }\end{array}$ \\
\hline 4 & $09 / 97$ & $\begin{array}{l}\text { Complete laboratory-scale testing with } \\
\text { FY 1996 cores }\end{array}$ \\
\hline 5 & $09 / 98$ & $\begin{array}{l}\text { Complete laboratory-scale testing with } \\
\text { FY 1997 cores }\end{array}$ \\
\hline 6 & $09 / 99$ & $\begin{array}{l}\text { Complete laboratory-scale testing with } \\
\text { FY 1998 cores }\end{array}$ \\
\hline 7 & $09 / 00$ & $\begin{array}{l}\text { Complete laboratory-scale testing with } \\
\text { FY 1999 cores }\end{array}$ \\
\hline
\end{tabular}

\subsubsection{TRU Removal by Solvent Extraction}

Statement of Issue. System studies have indicated that the overall HLW disposal volume for the Hanford Site tank wastes can be reduced by implementing advanced pretreatment processes. In particular, partitioning of the wastes into a small volume of HLW and a large volume of LLW will result in significant cost savings. The key element of this partitioning scheme is the separation of the TRUs from the bulk sludge components. The baseline process for achieving this separation is dissolution of the tank sludges in acid followed by extraction of the TRUs with octyl (pheny 1) $N, N$-diisobutyl carbamoyl-methylphosphine oxide (CMPO), which is 
often referred to as the TRUEX process (Horwitz et al. 1985). This section describes the development of this process; alternative TRU removal processes are discussed in Section 4.1.2.1.

Scope. The development of the TRUEX process will involve laboratory studies, bench-scale continuous counter-current tests, and pilot-plant tests.

The scope of the solvent extraction laboratory studies will include (1) preliminary batch contacts of actual dissolved sludge solutions with the TRUEX process solvent, (2) design of TRUEX process flowsheets for individual waste streams, and (3) testing of these flowsheets using batch contacts. The process flowsheets will then be demonstrated using bench-scale continuous counter-current solvent extraction equipment. Shakedown tests of the process flowsheets will be conducted using simulated waste (on a cold bench-scale solvent extraction unit); then tests will be done using actual wastes (on a hot bench-scale solvent extraction unit). It is expected that these bench-scale tests will be done on 1- to 25-L portions of waste. The bench-scale tests will focus primarily on process chenistry, but some engineering information will also be obtained. The pilot-plant tests will be designed to address both process chemistry and process engineering. It is expected that the pilot plant will be capable of processing $30 \mathrm{~L}$ of waste per hour. Again, shakedown tests wiil be conducted with simulated waste before tests with actual waste are done. Section 4.2.2 summarizes the development approach for solvent extraction.

Status. The TRUEX process was invented by E. P. Horwitz at Argonne National Laboratory (ANL) and development of this process has been ongoing at ANL, PNL, and WHC (Horwitz et al. 1985; Schulz and Horwitz 1988; Swanson 1991a, 1991b, 1991c; Lumetta et a1. 1992; Lumetta and Swanson 1993a, 1993b, 1993c). Japanese workers have conducted tests of the TRUEX process for treating high-level liquid waste from plutonium-uranium (PUREX) reprocessing plants (Ozawa et al. 1992).

TRUEX test results to date have been encouraging. For example, batch testing with actual dissolved NCRW sludge solutions suggests that greater than 99 percent of the TRUs can easily be separated from the bulk components of the sludge (e.g., zirconium and sodium). The status of the TRUEX processing of NCRW sludge has recently been described in detail (Lumetta and Swanson 1993b).

\section{Primary Uncertainties Regarding the TRUEX Process}

Although most work to date on the TRUEX process has yielded positive results, several areas of uncertainty will require study.

The largest uncertainty recarding the TRUEX process is how well the process will perform given widely different feed compositions. No matter what technology is ultimately chosen for pretreating Hanford Site tank wastes, variability of feed will be an issue; this problem is not unique to the TRUEX process. The only reliable way to address this uncertainty is to test the TRUEX process on each waste type. Such tests will be conducted as tank waste samples become available. 
A second uncertainty is the manner in which the TRUs will be stripped from the loaded solvent. Early TRUEX flowsheets for pretreating Hanford Site tank wastes called for using a $0.2 \mathrm{M}$ 1-hydroxyethane-1,1-diphosphonic acid (HEDPA) solution for stripping the TRUs prior to TRU extraction. Experimental results showed that this reagent was very effective at stripping the TRUs from the TRUEX solvent. However, two issues have precluded its use. First, this reagent not only strips the TRUs from the solvent, but also strips uranium. Because of the large inventory of uranium in the SSTs, it may be advantageous to separate the uranium from the TRUs prior to TRU extraction. Selective stripping of TRUs from uranium could not be achieved with HEDPA. Second, HEDPA contains two moles of phosphorus per mole of HEDPA. Because the TRUEX strip solution is a HLW, all of the phosphorus in the stripping agent would be in the feed to HWVP. Because of the low limits on phosphorus in the HWVP feed, using HEDPA would result in an excessive amount of glass being produced. A number of alternative stripping schemes are currently under consideration, but no decision has been made as to which is the best approach.

A third issue is interference by other sludge components, especially uranium, thorium, and bismuth. These three elements have been shown to be extracted by the TRUEX process solvent. If the TRUs must be separated from uranium and thorium, these two elements could be removed by extraction with tributyl phosphate (TBP) before extracting the TRUs with CMPO. Although much more extraction data are required for bismuth, preliminary extraction data suggest that the TRUs could be preferentially stripped, thus effecting a TRU/bismuth separation. The need to separate bismuth from the TRUs will depend on the impact that bismuth has on the HLW glass.

A fourth uncertainty is how well the TRUEX process will behave under continuous counter-current conditions. Plans are being made for procurement of the equipment needed for such testing with actual Hanford Site tank wastes.

A fifth uncertainty with TRUEX is the effects of solvent degradation. More detailed studies are needed concerning identifying the degradation products and the optimal method for removing them from the solvent.

A flowsheet has recently been proposed for pretreating NCRW sludge that should meet the overall objectives of separating the TRUs from the bulk sludge components (including uranium), and not introduce additional glass-limiting components into the HLW stream (Lumetta and Swanson 1993b). Although this flowsheet is proposed for pretreating NCRW sludge, it can be easily modified to pretreat other tank sludges. This flowsheet involves the following steps: (1) sludge washing to remove water-soluble components, (2) dissolution of the sludge in $\mathrm{HNO}_{3}$ (plus HF in the case of NCRW)), (3) extraction of uranium from the dissolved sludge solution with TBP, and (4) extraction of TRUs with CMPO. The flowsheet involves reduction of plutonium(IV) to plutonium(III) before the (TBP) cycle, so that plutonium is not coextracted with uranium in that cycle. Because the plutonium is primarily in the +3 oxidation state during the CMPO cycle, it can be stripped (along with americium) with dilute $\mathrm{HNO}_{3}$. A polishing strip with oxalic acid would remove any plutonium that was oxidized to plutonium(IV) during the extraction and scrub steps. Laboratory tests of this flowsheet will be conducted in FY 1993 with actual NCRW sludge. 
Workers at ANL have recently suggested that 2,3,4,5-tetrahydro-furantetra-carboxylic acid (THFTCA) could be used to strip the TRUs from the TRUEX process solvent, without stripping Uranium at the same time. Thus, the Uranium could be separated from the TRUs without using a TBP extraction cycle. However, results obtained with THFTCA by workers at PNL have not been as encouraging as those obtained by workers at ANL. This may be caused by differences in this material from lot to lot. Further development work is needed on this and other potential stripping agents to gain confidence that they will selectively strip TRUs from the TRUEX process solvent.

To date, no continuous counter-current tests of the TRUEX process have been performed using actual Hanford Site tank wastes. Small-scale tests ( $150 \mathrm{~L}$ processed) on laboratory wastes have been conducted at ANL (Chamberlain et a1. 1992) and on high-level liquid waste derived from the raffinate from PUREX processing of reactor fuel (Ozawa et al. 1992). Both of these tests gave promising results. issue.

Remaining Tasks. Completion of the following tasks will close this

- Design solvent extraction process flowsheets for each basic type of tank sludge to be processed.

- Conduct laboratory-scale solvent extraction tests for all TRU tank sludges using actual waste.

- Develop method to analyze for solvent degradation products.

- Design and install cold and hot bench-scale continuous counter-current solvent extraction unit.

- Conduct bench-scale continuous counter-current solvent extraction tests for representative TRU tank sludges using actual waste.

- Design and install solvent extraction pilot plant.

- Conduct pilot-scale solvent extraction tests for representative TRU tank sludges using actual waste.

Schedule Requirements/Milestone Table. The key milestones associated with the development of the solvent extraction process are listed in Table 4-7. The milestones shown are those that can be clearly defined at this time. Additional milestones will likely be added in the future.

\subsubsection{Strontium Removal by Solvent Extraction}

Statement of Issue. Strontium-90 is present in many of the Hanford Site tank sludges. Separation of this radioisotope from the nonradioactive constituents of the wastes is required to produce a LLW disposal form because this would lower the radiological hazard associated with the LLW form. Because the sludges will be dissolved in acid for TRU separation processes (see Sections 4.1.1.6 and 4.1.1.7), technologies are needed to extract the ${ }^{90} \mathrm{Sr}$ from acid solution. 
Table 4-7. TRU Removal Milestones.

\begin{tabular}{|c|c|c|}
\hline Milestone & Completion date & Milestone description \\
\hline 1 & $03 / 93$ & $\begin{array}{l}\text { Issue status report on NCRW TRUEX } \\
\text { development. }\end{array}$ \\
\hline 2 & $03 / 93$ & $\begin{array}{l}\text { Issue test plan for NCRW TRUEX design } \\
\text { basis. }\end{array}$ \\
\hline 3 & $03 / 93$ & $\begin{array}{l}\text { Issue functions and requirements for } \\
\text { bench-scale hot continuous solvent } \\
\text { extraction unit. }\end{array}$ \\
\hline 4 & $06 / 93$ & $\begin{array}{l}\text { Complete NCRW TRUEX design basis } \\
\text { experiment. }\end{array}$ \\
\hline 5 & $08 / 93$ & Issue update of PFP TRUEX flowsheet. \\
\hline 6 & $09 / 93$ & $\begin{array}{l}\text { Issue preliminary design of hot } \\
\text { bench-scale solvent extraction unit. }\end{array}$ \\
\hline 7 & $03 / 94$ & $\begin{array}{l}\text { Complete installation of cold bench-scale } \\
\text { solvent extraction unit. }\end{array}$ \\
\hline 8 & $09 / 94$ & $\begin{array}{l}\text { Complete laboratory-scale testing with } \\
\text { FY } 1992 \text { and FY } 1993 \text { cores. }\end{array}$ \\
\hline 9 & $09 / 95$ & Select primary TRU removal process. \\
\hline 10 & $09 / 95$ & $\begin{array}{l}\text { Complete laboratory-scale testing with } \\
\text { Fy } 1994 \text { cores. }\end{array}$ \\
\hline 11 & $03 / 96$ & $\begin{array}{l}\text { Complete installation of hot solvent } \\
\text { extraction bench-scale solvent extraction } \\
\text { unit. }\end{array}$ \\
\hline 12 & $09 / 96$ & $\begin{array}{l}\text { Complete laboratory-scale testing with } \\
\text { Fy } 1995 \text { cores. }\end{array}$ \\
\hline 13 & $09 / 97$ & $\begin{array}{l}\text { Complete laboratory-scale testing with } \\
\text { Fy } 1996 \text { cores. }\end{array}$ \\
\hline 14 & $09 / 98$ & $\begin{array}{l}\text { Complete laboratory-scale testing with } \\
\text { Fy } 1997 \text { cores. }\end{array}$ \\
\hline 15 & $09 / 99$ & Make decision on contractor type. \\
\hline 16 & $09 / 99$ & $\begin{array}{l}\text { Complete laboratory-scale testing with } \\
\text { Fy } 1998 \text { cores. }\end{array}$ \\
\hline 17 & $09 / 00$ & $\begin{array}{l}\text { Complete laboratory-scale testing with } \\
\text { Fy } 1999 \text { cores. }\end{array}$ \\
\hline
\end{tabular}

NCRW = Neutralized cladding removal waste.

PFP = Plutonium Finishing Plant.

TRU = Transuranic.

TRUEX = Transuranic extraction. 
Scope. The baseline process being considered for extracting strontium from acid-dissolved-sludge solutions is the strontium extraction (SREX) process (Horwitz, Dietz, and Fisher 1991). In this process, strontium is extracted from $\mathrm{HNO}_{3}$ solutions using a solution of

di-t-butyl cyclohexano-18-crown-6 (DtBC18C6) in 1-octanol. Consideration will also be given to the combined TRU/SREX process being developed at ANL (Horwitz, Dietz, Rogers, and Chamberlain 1992). The development of the SREX process will involve laboratory studies, bench-scale continuous counter-current tests, and pilot-plant tests.

The scope of the SREX laboratory studies will include: (1) preliminary batch contacts of actual dissolved sludge solutions with the SREX process solvent, (2) design of SREX process flowsheets for individual waste streams, and (3) testing of these flowsheets using batch contacts. The process flowsheets will then be demonstrated using bench-scale continuous counter-current solvent extraction equipment. Shakedown tests of the process flowsheets will be conducted using simulated waste (on a cold bench-scale solvent extraction unit); then tests will be done using actual wastes (on a hot bench-scale solvent extraction unit). It is expected that these bench-scale tests will be done on 1- to 25-L portions of waste. The bench-scale tests will focus primarily on process chemistry, but some engineering information will also be obtained. The pilot-plant tests will be designed to address both process chemistry and process engineering. It is expected that the pilot plant will be capable of processing $30 \mathrm{~L}$ of waste per hour. Again, shakedown tests will be conducted with simulated waste before tests with actual waste are done.

Status. Development of the SREX process is beginning. Initial work conducted by ANL indicates that this process is very promising for extracting strontium from dissolved tank sludges (Horwitz, Dietz, and Fisher 1991), but considerably more parametric data need to be collected to better define the operability of the process. An initial test of the SREX process with actual dissolved Hanford Site tank wastes resulted in a decontamination factor of 250 for strontium (Lumetta et al. 1993b).

The combined TRU/strontium extraction process being developed at ANL is still in an embryonic stage. Final formulation of the process solvent has not yet been achieved. issue.

Remaining Tasks. Completion of the following tasks will close this

- Confirm a reliable source for cis-syn-cis-di-t-butylcyclo-hexano-18-crown-6.

- Finalize formulation of the combined TRU/SREX solvent.

- Design SREX (or combined TRU/SREX) process flowsheets for each tank sludge to be processed.

- Conduct laboratory-scale SREX (or combined TRU/SREX) tests for each tank sludge to be processed. 
- Develop methods to analyze for solvent degradation producis.

- Conduct hydrolytic and radiolytic degradation studies.

- Design and install cold and hot bench-scale continuous counter-current solvent extraction unit.

- Perform bench-scale continuous counter-current SREX (or combined TRU/SREX) tests for representative tank sludges using actual waste.

- Design and install SREX pilot plant.

- Perform pilot-scale SREX (or combined TRU/SREX) tests for representative tank sludges using actual waste.

Schedule Requirements/Milestone Table. The key milestones associated with the development of the SREX process are listed in Table 4-8. The milestones shown are those that can be clearly defined at this time. Additional milestones will likely be added in the future.

\subsubsection{Pretreatment System Enhancements}

The following functions have been proposed as enhancements to the reference system that reduce the volume of $H L W$, reduce the volume and improve the type of low-level wastes generated, and improve the type of secondary wastes generated. The proposed technology development programs would provide bases for making final decisions on process deployment.

Table 4-8. Strontium Removal Milestones.

\begin{tabular}{|c|c|l|}
\hline Milestone & Completion date & \multicolumn{1}{|c|}{ Milestone description } \\
\hline 1 & $09 / 94$ & $\begin{array}{l}\text { Complete laboratory-scale testing with } \\
\text { FY 1992 and FY 1993 cores }\end{array}$ \\
\hline 2 & $09 / 95$ & $\begin{array}{l}\text { Complete laboratory-scale testing with } \\
\text { FY 1994 cores }\end{array}$ \\
\hline 3 & $09 / 96$ & $\begin{array}{l}\text { Complete laboratory-scale testing with } \\
\text { FY 1995 cores }\end{array}$ \\
\hline 4 & $09 / 97$ & $\begin{array}{l}\text { Complete laboratory-scale testing with } \\
\text { FY 1996 cores }\end{array}$ \\
\hline 5 & $09 / 98$ & $\begin{array}{l}\text { Complete laboratory-scale testing with } \\
\text { FY 1997 cores }\end{array}$ \\
\hline 6 & $09 / 99$ & $\begin{array}{l}\text { Complete laboratory-scale testing with } \\
\text { FY 1998 cores }\end{array}$ \\
\hline 7 & $09 / 00$ & $\begin{array}{l}\text { Complete laboratory-scale testing with } \\
\text { FY 1999 cores }\end{array}$ \\
\hline
\end{tabular}




\subsubsection{Alternate TRU Removal}

Statement of Issue. System studies have indicated that the overall cost of disposal of the Hanford Site tank wastes can be reduced by implementing advanced pretreatment processes. The key element of this partitioning scheme is the separation of the TRUs from the bulk sludge components. As was discussed in Section 4.1.1.7, the baseline process for achieving this separation is the TRUEX process. The biggest uncertainty regarding TRUEX is the variability in feed. That is, there may be certain waste types that are not amenable to pretreatment using the TRUEX process. Indeed, as further development work is performed, it may become apparent that TRUEX is not the best choice for the TRU separation process. Thus, the development of alternative and backup TRU removal technologies as a backup to TRUEX is desirable.

Scope. The development of alternative solvent extraction processes for TRU removal will involve laboratory studies, bench-scale continuous counter-current tests, and pilot-plant tests.

The scope of the solvent extraction laboratory studies will include the following:

- Identifying potential extractants

- Defining the extraction systems by measuring distribution coefficients for the various sludge constituents

- Choosing the most promising alternative extractant

- Making preliminary batch contacts of actual dissolved sludge solutions with the candidate extractant

- Designing process flowsheets for individual waste streams

- Testing these flowsheets using batch contacts. The process flowsheets will then be demonstrated using bench-scale continuous counter-current solvent extraction equipment. Shakedown tests of the process flowsheets will be conducted using simulated waste (on a cold bench-scale solvent extraction unit); then tests will be done using actual wastes (on a hot bench-scale solvent extraction unit). It is expected that these bench-scale tests will be done on 1 - to 25-L portions of waste. The bench-scale tests will focus primarily on process chemistry, but some engineering information will also be obtained. The pilot-plant tests will be designed to address both process chemistry and process engineering. It is expected that the pilot plant will be capable of processing $30 \mathrm{~L}$ of waste per hour. Again, shakedown tests will be conducted with simulated waste before tests with actual waste are done.

Status. A recent review of TRU extraction technology has revealed only two strong alternative extractants for pretreating Hanford Site tank wastes (Orme 1992). These are dihexyl-N, N-diethylcarbamoylmethyl phosphonate (CMP) and tetraalkylmalonamides. 
The process of using CMP to extract TRUs has been known for approximately 20 years. A systematic study of phosphoryl carbamoyl extractants revealed that phosphine oxides were superior over phosphonates as TRU extractants (Kalina et al. 1981 and Horwitz et al. 1982). Thus, CMPO was chosen over CMP for the TRUEX process. However, it was recently suggested that CMP may hold some advantages over CMPO (Marsh and Yarbro 1988). A study is currently (FY 1993) underway at PNL to assess the use of CMP in pretreating Hanford Site tank wastes.

The tetraalkylmalonamides extractants are under development in France (Cuillerdier, Musikas, and Nigond 1993). These reagents show some promise, but the development of these extractants is just beginning. Indeed, the French workers have not yet made a final decision on which tetraalkylmalon-amide is the best extractant. Potential problems with these extractants include high rates of hydrolytic degradation and the need for high nitrate content in the solvent extraction feed. A study is currently (FY 1993) underway at PNL to assess the use of tetraalkylmalonamides in pretreating Hanford Site tank wastes. The tetraalkylmalonamides to be used in this study will be provided by workers at Los Alamos National Laboratory (LANL). issue.

Remaining Tasks. Completion of the following tasks will close this

- Conduct laboratory testing of CMP using tank waste simulants.

- Compile CMP extraction data for all sludge constituents.

- Design CMP flowsheets for each individual waste type.

- Conduct laboratory tests of CMP TRU extraction flowsheets for all TRU tank sludges using actual waste.

- Screen tetraalkylmalonamide extractants.

- Choose best tetraalkylmalonamide extractant.

- Compile extraction data for all sludge constituents using the tetraalkylmalonamide extractant.

- Design flowsheets for the extraction of TRUs with the tetraalkylmalonamide extractant.

- Conduct laboratory testing on the tetraalkylmalonamide extractant using tank waste simulants.

- Conduct 1aboratory testing on the tetraalkylmalonamide extractant using actual tank waste.

- Choose alternative extractant.

- Conduct bench-scale continuous counter-current tests of alternative TRU extraction flowsheets for representative TRU tank sludges using actual waste. 
- Conduct pilot-scale tests of alternative TRU extraction flowsheets for representative TRU tank sludges using actual waste.

Schedule Requirements/Milestone Table. The key milestones associated with the development of alternate TRU removal process are listed in Table 4-9. time. Additional milestones will can be clearly defined at this point in time. Additional milestones will likely be added in the future.

Table 4-9. Alternate TRU Removal Milestones.

\begin{tabular}{|c|c|l|}
\hline Milestone & Completion date & \multicolumn{1}{|c|}{ Milestone description } \\
\hline 1 & $09 / 94$ & $\begin{array}{l}\text { Complete compilation of cMP extraction } \\
\text { data. }\end{array}$ \\
\hline 2 & $09 / 93$ & $\begin{array}{l}\text { Complete initial screening of } \\
\text { tetraalkylmalonamides. }\end{array}$ \\
\hline 3 & $09 / 93$ & $\begin{array}{l}\text { Choose tetraalkylmalonamide for further } \\
\text { study. }\end{array}$ \\
\hline 4 & $03 / 95$ & $\begin{array}{l}\text { Complete compilation of tetraalkylamide } \\
\text { extract ion data. }\end{array}$ \\
\hline 5 & $12 / 93$ & $\begin{array}{l}\text { Complete cMP test with one actual tank } \\
\text { waste. }\end{array}$ \\
\hline 6 & $09 / 94$ & $\begin{array}{l}\text { Complete tetraalkylamide test with one } \\
\text { actual tank waste. }\end{array}$ \\
\hline 7 & $09 / 95$ & \begin{tabular}{l} 
Choose alternate extractant. \\
\hline
\end{tabular}
\end{tabular}

CMP = Dihexyl-N, N-diethylcarbamoylmethyl phosphonate.

\subsubsection{Strontium and TRU Removal on Basic Side}

Statement of Issue. Strontium and TRU components are not generally very soluble in alkaline wastes unless complexants are present. Destruction of these complexants should solve much of the problem with strontium and TRU the CLEAN option alkaline waste. However, if the treatment goals outlined in alkaline wastes and sludge waste waters and TRU may have to be removed from may also generate neutral wastective leaching of TRU components of TRU components and may require additional treatment.

Scope. The scope of this task will include (1) batch contacts with actual sludge wash solutions, (2) development of process fiowsheets, and (3) testing of the flowsheets using batch contacts. If an ion exchange method or a precipitation method proves to be a viable technology, laboratory-scale testing will be performed with simulated wash solutions. If a solvent extraction process is identified, bench-scale testing with actual wastes will
be performed using continuous counter-current solvent extraction. 
Status. The number of possible techniques for the basic side removal has been identified (Orth and Kurath 1993 and Kolaric 1991). Precipitation methods are the most promising of the processes identified. These precipitation method processes include the use of sodium titanate, ferric hydroxide, titanium hydroxide, and calcium phosphate as the precipitating agent. The use of ion exchange has al so shown promise. Some of the ion exchangers that have been identified are sodium titanate, titanium-coated zeolites, and crystalline silico titanates. Some evidence shows that some of the solvent extraction techniques (such as the dicarbolides) may work on the basic side. issue.

Remaining Tasks. Completion of the following tasks will close this

- Complete literature review and technology assessment for the separation of TRUs and strontium from basic media.

- Conduct laboratory screening tests (batch contacts with simulants and actual wastes).

- Complete assessment of screening studies and recommend process or processes for additional development.

- Conduct laboratory-scale processing experiments with simulants and actual wastes.

- Decide on further effort on basic side processes for the removal of TRUs and strontium.

Schedule Requirements/Milestone Table. The key milestones associated with strontium and TRU removal are listed in Table 4-10.

\subsubsection{Cesium Removal on Acid Side}

Statement of Issue. Much of the cesium in the tank waste is expected to be soluble and will be removed from the sludge during the alkaline sludge washing step. However it appears that significant amounts of cesium will remain in the sludge and will be acidified with the sludge for processing. Much of this cesium will have to be removed if it is determined that the LLW form must meet the Class A LLW criteria.

Scope. The scope of this task includes the (1) batch contacts with actual dissolved sludge solutions, (2) developing process flowsheets and (3) testing the flowsheets using batch contacts. The process flowsheets will then be demonstrated with laboratory-scale equipment. If a solvent extraction process is the chosen technology, a bench-scale test will be performed with continuous counter-current solvent extraction equipment using actual wastes. If a precipitation method or an ion exchange method is chosen, 
Table 4-10. Strontium and TRU Removal on Basic Side.

\begin{tabular}{|c|c|l|}
\hline Milestone & Completion date & Milestone description \\
\hline 1 & $09 / 93$ & $\begin{array}{l}\text { Complete laboratory } \\
\text { studies of radionuclide } \\
\text { removal. }\end{array}$ \\
\hline 2 & $04 / 94$ & $\begin{array}{l}\text { Design alkaline } \\
\text { supernatant polishing } \\
\text { process for strontium } \\
\text { and TRU removal. }\end{array}$ \\
\hline 3 & $05 / 97$ & $\begin{array}{l}\text { Design and fabricate } \\
\text { CPU for alkal ine } \\
\text { strontium and TRU } \\
\text { removal. }\end{array}$ \\
\hline 4 & $12 / 97$ & $\begin{array}{l}\text { Complete radioactive } \\
\text { testing of alkaline } \\
\text { polishing in CPU. }\end{array}$ \\
\hline
\end{tabular}

CPU $=$ Compact processing unit.

TRU = Transuranic.

laboratory-scale testing will be performed with waste simulants (assuming the acidified sludge can be adequately characterized and waste simulants developed), then with actual wastes.

Status. The processes to remove cesium from acidified tank waste sludges is relatively undeveloped. While numerous technologies have been examined to remove cesium from acidic waste, few have focused on actual acidified sludges. Experiments were performed on various cesium removal technologies as part of a CC waste exploratory study (Lumetta et al. 1993a). These were performed under limited conditions and focused on few technologies. Of these tests, only precipitation with sodium phosphotungstate showed much promise. Additionally, the removal of cesium from acidic waste has not been scaled up. Only sodium phosphotungstate to recover cesium from PUREX process HLW has been studied on a large-scale at the Hanford Site. issue.

Remaining Tasks. Completion of the following tasks will close this

- Complete literature review and technical assessment of technologies for the separation of cesium from acidic media.

- Conduct laboratory screening tests (batch contacts with simulant and actual wastes).

- Develop preliminary flowsheets for each separation technology.

- Complete assessment of screening studies and recommend process or process(es) for additional development. 
- Conduct laboratory-scale continuous processing experiments with simulant and actual waste

- Develop a preliminary flowsheet.

- Conduct pilot-scale continuous processing experiments with simulant and actual waste.

- Develop a final optimized flowsheet.

Schedule Requirements/Milestone Table. The key milestones associated with cesium removal (acid side) are listed in Table 4-11. The milestones shown are those that can be clearly defined at this point in time. Additional milestones will likely be added in the future.

Table 4-11. Cesium Removal (Acid Side) Milestones.

\begin{tabular}{|c|c|l|}
\hline Milestone & Completion date & \multicolumn{1}{|c|}{ Milestone description } \\
\hline 1 & $07 / 93$ & $\begin{array}{l}\text { Issue report on literature review and } \\
\text { technology assessment. }\end{array}$ \\
\hline 2 & $09 / 93$ & Complete laboratory screening studies. \\
\hline 3 & $09 / 94$ & $\begin{array}{l}\text { Complete experimental and engineering } \\
\text { assessment. }\end{array}$ \\
\hline 4 & $09 / 95$ & Complete laboratory-scale testing. \\
\hline 5 & $09 / 95$ & Issue prel iminary flowsheet. \\
\hline 6 & $03 / 97$ & Compete pilot-scale testing. \\
\hline 7 & $03 / 97$ & Issue final flowsheet. \\
\hline
\end{tabular}

\subsubsection{Convert/Remove Nitrates}

Statement of Issue. Nitrate is regulated as a toxic anion and may require destruction or removal from tank wastes to meet requirements for $L L W$ disposal. Nitrate has a limit of $10 \mathrm{ppm}$ in drinking water. The tank waste contains over 80,000 metric tons of nitrate. Current]y, the majority of nitrates are expected to be disposed of in grout as LLW. The effect of nitrate on grout performance with respect to stability and leachability is being evaluated using laboratory testing and performance assessments. If these studies determine that nitrate is creating unacceptable risk, nitrate conversion or separation from the tank waste will be required.

Work Scope. The ongoing laboratory studies and performance assessments will be monitored and evaluated. If the studies determine that nitrate conversion/removal is required, the criteria for nitrate conversion/removal will be determined and a demonstration program established. Candidate destruction technologies to be considered include thermochemical, thermal, 
electrochemical, and catalytic. Possible separation technologies include anion exchange, liquidalysis, membrane separations, and crystallization.

Status. Laboratory grout performance studies and performance assessments are ongoing and will be used to determine the necessity of nitrate conversion/removal.

Remaining Tasks and Schedule Requirements/Milestone Table. The remaining ticks are indicated as deliverables in milestone Table 4-12.

Table 4-i2. Nitrate Removal Milestones.

\begin{tabular}{|c|c|l|}
\hline Milestone & Completion date & \multicolumn{1}{|c|}{ Milestone description } \\
\hline 1 & $9 / 93$ & $\begin{array}{l}\text { Complete grout performance } \\
\text { laboratory studies and } \\
\text { performance assessments. }\end{array}$ \\
\hline 2 & $4 / 94$ & $\begin{array}{l}\text { Determine criteria for } \\
\text { nitrate conversion/removal. }\end{array}$ \\
\hline$s$ & $5 / 94$ & $\begin{array}{l}\text { Initiate program for } \\
\text { demonstrating nitrate } \\
\text { conversion/removal using or } \\
\text { adapting commercially } \\
\text { available technology. }\end{array}$ \\
\hline
\end{tabular}

\subsubsection{Iodine Removal.}

Statement of Issue. There is an estimated $30 \mathrm{~kg}$ of ${ }^{129} \mathrm{I}$ in the liquid and salt cake stored in Hanford Site SSTs, at a concentration of $0.00006 \mathrm{nCi} / \mathrm{g}$. Because of the long half-life of ${ }^{129} \mathrm{I}$ ( $17 \mathrm{million}$ years), the mobility of soluble iodine species through the Hanford Site soil, and the inability of currently planned near-surface disposal options (grout) to immobilize ${ }^{129}$ I when exposed to environmental conditions, a method might be needed to remove and concentrate radioiodine from the alkaline aqueous wastes stored at the Hanford Site, and possibly from aqueous wastes stored at other DOE sites. Such removal and concentration wi?l al so require development of a suitable waste form and strategy because no inmobilization form currently exists.

Scope. No method has been identified or developed for separating radioiodine from alkaline aqueous wastes stored at the Hanford Site or at other DOE sites, nor has a tecinnology or strategy been developed that will ensure long-term disposal of the ${ }^{129}$ I. The objective of this work, if it is determined that the iodine will require removal from the waste, would be to develop technologies for (1) senarating radioiodine from alkaline aqueous wastes stored in underground ridioactive waste storage tanks, and (2) alternative waste forms for long-term disposal of the resulting ${ }^{129} \mathrm{I}$ waste. The initial emphasis will be on anionic exchange resins and silver zeolites to recover and concentrate from th waste supernates. Other techniques to be investigated rould include precipitation of insoluble iodine 
species, such as silver iodide. A literature survey would be performed to identify other candidate technologies. To develop an immobilization form, previous technologies preparing a waste form (silver iodide or other low-solubility iodides or iodates in cement or iodine immobilized in sodalite) would be evaluated.

Status. Currently, no technology development activities are being conducted for this function. Additional analys is is required to determine whether iodine in the tank wastes will require removal. Historically, some work has been done on separation and immobilization of radioiodine. This work would form the foundation for future technology development work, if required. issue.

Remaining Tasks. Completion of the following tasks will close this

- Perform screening studies for candidate separation methods.

- Verify separation methods with synthetic and actual wastes.

- Evaluate options for disposal forms.

- Prepare waste forms and complete durability tests.

Schedule Requirenents/Milestone Table. Table 4-13 presents the key milestones associated with iodine removal and immobilization.

\subsubsection{Technetium Removal.}

Statement of Issue. Technetium is one of the major contributors to long-term risk associated with the disposal of LLW in grout. This is a result of its relativeiy long half-life (213,000 years) and relatively high mobility. To meec the Class A limit for technetium in grout, a decontamination factor (DF) of $\approx 1.5$ is required for DST waste. Technetium removal from SST waste is not required. However, as low as reasonably achievable (ALARA) limits may require a total technetium DF of 100.

Scope. Separations processes are required for caustic and acidic conditions because both soluble and insoluble technetium are expected. Potential processes to be investigated include anion exchange, solvent extraction, water-soluble chelating polymers (WSCP), and electrochemical methods. Initial experiments will be conducted with laboratory batch contacts to define key parameters and develop rough flowsheets. A technology assessment will be conducted in parallel with the laboratory work and will define the treatment requirements for technetium removal from both acidic and alkaline waste streams. This technology assessment will provide recommendations on further development needs for the processes. If a solvent extraction process is the chosen technology, a bench-scale test will be performed with continuous counter-current solvent extraction equipment. other technologies that may be chosen will be demonstrated with laboratory-scale equipment. 
Table 4-13. Iodine Removal Milestones.

\begin{tabular}{|c|c|c|}
\hline Milestone & Completion date & Milestone description \\
\hline 1 & $03 / 94$ & $\begin{array}{l}\text { Identify disposal and isolation } \\
\text { strategies/deliver report. } \\
\end{array}$ \\
\hline 2 & $06 / 94$ & $\begin{array}{l}\text { Evaluate options for disposal } \\
\text { forms/deliver report. }\end{array}$ \\
\hline 3 & $05 / 95$ & $\begin{array}{l}\text { Verify separation methods using actual } \\
\text { waste/deliver report. }\end{array}$ \\
\hline 4 & $06 / 95$ & $\begin{array}{l}\text { Perform screening study to identify } \\
\text { disposal forms based on physical and } \\
\text { chemical tests/deliver report. }\end{array}$ \\
\hline 5 & $11 / 95$ & $\begin{array}{l}\text { Perform screening studies for candidate } \\
\text { separation methods/deliver report. }\end{array}$ \\
\hline 6 & $02 / 96$ & $\begin{array}{l}\text { Screen disposal forms identified for } \\
\text { wastes produced from developed } \\
\text { separations methods/deliver report. }\end{array}$ \\
\hline 7 & $02 / 96$ & $\begin{array}{l}\text { Perform small-scale process tests using } \\
\text { synthetics/deliver report. }\end{array}$ \\
\hline 8 & $08 / 96$ & $\begin{array}{l}\text { Perform first set long-term durability } \\
\text { tests/deliver report. }\end{array}$ \\
\hline 9 & $10 / 96$ & $\begin{array}{l}\text { Verify smal1-scale performance using } \\
\text { actual wastes/deliver report. }\end{array}$ \\
\hline 10 & $06 / 97$ & $\begin{array}{l}\text { Performed long-term durability tests for } \\
\text { separations methods disposal forms/ } \\
\text { deliver report. }\end{array}$ \\
\hline 11 & $11 / 97$ & $\begin{array}{l}\text { Determine scaled performance of large } \\
\text { batch of material/deliver report. }\end{array}$ \\
\hline 12 & $11 / 97$ & $\begin{array}{l}\text { Issue final report on disposal form and } \\
\text { strategies. }\end{array}$ \\
\hline
\end{tabular}

Status. A number of separations technologies have been investigated for removing technetium from acidic and alkaline media. Technologies investigated include solvent extraction, anion exchange, and electrolytic deposition. Much of the work has been directed at separation of technetium(VII) from acidic high-level waste (Kolarik 1991).

Laboratory batch contacts were conducted with simulant and actual CC waste (Lumetta et a1. 1993a). Technetium distribution coefficiєilts were measured for the TRUEX process and tetraalkylammonium salts using cyclohexanone or 1-0ctanol as diluents. 


\section{Remaining Tasks.}

- Determine the grout disposal criteria for $\mathrm{TcO}_{4}^{-}$so that the separation requirements can be defined.

\section{Remaining Tasks for Anion Exchange.}

- Assess available anion exchange resins for applicability to the treatment of Hanford Site tank wastes.

- Determine the adsorption $\mathrm{Kd}^{\prime} \mathrm{s}$ and isotherms for $\mathrm{TCO}_{4}^{-}$using recommended resins.

- Determine the stability of the resins to heat and radiation.

- Determine the elution behavior of $\mathrm{TcO}_{4}^{-}$.

- Investigate resin performance with simulants and actual tank wastes.

- Investigate methods for acid recycle for the nitric acid eluant.

- Explore alternatives to elution with nitric acid (e.g., reaction with hydroxide to destroy the anionic site, low-temperature ashing, reduct ive eluants.)

- Develop flowsheets for the treatment of alkaline supernates and TRUEX raffinates.

\section{Remaining Tasks for Solvent Extraction.}

- Determine extraction $\mathrm{Kd}^{\prime} \mathrm{s}$ for $\mathrm{TCO}_{4}^{-}$, into $\mathrm{Al}$ iquot 336 , TRUEX, and other promising solvents.

- Assess solvent formulations and recommend one for scaleup.

- Investigate technetium stripping behavior

- Test with Hanford Site waste simulants.

Remaining Tasks for Water Soluble Chelating Polymers.

- Synthesize WSCP functionalized with quaternary nitrogen pendant.

- Determine batch extraction Kd's using waste simulants.

- Assess stability of polymer to radiolysis, caustic, and acidic environments.

Remaining Tasks for Electrochemical Methods.

- Conduct bench-scale testing with Hanford Site waste simulants to obtain data on key parameters. 
- Complete technology evaluation to recommend process for technetium removal. This involves developing preliminary flowsheets and identifying key issues.

- Conduct laboratory-scale process testing of recommended process.

- Conduct pilot-scale testing of recommended process.

Schedule Requirements/Milestone Table. Table 4-14 presents the key milestones associated with the technetium removal function.

Table 4-14. Technetium Removal Milestones.

\begin{tabular}{|c|c|l|}
\hline Milestone & Completion date & \multicolumn{1}{|c|}{ Milestone description } \\
\hline 1 & $02 / 94$ & Evaluate technetium removal processes. \\
\hline 2 & $02 / 94$ & Complete bench-scale testing. \\
\hline 3 & $02 / 94$ & $\begin{array}{l}\text { Provide evaluation report on bench-scale } \\
\text { testing; decide recommended technology. }\end{array}$ \\
\hline 4 & $04 / 95$ & $\begin{array}{l}\text { Design/construct laboratory-scale } \\
\text { technetium removal system. }\end{array}$ \\
\hline 5 & $04 / 96$ & Complete laboratory-scale testing. \\
\hline 6 & $04 / 98$ & $\begin{array}{l}\text { Design and construct pilot-scale } \\
\text { technetium removal system. }\end{array}$ \\
\hline 7 & $04 / 99$ & Complete pilot-scale testing. \\
\hline
\end{tabular}

\subsubsection{LLW Organic Destruction}

Statement of Issue. The IPM is designed to process the safety tanks, including organic safety tanks. Other tanks that will not be processed by the IPM may require the organics be destroyed before further processing or disposal. For example, complexants may be destroyed to precipitate complexed and soluble radionuclides or future feed pretreatment may require organic destruction in acids. These tanks may have different organic constituents and destruction criteria than the IPM, and alternative organic destruction technologies may be more effective with respect to cost or schedule.

Scope. The overall requirements for organic destruction will be determined and compared to the requirements for the IPM. Organic destruction requirements that are outside the scope of the IPM will be further refined and performance criteria established. Organic destruction technologies will be developed to meet the performance criteria and may include adapting IPM organic destruction technologies or developing new technologies. For example, an IPM-developed technology may only be required to convert organics to oxalate, but could be further developed to convert the organic material to carbonate. Less mature but more effective technologies could be developed with the extended deployment schedule. Possible LLW organic destruction 
technologies include thermal, chemical, electroprocesses, ultraviolet, and catalytic.

Status. Many applicable organic destruction technologies are being evaluated in laboratory studies. When organic destruction criteria and technology have been selected for the IPM, the technologies not selected will be further evaluated with respect to the LLW organic destruction criteria. issue.

Remaining Tasks. Completion of the following tasks will close this

- Continue laboratory evaluations.

- Select technologies for development.

Schedule Requirements/Milestone Table. Table 4-15 presents the key milestones pertaining to the LLW organic destruction function. Additional milestones will be added once processes are selected for the IPM and their capabilities are known.

Table 4-15. Low-Level Waste Organic Destruction Milestones.

\begin{tabular}{|c|c|l|}
\hline Milestone & Completion date & \multicolumn{1}{|c|}{ Milestone description } \\
\hline 1 & $01 / 93$ & Establish design requirements. \\
\hline 2 & $03 / 93$ & $\begin{array}{l}\text { Prepare and issue organic destruction } \\
\text { process flowsheet. }\end{array}$ \\
\hline 3 & $04 / 94$ & $\begin{array}{l}\text { Determine LLW organic destruction } \\
\text { criteria and feeds. }\end{array}$ \\
\hline 4 & $05-09 / 94$ & $\begin{array}{l}\text { Develop LLW organic destruction } \\
\text { technologies. }\end{array}$ \\
\hline 5 & $09 / 97$ & $\begin{array}{l}\text { Design and install hot bench-scale } \\
\text { process }\end{array}$ \\
\hline 6 & $09 / 98$ & \begin{tabular}{l} 
Complete bench-scale tests. \\
\hline
\end{tabular}
\end{tabular}

$L L W=$ Low-level waste.

\subsubsection{Alternate Strontium Removal - Acid Side}

Statement of Issue. Strontium-90 is present in many of the Hanford Site tank sludges. Separation of this radioisotope from the nonradioactive constituents of the wastes is desirable because this would lower the radiological hazard associated with the LLW form. Because the sludges will be dissolved in acid for TRU separation processes (see Sections 4.1.1.6 and 4.1 .1 .7 ), technologies are needed to separate ${ }^{90} \mathrm{Sr}$ from acid solution. Currentiy, solvent extraction is considered to be the baseline approach to strontium removal (see Section 4.1.1.8). In this activity, the utility of other separation methods will be explored. 
Scope. A study will be conducted in FY 1993 to identify strontium separation processes that have potential application in pretreating Hanford Site tank wastes. Laboratory tests will be conducted to evaluate the utility of these processes. Eventually, one or more strontium separation methods will be chosen for further development, which will include bench-scale tests with actual wastes and pilot-plant tests, if warranted.

Status. Preliminary tests with extraction chromatographic materials for the separation of strontium from the Hanford Site tank wastes were conducted in FY 1992 (Lumetta et al. 1993c). These tests were very promising. issue.

Remaining Tasks. Completion of the following tasks will close this

- Identify strontium separation methods.

- Conduct laboratory tests with simulated wastes.

- Conduct laboratory tests with actual wastes.

- Conduct hydrolytic and radiolytic degradation studies.

- Choose one or more alternate strontium separation processes.

- Conduct bench-scale tests with simulated wastes.

- Conduct bench-scale tests with actual wastes.

- Design and install pilot plant.

- Conduct pilot-scale tests for representative tank sludges using actual waste.

Schedule Requirements/Milestone Table. The key milestones associated with the development of the alternate strontium separation process(es) are listed in Table 4-16. The milestones shown are those that can be clearly defined at this time. Additional milestones will likely be added in the future.

\subsubsection{Technology Alternatives}

\subsubsection{Sludge Leaching, Precipitation or Solid Sorbents}

Statement of Issue. Alternative processes and flowsheets are being evaluated for the treatment of tank sludges to provide an intermediate-term process for pretreating of tank sludges while minimizing the amount of glass produced. Most development efforts have been directed at the recovery of radionuclides from acidified sludges using solvent extraction (i.e., TRI'EX). While this technology appears to be feasible, it will most likely requ, it a new pretreatment plant, which is not expected to be online until after the year 2010. Feed for the HWVP is required shortly after startup in 
Table 4-16. Milestones for SREX Process Development.

\begin{tabular}{|c|c|l|}
\hline Milestone & Completion date & \multicolumn{1}{|c|}{ Milestone description } \\
\hline 1 & $02 / 93$ & $\begin{array}{l}\text { Identify alternative Strontium separation } \\
\text { technologies }\end{array}$ \\
\hline 2 & $09 / 95$ & Choose process for further development \\
\hline 3 & $09 / 97$ & $\begin{array}{l}\text { Complete bench-scale demonstration with } \\
\text { an actual waste sample }\end{array}$ \\
\hline 4 & $12 / 97$ & $\begin{array}{l}\text { Decide if further development is } \\
\text { warranted }\end{array}$ \\
\hline
\end{tabular}

December 1999. While this can be provided with a sludge washing process, the number of glass canisters produced is expected to be relatively high. The processes to be investigated in this task are directed at providing feed to the HWVP until a new pretreatment plant is available, while minimizing the amount of glass produced. Processes are expected to be simple and could be performed in existing tanks or new tanks constructed of appropriate materials.

Scope. This task includes developing flowsheets for sludge leaching processes, precipitation processes, and using solid sorbents for radionuclide separation. Laboratory work will be required where insufficient data are available to develop flowsheets. Laboratory work associated with the selective leaching of sludge is discussed in Section 4.1.1.4. Technology development of cesium removal processes from acidic media is discussed in Section 4.1.2.3. Technology development associated with removal of technetium is discussed in Section 4.1.2.6. Once processes have been selected for further development, laboratory- and pilot-scale testing will be performed.

Status. Flowsheets are being developed for sludge leaching processes, precipitation processes, and the use of solid sorbents. Sludge leaching is directed at either leaching inert components such as aluminum, chromium, $\mathrm{PO}_{4}$, zirconium, and bismuth or at the leaching of radionuclides such as plutonium, americium, strontium, technetium, and cesium. Precipitation and solid sorbent methods are being examined for removing the radionuclides of interest from both alkaline supernatants and acidified sludges.

Remaining Tasks. Completion of the following tasks closes this issue.

- Complete a pretreatment systems evaluation of the alternative fiowsheets.

- Identify additional experimental needs to support flowsheet development.

- Identify additional components that could be leached (i.e., bismuth, uranium, cesium)

- Complete bench-scale laboratory work with simulant and actual waste to verify assumptions made in systems evaluation. 
- Complete testing with additional waste types to gain confidence that the processes are robust.

- Update the flowsheets annually.

- Update the pretreatment systems evaluation annually.

- Identify and reserve mixing and solids suspension issues.

- Develop and test solid/liquid separation techniques.

- Conduct laboratory-scale testing with simulant and actual wastes.

- Conduct pilot-scale testing with simulant and actual wastes.

Schedule Requirements/Milestone Table. Preliminary milestones for the development of sludge leaching, precipitation or solid sorbents are presented in Table-17. Additional milestones will be added after preliminary testing is completed.

Table 4-17. Sludge Leaching Milestones.

\begin{tabular}{|c|c|l|}
\hline Milestone & Completion date & \multicolumn{1}{|c|}{ Milestone description } \\
\hline 1 & $02 / 93$ & $\begin{array}{l}\text { Recommend processes for laboratory } \\
\text { development. }\end{array}$ \\
\hline 2 & $09 / 93$ & Complete screening tests. \\
\hline 3 & $09 / 93$ & $\begin{array}{l}\text { Complete initial flowsheets and } \\
\text { assessment. }\end{array}$ \\
\hline 4 & $09 / 94$ & Issue report on laboratory studies. \\
\hline 5 & $09 / 94$ & Issue updated assessment of technologies. \\
\hline 6 & $09 / 94$ & Decide which processes to pursue. \\
\hline
\end{tabular}

\subsubsection{Calcining and Leaching}

Statement of Issue. This activity is being performed in conjunction with the calcining process as developed under section 4.1.1.3, Organic/Ferrocyanide Destruction. As calcination is developed as a method for organic destruction, it becomes necessary to evaluate the characteristics of the remaining solids. This activity will investigate the water solubility and acid leachability of the remaining solids.

Calcination is also proposed as an alternate approach to pretreatment, in place of the acid dissolution schemes currently advocated. 
Scope. To investigate the chemistry of the calcine/dissolution approach to processing, a program of literature and laboratory studies began in FY 1993. following this phase, a testing program to investigate the chemistry of the actinides in sodium hydroxide melts and highly-alkaline solutions will be pursued. The proposed testing program will then proceed through laboratory cold and hot tests. Finally, the need for further pretreatment will be identified and processes selected to achieve the desired separations. Pretreatment studies at this point will be directed to determine the applicability of the aqueous-based separations methods previously explored on the resulting calcined solids and liquids.

Remaining Tasks. The following tasks are needed to bring this technology to completion.

- Review sodium hydroxide solution chemistry literature on solution composition and insoluble phases expected from dissolution of sodium hydroxide melt materials.

- Identify standard dissolution kinetic tests by reviewing American Society for Testing and Materials or related standards.

- Perform cold tests of sodium hydroxide melt dissolutions using materials prepared for calcination cold melt tests. Measure dissolution speed, analyze solutions and identify solid phases. Derive material balances.

- Perform dissolution test of HLW calcination products. Measure dissolution speed, analyze solutions and identify solid phases. Derive material balances.

- Review literature on expected chemistry of the actinides (TRU) neptunium, plutonium, and americium in the sodium hydroxide melt and related solutions. Also, investigate the fate of uranium in the sodium hydroxide.

- Investigate the chemistry of TRU in sodium hydroxide melt as a function of temperature, the electrochemical potential of the melt, and the concentrations of selected other components. Identify TRU solid phases present and determine TRU oxidation states in the melt.

- Study the dissolution of TRU-bearing sodium hydroxide melts prepared in calcination tests. Determine the oxidation state and solubility of the TRU elements and identify solid phases. Determine the electrochemical potential of the solution and test possible reducing agents.

Schedule Requirements/Milestone Table. The key milestones associated with the development of the sludge washing process are listed in Table 4-18. the milestones shown are those that can be clearly defined at this point in time. Additional milestones will likely be added in the future. 
Table 4-18. Calcine/Leach Milestones.

\begin{tabular}{|c|c|c|}
\hline Milestone & $\begin{array}{c}\text { Completion } \\
\text { date }\end{array}$ & \multicolumn{1}{|c|}{ Milestone description } \\
\hline 1 & $09 / 93$ & Report calcine solubility in reference process. \\
\hline 2 & $09 / 94$ & Report calcine residue treatment results. \\
\hline
\end{tabular}

\subsubsection{CLEAN}

CLEAN is an alternative pretreatment system that applies more aggressive pretreatment of the tank wastes to reduce the quantity of HLW requiring vitrification and the radionuclide and hazardous material content of the LLW product. The specific goals of the CLEAN option (Straalsund et al. 1992), which have been adopted to formulate an aggressive, but feasible, strategy, are summarized below.

- The radioactivity will be removed from the bulk of the waste as that the radionuclides in the remaining LLW will not exceed NRC Class $A$ maximum allowable concentrations for shallow land burial of radioactive materials.

- The maximum allowable concentrations for technetium and iodine are further reduced below the Class $A$ limits to ALARA levels.

- Additional radioactivity will be removed from the LLW where significant reductions can be achieved through minor modifications to the process scheme.

- Uranium will be separated at sufficient purity to be sent to a stockpile and will not become part of the HLW or LLW form.

- The LLW will be disposed of in a manner that complies with U.S. Environmental Protection Agency and Washington State regulations regarding hazardous wastes.

- The radionuclides that have been removed from the bulk of the waste will be disposed of within about 1,000 canisters of a borosilicate glass that meets current HWVP glass specifications.

- Waste minimization principles will be used to limit the volume of LLW.

Statement of Issue. The CLEAN option relies on the extrapolation of laboratory experience to industrial application. A committee of national technical experts (Straalsund, et a1. 1992) agreed that the process chemistry for a CLEAN option is feasible, and identified a set of technical issues to be resolved before a decision is made to consider implementing the CLEAN option. 
The major issues are divided into the following three categories or areas of significant concern.

1. Feasibility issues that, if not resolved, make it impossible for the CLEAN option to succeed.

2. Key issues that, if not resolved, affect the ability of the CLEAN option to meet its goals.

3. Optimization issues where a high degree of confidence exists that a problem can be resolved with only minor development.

The technical issues listed in Table 4-19 were then derived to serve as a basis for a technology development program.

Table 4-19. Clean Option Technical Issues.

\begin{tabular}{|l|c|c|c|}
\hline \multicolumn{1}{|c|}{ Main issues } & Feasibility & Key success & Optimization \\
\hline $\begin{array}{l}\text { Complete dissolution or accepted } \\
\text { residual }\end{array}$ & $X$ & & \\
\hline $\begin{array}{l}\text { Specific separation americium, } \\
\text { strontium/barium, technetium }\end{array}$ & & $X$ & \\
\hline Variable composition & & & $X$ \\
\hline Resin, solvent, organic destruction & & $X$ & \\
\hline Neptı!rium chemistry-oxidation state & & & $X$ \\
\hline Recycle & & $X$ & \\
\hline Actual field decontamination factor & & & \\
\hline Backup assurance-polishers & & $X$ & \\
\hline Process flexibility and robustness & & & \\
\hline Solid/liquid separations & & & \\
\hline Process chemistry/ equipment & & & \\
\hline Secondary waste generation & & & \\
\hline Nitrate destruction & & & \\
\hline Maintenance and operability & & & \\
\hline
\end{tabular}

The feasibility issues were dissolution of solids, actual decontamination factors achievable in full-scale operating facilities, and liquid/solid separations. If heat generation is ignored, the amount and composition of the undissolved solids with TRU content greater than LLW limits may determine the number of glass canisters needed to dispose of tank waste. Actual decontamination factors achieved by the individual processes are uncertain. The conditions achievable in the laboratory or pilot plants are 
often difficult to maintain in a full-scale facility. Reasons for this include cross contamination, contaminant breakthrough, and solid carryover in the liquid/solid separation. However, improved onl ine instrumentation or sequential processing with lag storage, where decontamination of individual batches is verified before moving on to the next step, should eliminate many of these problems.

Scope. The CLEAN option technology development is focused primarily on developing the reference system and enhanced system functional needs to a higher level of decontamination performance. These technology needs were described in Sections 4.1.1 and 4.1.2. In addition, the functional needs described in Table 4-20 must be met to achieve the objectives of the CLEAN option.

Table 4-20. CLEAN Option Functional Needs.

\begin{tabular}{|l|l|l|}
\hline \multicolumn{1}{|c|}{ Waste constituent } & \multicolumn{1}{|c|}{ Disposition } & \multicolumn{1}{c|}{ Reason(s) } \\
\hline $\begin{array}{l}\text { Aluminium, Barium, Iron, } \\
\text { Sodium, silicates, } \\
\text { aluminosilicate } \\
\text { Straalsund 1992) }\end{array}$ & Grout & $\begin{array}{l}\text { The masses of these } \\
\text { materials ai removed } \\
\text { from the HLW stream for } \\
\text { disposal in grout. This } \\
\text { significantly reduces } \\
\text { HLW canister production } \\
\text { requirements. }\end{array}$ \\
\hline $\begin{array}{l}\text { Nickel, light } \\
\text { lanthanides, noble } \\
\text { metals }\end{array}$ & Grout & $\begin{array}{l}\text { Low solubilities of } \\
\text { these materials in glass } \\
\text { imit waste loading, } \\
\text { thereby producing more } \\
\text { canisters. }\end{array}$ \\
\hline Heavy lanthanides & Glass & $\begin{array}{l}\text { Decrease radionuclide } \\
\text { content of grout. }\end{array}$ \\
\hline Uranium & $\begin{array}{l}\text { Useful if purified; } \\
\text { disposal in glass would } \\
\text { result in large volumes } \\
\text { Possible release would } \\
\text { present performance } \\
\text { problems in grout and or } \\
\text { ALARA reduct ion of } \\
\text { radioactivity in grout. }\end{array}$ \\
\hline
\end{tabular}

$H L W=$ High-level waste

ALARA = As low as reasonably achievable.

Status. Currently the technology needs of the CLEAN option, beyond the needs of the reference system and enhancements, have been identified based on flowsheet analyses of pretreatment and disposal of the Hanford Site tank wastes. The needs associated with the CLEAN option are being examined further in FY 1993. Pending the results of these analyses, decisions will be needed regarding funding of the long-term development of technologies. 
WHC-EP-0629

\subsection{CROSSCUTTING OR TECHNOLOGY DEVELOPMENT SUPPORT ACTIVITIES}

\subsubsection{Corrosion Support}

\subsubsection{Corrosion Probe Development}

Statement of Issue. Proven corrosion instrumentation meets two important needs: (1) it can act as process control instrumentation to determine when the process chemistry gets out of control, and (2) it can make the practical connection between a material's performance "in the process environment" with the more extensive data base existing in the laboratory; thereby, making predictions possible. The effects of radiation in the actual working environment are difficult to simulate in the laboratory, but hardened corrosion probes can provide the connection. Other chemical-sensing instrumentation that can assist in the process control of the chemistry should be evaluated and developed. Examples are radiation-hardened $\mathrm{pH}$ electrodes and nitrate and nitrite electrodes, with. pH electrode being the most important of the chemical sensors.

Scope. Evaluation of reference electrodes in a radiation field was started in FY 1993. This work should be completed in FY 1994. Work should start on developing the process instrumentation necessary for controlling and acquiring the data from corrosion probes. It appears that a commercial source for the instrumentation (Gamry Instruments) is available, but the software must be modified to collect the data. Probe packages have been assembled and tested at the Savannah River and the Hanford Site, but they may need some modification and evaluation to fit current chemical-processing plans. Optimal locations in the chemical treatment plant must be identified and probe packages modified before being installed in those locations. Development work should be carried out to radiation harden chemical instrumentation that would be valuable in controlling the chemical processing steps. Development of a operative $\mathrm{pH}$ electrode would be the first step.

Status. Evaluation of reference electrodes in $\gamma$-radiation fields was started in FY 1993.

Schedule Requirements/Milestone Table. Table 4-21 presents the milestones associated with corrosion suppo: $t$. Milestones ior this work are shown as Subtask "1" activities.

\subsubsection{Organic Destruction}

Statement of Issue. Organic compounds are present in some of the waste tanks. The organic compounds originated as complexing agents or carryover from the organic solvent extraction. They must be destroyed to prevent interference with chemical processing of the waste. Three processes are currently under evaluation by WHC: (1) wet oxidation at elevated temperatures, (2) reaction with ozone, and (3) calcining. Very little is known about the performance of materials when exposed to the combined variables of an extreme oxidizing environment and Hanford Site waste chemistry. Safety and reliability of the process apparatus requires assurances that the construction materials are correctly chosen. 
Table 4-21. Long-Term Milestones for Corrosion Support.

\begin{tabular}{|c|c|c|}
\hline $\begin{array}{l}\text { Milestone (by } \\
\text { Corrosion } \\
\text { Subtask) }\end{array}$ & Completion date & Milestone description \\
\hline 1.1 & $02 / 94$ & $\begin{array}{l}\text { Complete development of radiation-hard } \\
\text { reference electrode. }\end{array}$ \\
\hline 1.2 & $02 / 95$ & $\begin{array}{l}\text { Complete development of corrosion probe } \\
\text { electrochemical instrumentation. }\end{array}$ \\
\hline 1.3 & $02 / 96$ & $\begin{array}{l}\text { Finish in-tank testing of corrosion probe } \\
\text { and instrumentation. }\end{array}$ \\
\hline 1.4 & $02 / 96$ & $\begin{array}{l}\text { Complete remaining hardened } \\
\text { instrumentation. }\end{array}$ \\
\hline 2.1 & $02 / 96$ & $\begin{array}{l}\text { Complete corrosion testing supporting } \\
\text { chosen process, at laboratory scale. }\end{array}$ \\
\hline 2.2 & $02 / 97$ & $\begin{array}{l}\text { Select construction material for } \\
\text { pilot-scale equipment. }\end{array}$ \\
\hline 2.3 & $02 / 00$ & $\begin{array}{l}\text { Complete corrosion analysis of } \\
\text { pilot-plant tests. }\end{array}$ \\
\hline 3.1 & $01 / 94$ & $\begin{array}{l}\text { Complete first set of tests to determine } \\
\text { chemistry controls consistent with safe } \\
\text { washing operations. }\end{array}$ \\
\hline 3.2 & $04 / 94$ & $\begin{array}{l}\text { Complete tests to determine minimum } \\
\text { inhibitor concentrations for safe } \\
\text { washing. }\end{array}$ \\
\hline 3.3 & $04 / 75$ & $\begin{array}{l}\text { Test inhibitor concentrations in } \\
\text { pilot-scale washing experiments. }\end{array}$ \\
\hline 4.1 & $04 / 93$ & $\begin{array}{l}\text { Determine whether candidate alloys are } \\
\text { highly susceptible to SCC/pitting. }\end{array}$ \\
\hline 4.2 & $04 / 94$ & $\begin{array}{l}\text { Complete sensitive tests of SCC } \\
\text { resistance. }\end{array}$ \\
\hline 4.3 & $04 / 94$ & $\begin{array}{l}\text { Complete first round of testing on new } \\
\text { candidates, if first serias proves } \\
\text { deficient. }\end{array}$ \\
\hline 4.4 & $04 / 95$ & $\begin{array}{l}\text { Complete evaluation of new candidates for } \\
\text { SCC and pitting. }\end{array}$ \\
\hline
\end{tabular}

SCC $=$ Stress corrosion cracking. 
Scope. Initially, PNL will provide cognizant oversight on the development of the oxidation processes because it is not certain which processes are most viable. Later, the work will switch to corrosion testing in the process chemistry at PNL.

Status. The project started in FY 1993 as an oversight program.

Schedule Requirements/Milestone Table. The milestones for this activity are presented in Table 4-21 as Subtask "2".

\subsubsection{Sludge Washing}

Statement of Issue. Sludge washing studies that are started in FY 1993 probably will not be completed until FY 1994. The studies will define the process chemistry in which carbon steel is either virtually immune or susceptible to stress-corrosion cracking, pitting, or general corrosion. In the interests of greatest washing efficiency, this laboratory work will attempt to define the boundary between corroding and benign environments and to specify wash-water chemistry that minimizes additives like sodium hydroxide and sodium nitrite. It will be important to do followup studies on tanks used at the pilot-scale level, to final operational status with full-scale tanks.

Scope. As future pilot-scale testing is done using actual waste cores, specimens designed to be vulnerable to stress-corrosion cracking or pitting will be added to the container. These tests will be run using wash water off typical chemistry and will be monitored for indications of stress corrosion cracking (SCC) or pitting in this more realistic environment of changing chemistry during washing. An electrochemical corrosion probe will be used during these tests to detect these corrosion types on a nearly real-time basis. Initial full-scale washing operations should also be monitored in this manner.

Status. Work began in February 1993 on corrosion tests that will expose carbon steel to a statistically designed matrix of chemical environments in which nitrate, nitrite, and hydroxide are varied. The work will include specimens to examine tendencies for SCC or pitting, as well as general corrosion.

Remaining Tasks. At the end of the first series of tests, the composition limits on nitrate, nitrite, and hydroxide are consistent with safe use of the carbon steel tanks for washing operations, at least roughly defined. Confirmatory tests to more closely define composition boundaries may be necessary, depending on the variability of initial results. After completing these confirmatory tests (if necessary), the subtask will be more closely connected with washing operations and pilot-and full-scale operations can be monitored for indications of corrosion problems.

Schedule Requirements/Milestone Table. The milestones for this work are shown in Table 4-21 as Subtask "3" activities. 
WHC-EP-0629

\subsubsection{Corrosion Testing, TRU Removal, and Solvent Extraction (including acid dissolution)}

Statement of Issue. The combination of nitric and hydrofluoric acids used for sludge dissolution is quite aggressive toward most common construction materials. For example, uniform corrosion testing done in Fy 1992 showed, corrosion rates of several inches per year in 304 staintess steel in the most aggressive solution. When tested in all four solutions, several less common alloys, particularly those high in chromium and nickel, showed rates of general corrosion that would be quite acceptable. Work planned for FY 1993 will determine whether these alloys will be susceptible to corrosion mechanisms such as pitting or SCC, behavior which would probably eliminate them from contention. This work should be completed by early FY 1994.

The next stage of this work depends highly on the results produced in the next two years. If, for instance, a reasonably available alloy is immune to SCC and pitting in typical solutions, the next stage would be to evaluate pilot-scale hardware, such as centrifugal contractors, for any erosion-corrosion problems or corrosion at welds. On the other hand, if all alloys being considered fail the second round of testing, a new suite of materials would have to be chosen and the evaluation process would continue. This second scenario is unlikely but possible.

Scope. The work planned beyond FY 1994 would be a natural outgrowth of that presently being done. It would include all necessary corrosion evaluations to ensure that candidate alloys would survive the planned operations, which include intense mixing and changes in solution chemistry, for at least several years.

Status. The first round of screening tests is complete. Results revealed marked differences in the uniform corrosion behavior of the several candidate alloys tested.

Remaining Tasks. Testing will resume early in FY 1993 with evaluation of SCC or pitting tendencies in the alloys surviving the uniform corrosion tests. The new tests will use the same series of prototypic solutions used in the previous work. By the end of FY 1993, we should know whether the alloys are extremely susceptible to either of these two mechanisms. Assuming that one or more alloys survive this round of testing, a possibility remains that SCC could occur with a long incubation period. To check this, it would be prudent to test a bolt-loaded WOL (wedge-opening load), which is designed to incubate a crack promptly and yield a value for the critical stress-intensity factor in the environment. This information is very useful in design. WOL specimens were left out of the first round of testing because of their expense.

Schedule Requirements/Milestone Table. To interface with the rest of the schedule for pretreatment, the construction material for tankage, pipes, and other hardware for this part of the processing should be made by 1996. This task is planned to provide the necessary information to make that choice. Milestones are shown in Table 4-21 as Subtask "4" activities. 


\subsubsection{General Corrosion Support}

Statement of Issue. The corrosion work planned in the TWRS Pretreatment Technology Development FY93 Project Work Plan, TWRSPP-93-005 (WHC 1992), will be completed in FY 1994. During that time period, work done in other tasks will eliminate some of the options from the array presently under consideration. Although the corrosion work will serve to guide materials choices, it would be naive to assume that no corrosion problems will occur during larger scale trials culminating in full-scale operations. Despite well-planned and well-conducted work, the history of corrosion problems in full-scale, long-term operations is replete with unanticipated problems originating from subtle differences in chemistry or physical factors not originally imagined to be important.

Scope. This subtask supports the continuing involvement by PNL corrosion specialists in the preparations for waste pretreatment operations. Funding will provide for key personnel, as necessary. It is difficult to be specific about the nature of the support provided in this subtask, but it would most likely involve such items as suggesting less expensive alternative construction material and evaluating these alternatives as needed and on-call consultations for solutions to probiems as they arise. These consultations will involve analyzing the problem, and defining a rationale for its solution.

Status. This subtask will start in FY 1994 and continue for 10 years, which should cover most difficulties encountered as pretreatment concepts are brought beyond the pilot scale.

Remaining Tasks. This subtask will begin in FY 1994, so the work outlined here is all in this category.

Schedule Requirements/Milestone Table. This subtask must be flexible to handle problems as they arise. Accordingly, it is not possible to define a schedule in any but the most general terms (as was done above) or to provide milestones.

\subsubsection{Pilot-Plant Strategy}

The historical development of processes for fuel reprocessing is used as a method of establishing the engineering approach or pilot-plant strategy for process scale-up and verification of the pretreatment processes. However, the wide variety of waste compositions that exist in the Hanford Site tanks will require a more substantial effort to ensure successful pretreatment operations on a plant scale. Generally, engineering development method involves the following:

- Laboratory-scale testing with actual and, in some cases, simulated radioactive wastes to verify the basic process chemistry

- Pilot-scale testing with simulated wastes to verify equipment system performance and provide data for the engineering design 
- Pilot-scale radioactive testing to provide final confirmation of process scale-up, provide feed for waste form qual ification (WFQ) testing of the HLW form, and meet process verification requirements for Resource Conservation and Recovery Act of 1976 (RCRA) permitting.

The following paragraphs summarize the basic test systems required to implement pretreatment processes and their primary objectives. The information that is to be obtained from each test system is identified in Table 4-22.

NOTE: The pilot-plant strategy is presented as an approach to develop pretreatment technologies. Actual deployment of pilot facilities, particularly radioactive facilities, will depend on the final pretreatment option and results of development work and needs to provide treated wastes to other TWRS program elements.

Laboratory-Scale Batch Tests with Actual Wastes. The first step in developing a specific chemical flowsheet for the processing of a particular waste type is batch testing with actual waste materials. The batch testing will establish the basic approach to condition the wastes for pretreatment, determine feed stability, and establish process performance. Because of the large number and variety of Hanford Site wastes (e.g., NCRW, PFP waste, CC waste), laboratory-scale batch testing may have to be performed throughout the entire tank remediation effort.

Laboratory-Scale Continuous Tests with Simulated Wastes. The primary objective of laboratory-scale testing using simulated feeds, which may contain tracer levels of radionuclides, is to develop a model relationship between the fully radioactive laboratory-scale tracer test system and the pilot-scale testing system. The laboratory-scale tracer test system also confirms separations performance and can be used to test and evaluate specific process operating parameters (i.e., establishing the range of chemical operability of the process.)

Laboratory-Scale Continuous Tests with Actual Wastes. Continuous laboratory-scale testing with actual wastes is the primary means for establishing the chemical flowsheet for processing of each waste type. The major technical information to be obtained during continuous laboratory-scale testing is related to the specific process chemistry of each waste type. This information includes waste feed preparation, feed stability, range of chemical operation, and separations performance.

Continuous laboratory-scale testing with actual wastes using feed volumes of 5 to $10 \mathrm{~L}$ will be conducted throughout the development, design, and verification of the pretreatment processes. Methods will need to be developed as part of the tank waste sampling program to retrieve large volumes of waste, up to $25 \mathrm{~L}$, for process testing. Radioactive continuous testing of each pretreatment process may be required for each waste type. 
Table 4-22. Summary of Technical Information Needs for Pretreatment Process Testing. (2 sheets)

\begin{tabular}{|c|c|c|c|c|c|c|c|c|c|c|c|}
\hline 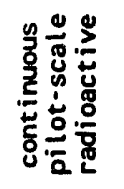 & & $\times \times$ & $x$ & $x$ & $x$ & & & & $x$ & $x$ & $x$ \\
\hline 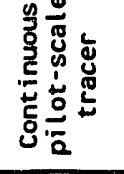 & & $x$ & & & $x$ & & $x$ & & & $x$ & $x$ \\
\hline 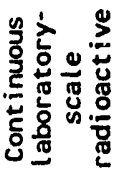 & & $x$ & $x$ & $x$ & $x$ & $x$ & $x$ & & & & \\
\hline  & & $x$ & & & $x$ & & $x$ & & & & \\
\hline 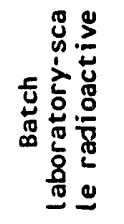 & & $x$ & $x$ & $x$ & $x$ & $x$ & $\times$ & & & & $x$ \\
\hline  & 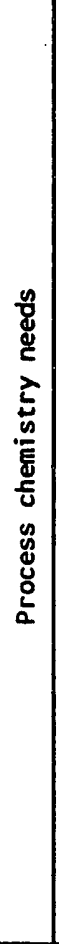 & 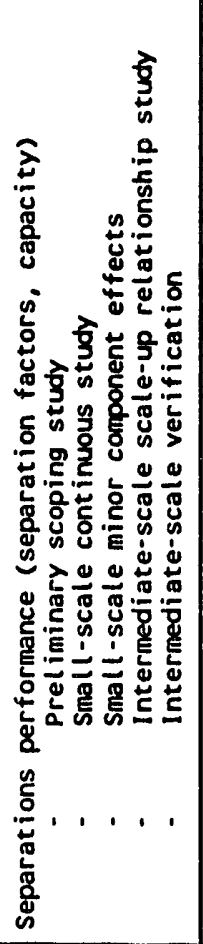 & 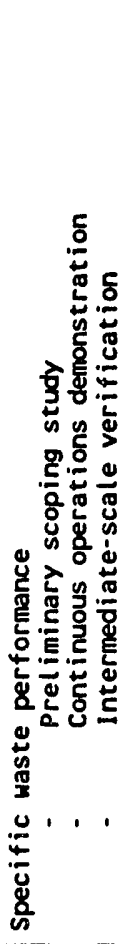 & 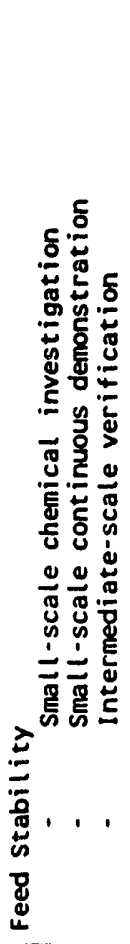 & 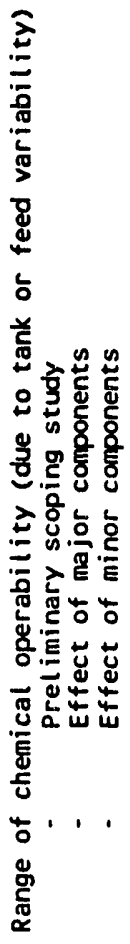 &  & 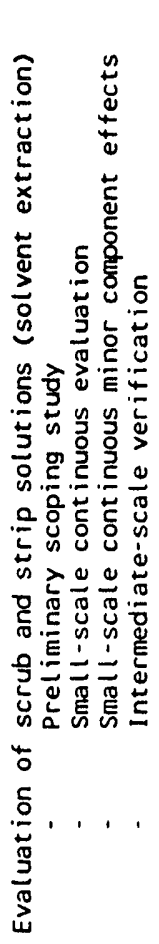 & 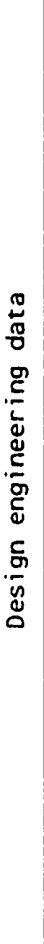 & 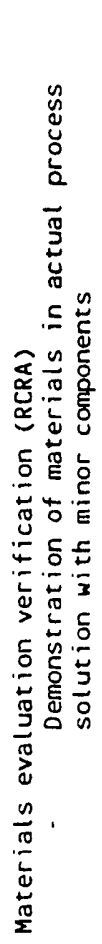 & 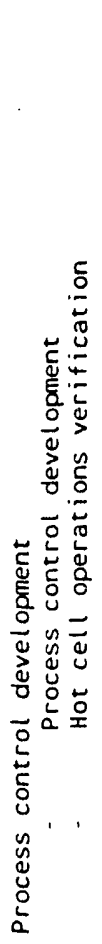 & 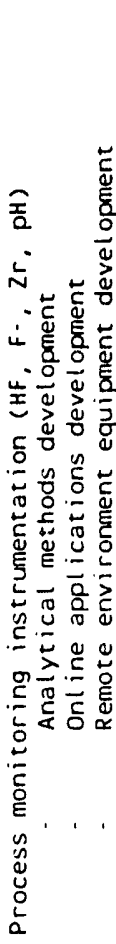 \\
\hline
\end{tabular}


WHC-EP-0629

Table 4-22. Summary of Technical Information Needs for Pretreatment Process Testing. (2 sheets)

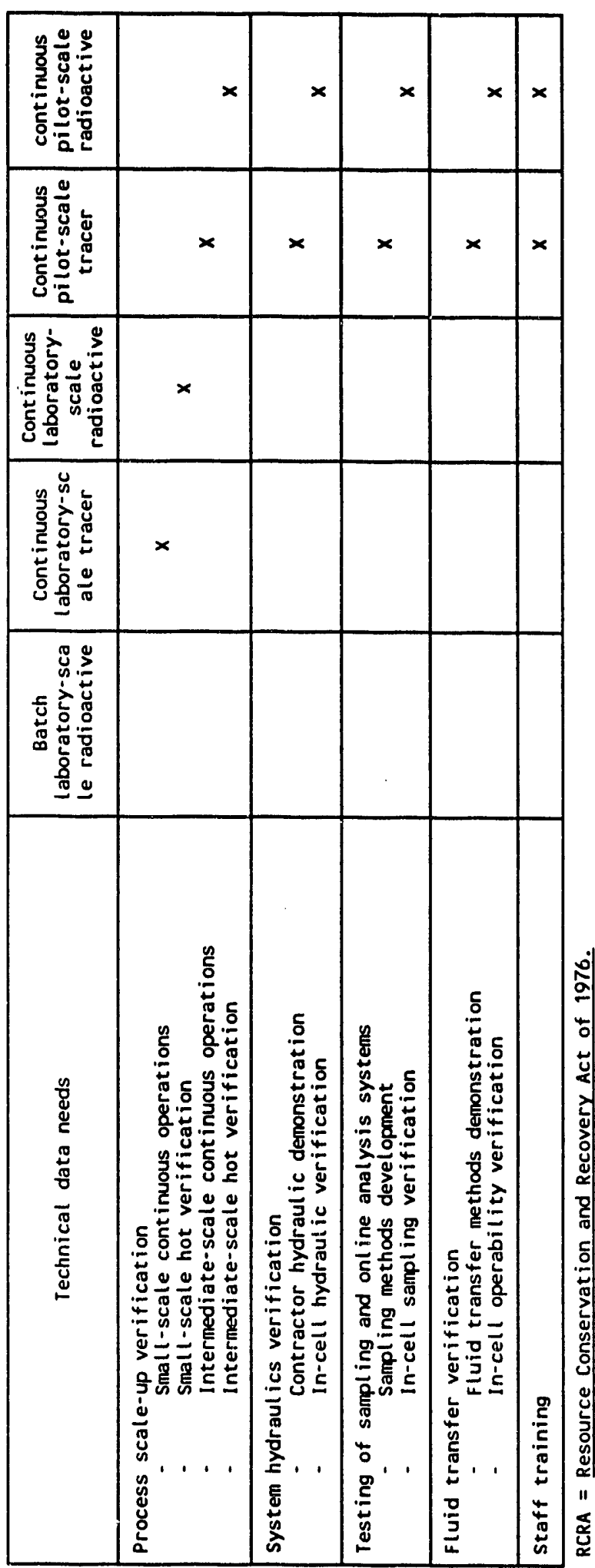


Pilot-Scale Continuous Tests with Simulated Wastes. The majority of the technical information needed for engineering design and verification of equipment performance will originate from pilot-plant testing. This testing will be done with a complete process system using simulated wastes. The majority of the testing on the pilot-scale systems must be completed before the start of the detailed design of the new pretreatment facilities.

Depending on the specific process performance and the validity of the process scale-up model, additional testing may be done at more than one scale of pilot testing. Also, pilot operations of specific units, such as solvent extraction contractors, will be completed for final equipment development and process confirmation. Pilot-scale testing may also involve the use of tracer levels of radionuclides. Nonradioactive testing of each pilot-scale process system will continue until all design data are obtained, process operational data are established, and initial training of staff is completed.

Pilot-Scale Continuous Tests with Actual Wastes. The primary objectives in the operation of a pilot-scale system using actual radioactive waste may include all or some of the following.

- Verify that the process can treat the targeted wastes.

- Provide treated waste for vitrification testing in a small-scale radioactive melter.

- Provide final data on process and equipment system performance and thus support RCRA permitting of new pretreatment facilities and verification of the process performance models.

- Support the operation of the full-scale process.

\subsubsection{Systems Engineering Studies}

Statement of Issue. The functional needs have been identified to address specific pretreatment needs (i.e., cesium removal). However, the effect of deploying a technology must be evaluated in terms of its effect on the overall system, which includes the following components:

- Waste volume and composition for HWVP

- Waste volume and composition for grout

- Generation of secondary waste streams recuiring treatment

- Requirements and constraints imposed on the pretreatment processing facility (i.e., a CPU, the IPM, or the SPM)

- Economics of the integrated system.

These effects must be identified and evaluated before making final technology selections to ensure that a technology that best meets a particular functional need does not adversely affect operations in another part of the waste processing system, thus negating the benefits of the technology. Similarly, as a suite of technologies are identified and proposed for deployment as a system, they must be analyzed for their mutual compatibility and/or identification of operating constraints that are imposed by one process on another (i.e., limiting concentration of a particular species leaving one 
process so that the next process can meet its performance specifications). Failure to adequately address the effects on the overall system could result in deployment of technologies that create problems and adversely affect pretreatment system performance.

Scope. The scope of this subtask is to provide in-depth systems analyses for each of the technology systems (reference, enhancements, CLEAN, and a)ternatives) as candidate technologies for each functional need are eliminated and final decisions on technologies for deployment need to be made. Brief systems evaluations will also be a component of the early evaluation of all candidate technologies to ensure that investments are not made in technologies deemed inappropriate from a systems perspective. In part, this was the basis for selecting and prioritizing the candidate technologies currently identified for each functional need.

Status. This subtask will be a new task beginning in FY 1994 and continue until final decisions have been made on technologies for deployment.

Schedule Requirements/Milestone Table. These analyses must be completed as needed; milestone dates have not yet been established.

\subsubsection{Thermodynamic Modeling of Waste Tank Constituents}

Statement of Issue. The objective of this work is to develop a capability to predict and evaluate the performance of proposed pretreatment processes for Hanford Site tank wastes. Because these wastes contain a wide variety of constituents, predicting their chemical behavior is very difficult. An accurate thermodynamic model for predicting the chemistry of the tank wastes is needed. This model will be used as a guide in defining and evaluating such operations as sludge washing, leaching, and dissolution.

Scope. A thermodynamic model will be developed to predict solid-liquid or vapor-liquid equilibrium that would occur during tank waste pretreatment processes using existing commercial software including, but not limited to, ASPEN PLUS*. ASPEN PLUS contains equations to accurately model highly concentrated solutions (high ionic strength) and reactions with solids such as sludges. Because ASPEN PLUS databanks currently lack much of the data required to accurately simulate Hanford Site sludge and slurry systems, experiments on simple two- or three-component systems will be performed to obtain the needed thermodynamic parameters. Because of the complexity of the tank waste chemical system, this work will focus on the specific problems relevant to waste pretreatment.

Model predictions will be compared with experimental results using more complex mixtures, as well as with sludge dissolution tests using actual tank waste. The model will then be integrated into other TWRS process modeling and evaluation tasks. This model will be used to help guide dissolution studies with actual wastes. The model also is expected to significantly reduce the cost and time required to developed the pretreatment process and make pretreatment operations more effective.

"ASPEN PLUS is a trademark of ASPEN Technology, Inc. 
Status. A large amount of thermodynamic data that can be used to develop a sludge dissolution model were collected through a literature review (Silva, Felmy, and Ding 1993). Some of this information has been analyzed, regressed, and reduced to the form needed for input to ASPEN PLUS. Important gaps in the existing data were identified, and an experimental program for collecting this missing information was recommended. Silica solubility studies and sodium nitrate/sodium nitrite isopiestic studies were conducted. Much more work is needed to collect data, regress model parameters from the data, and validate the model before an early version of this model will be useful for predicting sludge pretreatment performance. A model for predicting chemical equilibrium of supernatant and salt cake chemical equilibrium could be provided earlier because these wastes do not contain as many chemical components as sludge. issue.

Remaining Tasks. Completion of the following tasks will close this

- Conduct experiments (i.e., isopiestic, solubility) on simple two- to three-component systems to obtain data for thermodynamic model parameters.

- Regress thermodynamic data from the literature and from ongoing experiments.

- Compare thermodynamic model predictions with experimental results from sludge dissolution tests or other tests designed for this purpose.

- Incorporate thermodynamic model into TWRS process and system engineering flowsheet development tasks.

Schedule Requirements/Milestone Table. The key milestones associated with the development of the thermodynamic model are listed in Table 4-23. The milestones shown are those that can be clearly defined at this time.

Additional milestones will likely be added in the future.

Table 4-23. Thermodynamic Modeling Milestones.

\begin{tabular}{|c|c|l|}
\hline Milestone & $\begin{array}{c}\text { Completion } \\
\text { date }\end{array}$ & \multicolumn{1}{|c|}{ Milestone description } \\
\hline 1 & $06 / 94$ & $\begin{array}{l}\text { Regress model parameters for supernatant and } \\
\text { salt cake. }\end{array}$ \\
\hline 2 & $09 / 96$ & Define acid and alkaline bulk con'stituent models. \\
\hline 3 & $06 / 97$ & $\begin{array}{l}\text { Regress model parameters for major sludge } \\
\text { constituents. }\end{array}$ \\
\hline 4 & $09 / 97$ & Model verification. \\
\hline
\end{tabular}




\subsubsection{Characterization and Analytical Requirements}

Statement of Issue. The development of technologies for each of the functional needs will require extensive characterization of samples and analysis of process streams to characterize the separations performance and composition of resulting waste streams. This characterization and analysis is essential to decision making on pretreatment technologies for deployment and also for determination of the optimum operating conditions for each selected technology. To the extent possible, sample characterization data will be obtained from the ongoing tank waste characterization program. Funding has been included for a number of analytical samples for all laboratory and pilot-scale testing for each functional need. However, there is uncertainty that capability exists at the Hanford Site to provide this analytical support consistent with the pretreatment program schedules. It will be essential for the fiscal year work plans to address the number and types of analytical samples required and negotiate with the PNL and WHC facilities to provide adequate support in the timely reporting of analytical results. If this service can not be provided to the pretreatment program, then technology development schedules may be delayed or alternate arrangements made (i.e., offsite laboratories or procurement of dedicated analytical instruments for selected pretreatinent processes). Obviously, the more extensive the pretreatment program is (i.e., the more technologies to be developed), the greater the analytical requirements will be and the greater the impact will be or existing analytical capabilities.

Scope. The scope of characterization and analytical requirements includes any and a 11 testing programs conducted for a.11 system scenarios (reference, enhancements, CLEAN and alternatives). Sample analys is will be required throughout the test program from lab-scale batch tests with waste simulants thru pilot-scale tests with actual wastes.

Status. Currently, a few laboratory tests with waste simulants and actual wastes have been/are being conducted for different pretreatment technologies being evaluated. However, the scope of this analytical need is expected to increase dramatically as the pretreatment program matures.

\section{Remaining Tasks}

- Provide characterized waste simulants and waste samples for technology development testing.

- Provide analytical support during and after process testing to provide data on process operations and efficiencies.

Schedule and costs. The schedule and costs are included in the milestones and costs established for each functional need. However, ensuring that these schedules can be met will need to be verified by coordination with the analytical facilities each year and/or as analytical requirements change. 


\subsection{SCHEDULE}

Appendix A presents a summary level pretreatment master schedule. The schedule is a Tri-Party Agreement compliant schedule and assumes that resource and budget requirements are unconstrained. Included in the schedule are activities that are not included in the technology plan. These additional activities represent expected HWVP activities, pretreatment engineering activities, and pretreatment facility and operations activities. The additional activities are presented to illustrate the time frame in which process design information will be required to support project design and construction activities.

\subsubsection{PROGRAM ASSUMPTIONS AND CONSTRAINTS AFFECTING PRETREATMENT TECHNOLOGY DEVELOPMENT}

The following is a summary list of assumptions and constraints used in developing the waste pretreatment work scope. This list reflects assumptions documented in the FY 1993 Work Plan and other specific guidance. Additional detailed assumptions associated with specific tasks may have al so been used. Additional key assumptions and constraints that will impact the planned work scope are expected in the new TWRS strategy.

- The HWVP will begin hot operations in December 1999.*

- Advanced separation processes (i.e., processes beyond cesium ion exchange and sludge washing) are required to minimize the number of glass canisters produced.

- The available characterization and Tracks Radioactive Components (TRAC) data provide an adequate planning base for pretreatment processes. New sample data shall be available to support development and implementation of pretreatment processes.

- Tank space is available to support pretreatment operations in accordance with the annual waste volume projections.

- In-Tank sludge washing and the IPM will provide sufficient feed for at least 6 to 15 years of operation of HWVP and the Grout Facility.

- All SST waste will be retrieved for processing and disposal.

- There will be no change in the NRC position on HLW.

- Tri-Party Agreement milestones will not be accelerated.

- The TWRS-Environmental Impact Statement (EIS) and ROD provide sufficient National Environmental Policy Act of 1969 (NEPA) documentation coverage for in-tank processing of DST wastes.

\footnotetext{
*Assumption likely to change based on proposed TWRS new technical strategy.
} 
The TWRS-EIS and resulting ROD shall provide NEPA documentation coverage for the second pretreatment module and subsequent pretreatment facilities, if required. The TWRS-EIS ROD shall not delay detailed design for the SPM.

- First priority of pretreatment is safety remediation.

- Ten to 17 tanks require safety remediation through IPM.

- Tanks 106-C and 105-C will have early retrieval.

- No additional tank waste radionuclide removal will be required to complete the first 14 grout campaigns."

- WFQ feeds must be available 2 years before HWVP hot startup.

- Pretreatment logic covers multiple pretreatment options, up to the "Clean" option, excluding specific elements of sludge processing associated with the "Clean" option.

- The following inputs from Characterization go to all laboratory studies in pretreatment. (This is not shown in pretreatment logic because it would mask underlying ties).

- Characterization of core samples

- Liquid and solid samples from tank farm coring activities.

- Requirements Analysis Activity for each process has inputs from the following:

- Characterization

- Retrieval

-- dilution amount

-- tank sequence

- HWVP waste feed specifications

- Grout feed specifications.

- All pretreatment laboratory testing and pilot plant operations are tied to Grout Formulation and Testing. The following items list input from Grout and the response from Pretreatment respectively.

-- Grout feed specifications

-- Pretreatment process capabilities and expected product compositions

- Retrieval will supply small-scale solids samples (25 to $50 \mathrm{~L}$ ) to all bench-scale activities.

- Retrieval will supply pilot-scale solids samples (1,135 L [300 gal]) to all pilot-scale activities.

*Assumption likely to change based on proposed TWRS new technical strategy. 
- The Grout facility will fill 4 vaults per year.

- HWVP Characteristics Report is produced out of Pretreatment Technical Administration (Integration).

- Solvent extraction processes contractor equipment development is included under the Cold Solvent Extraction Pilot Plant. The contactors equipment includes the following:

- Centrifugal Contactors

- Mixer Settlers

- Pulsed Columns.

- Outer years of engineering analyses of solvent extraction tests of FYXX core samples feed SPM operations.

- One alternate process, with multiple functions, will be carried forward with detailed continuous testing.

- Intermediate process screening studies include technical evaluation and laboratory testing.

- Sludge wash pilot plant can be used for intermediate process testing. Minor modifications may be needed.

- SPM operating strategy includes the following:

- Feed variability

- Blending of pretreatment feed and products from acid side/SPM processes (i.e., TRU stream form TRUEX).

- Clean option screening studies of polishing processes includes technetium, strontium, iodine, TRU, etc.

- Sodium LLW form (to reduce vaults) should be investigated. Leave this issue to LLW group via integration team.

- Requirements for organic destruction to meet LLW disposal specifications will be more stringent than requirements for organic destruction (by IPM) to resolve safety issues.

- The required hot startup date for IPM is December 1999.

- To meet schedule requirements, design and construction of the IPM is anticipated to occur in two phases. Phase 1 construction is scheduled to start before Phase 2 design will have progressed sufficiently to support finalization of the Preliminary Safety Analysis Report (PSAR) and environmental permit applications. It is assumed that a limited scope safety analys is will be sufficient for authorization of Phase 1 construction, to be followed by preparation of a comprehensive PSAR in full compliance with DOE orders, based on Phase 2 detailed design. The comprehensive PSAR will be approved by DOE before the start of Phase 2 construction. Similarly, it is assumed that the regulatory agencies will allow Phase 1 construction 
to proceed before submittal of environmental permit applications that will necessarily contain Phase 2 detailed design information.

- The first feed to the IPM will be from tank 241-SY-SY.

- The primary function of the IPM will be to resolve any remaining safety issues after mitigation actions are complete.

- Nitrate/nitrite destruction, although desirable, has been specifically excluded from IPM criteria.

\subsection{FACILITY/CAPITAL EQUIPMENT NEEDS}

Technology development for pretreatment activities will require significant facilities. These facilities will be needed at the Har.ford site and at other COE sites. Facilities will be required to support expanded pretreatment activities to support laboratory batch studies, continuous testing of pretreatment processes with actual wastes, pilot-scale testing of pretreatment processes with simulated and actual tank sludges, and analytical requirements. The facility requirements for the laboratory and analytical support activities are currently being developed and are not included in this version of the technology plan.

Pilot facilities are expected to be required to develop necessary process engineering data to support pretreatment plant design, construction, and operations. To support pilot-scale testing with simulated wastes, it is projected that the WHC Chemical Engineering Laboratory will have to be doubled in available floor space. To support pilot-scale activities with actual wastes, either a new or retrofitted facility will be required. This technology plan assumes that a core hot-pilot plant facility will be constructed and available by January 1998. Modular pilot units will either be attached to or incorporated within this hot-pilot facility for testing of specific processes. The modular units will be selected at a later date, but configuration of the modules may be compatible with either a large fixed facility or may be compatible with a CPU. The central facility is included in the pretreatment technology plan as a separate project. The individual modules are included as either pilot facilities under the appropriate development function or as a compact processing unit.

This technology plan does not incorporate capital construction funds for facilities pertaining to laboratory-scale testing or for analytical support facilities. However, it is expected and capital costs are included for on ine analytical equipment to support technology development activities. Capital funds are also included for the core hot-pilot facility. It is assumed that any pilot-scale modules and compact processing units constructed for development purposes will be used for 2 to 3 years, which will allow the module to be constructed with expense funding. Finally, the expansion for the Chemical Engineering Laboratory to support cold pilot-scale testing is expected to be a capital project. 


\subsection{TIME-PHASED BUDGET ESTIMATES}

Budget estimates have not been included in this document. At this time extensive revisions are being made to the TWRS strategy in response to the TWRS leadership council. These revisions may significantly affect the pretreatment technology development strategy, time frame, and costs. Until the TWRS program strategy is accepted by all interested parties, including the DOE, the EPA, the State of Washington, the State of Oregon, the Yakima Indian Nation, and other interested parties, the costs for the pretreatment technology development program are subject to change.

Projected costs relating to the pretreatment technology program will be published in the Integrated Technology Plan (DOE-RL 1993), and in the TWRS Multi-Year Program Plan. In addition, costs pertaining to pretreatment technology will be published in future revisions of this document.

\subsection{BREAKOUT OF WORK SCOPE BY SITE/PARTICIPANT}

Development of pretreatment technologies for use at the Hanford Site to treat tank wastes is a cooperative effort between the DOE programs for Environmental Waste Management, EM-30, and the Office of Technology Development, EM-50. The Office of Technology Development, through the Underground Storage Tank Integrated Demonstration and the Efficient Separations Processes Integrated Program, is supporting Environmental Waste Management by supporting research throughout the DOE complex pertaining to the basic and developmental research for pretreatment processes arid for al ternate facility approaches. Sites participating in the pretreatment technology program include the Hanford Site, Argonne National Laboratory, Los Alamos National Laboratory, Oak Ridge National Laboratory, Sandia National Laboratory, Savannah River Technology Center, and the West Valley Site. In addition, research is ongoing at a number of universities, at industrial participants, and at foreign sites.

A summary of ongoing activities at various DOE sites that support the TWRS Pretreatment Program is presented in Table 4-24. The total scope of work at sites other than the Hanford Site is increasing as knowledge of specific Hanford Site problems is identified. 
WHC-EP-0629

Table 4-24. Ongoing Pretreatment Technology Activities Other than the Hanford Site or Funded by EM-50.



ANL = Argonne National Laboratory

INEL = Idaho National Engineering Laboratory.

LANL = Los Alamos National Laboratory.

ORNL = Oak Ridge National Laboratory.

PFP $=$ Plutonium Finishing Plant.

PNL = Pacific Northwest Laboratory.

SNL = Sandia National Laboratory.

$T R U=$ Transuranic.

TRUEX = Transuranic extraction.

WHC = West inghouse Hanford Company.

WSRC = Westinghouse Savannah River Company. 
WHC-EP-0629

This page intentionally left blank. 


\subsection{REFERENCES}

Chamberlain, D. B., G. F. Vandegrift, D. G. Wygmans, R. A. Leonard, J. C. Hutter, and E. H. Van Deventer, 1992, TRUEX Processing of Plutonium Analytical Sample Residues, Presented at the l6th Annual Actinide Separations Conference, Estes Park, Colorado, May 11-14, 1992.

Cuillerdier, C., C. Musikas, and L. Nigond, 1993, "Diamides as Actinide Extractants for Various Waste Treatments," Separation Science and Technology, 28:155-175.

DOE, 1987, Final Environmental Impact Statement, Disposal of Hanford Defense High-Level, Transuranic and Tank Wastes, Hanford Site, Richland, Washington, DOE/EIS-0113, V01. 1 through 5, U.S. Department of Energy, Washington, D.C.

DOE, 1988, "Final Environmental Impact Statement for the Disposal of Hanford Defense High-Level, Transuranic and Tank Wastes, Hanford Site, Richland, Washington; Record of Decision," Federal Register, Vol. 53, No. 72, pp. 12449-12453, U.S. Department of Energy, Washington, D.C.

DOE-RL, 1993, Tank Waste Remediation System Integrated Technology Plan, DOE/RL-92-61, Draft, U.S. Department of Energy, Richland Field Office, Richl and, Washington.

Ecology, EPA, and DOE, 1992, Hanford Federal Facility Agreement and Consent Order, 2 vols., Washington State Department of Ecology,

U.S. Environmental Protection Agency, and U.S. Department of Energy.

Horwitz, E. P., M. L. Dietz, and D. E. Fisher, 1991, "SREX: A New Process for the Extraction and Recovery of Strontium from Acidic Nuclear Waste Streams," Solvent Extraction and Ion Exchange, 9:1-25.

Horwitz, E. P., M. L. Dietz, R. D. Rogers, and D. B. Chamberlain, 1992. A Combined TRUEX-SREX Extraction/Recovery Process, Presented at the 16 th Annual Actinide Separations Conference, Estes Park, Colorado, May 11-14, 1992.

Horwitz, E. P., D. G. Kalina, H. Diamond, G. F. Vandegrift, and W. W. Schulz, 1985, "The TRUEX Process - A Process for the Extraction of the Transuranic Elements From Nitric Acid Wastes Utilizing Modified PUREX Solvent," Solvent Extraction and Ion Exchange, 3:75-109.

Horwitz, E. P., D. G. Kalina, L. Kaplan, G. W. Mason, and H. Diamond, 1982, "Selected Alkyl (phenyl)-N,N-dialkylcarbamoylmethylphosphine 0xides as Extractants for Am(III) from Nitric Acid Media, Separation Science and Technology, 17:1261-1279.

Kalina, D. G., E. P. Horwitz, L. Kaplan, and A. C. Muscatel10, 1981, "The Extraction of $A m$ (III) and $F e(I I I)$ by Selected

Dihexyl-N,N-Dialkylcarbamoyl-methy1-Phosphonates, -Phosphinates, and -Phosphine Oxides from Nitrate Media," Separation Science and Technology, $16: 1127-1145$. 
Kolaric, Z., 1991, Separation of Actinides and Long-Lived Fission Products from High Level Radioactive Waste (a review), "̈fK 4945, Kernforschungszentrum Karlsruhe GrmbH, Karl sruhe, Germany.

Lumetta, G. J., L. A. Bray, D. E. Kurath, J. R. Morrey, J. L. Swanson, and D. W. Webster, 1993, Exploratory Complex and Concentrate Waste Processing Study, PNL-8438, Pacific Northwest Laboratory, Richland, Washington.

Lumetta, G. J. and J. L. Swanson, 1993a, Pretreatment of Neutralized Cladding Removal Waste (NCRW) Sludge - Results of FY 1991 Studies, Manuscipt in preparation, Pacific Northwest Laboratory, Richland, Washington.

Lumetta, G. J. and J. L. Swanson, 1993b, Pretreatment of Neutralized Cladding Removal Waste (NCRW) Sludge: Status Report, Manuscript in preparation, Pacific Northwest Laboratory, Richland, Washington.

Lumetta, G. J. and J. L. Swanson, 1993c, Pretreatment of Plutonium Finishing Plant (PFP) Sludge Waste: Report for the Period October 1990 to March 1992, Manuscript in preparation, Pacific Northwest Laboratory, Richland, Washington.

Lumetta, G. J., J. L. Swanson, and S. A. Barker, 1992, Process Chemistry For the Pretreatment of Hanford Tank Wastes, PNL-SA-20608, Pacific Northwest Laboratory, Richland, Washington, Presented at the 204 th National Meeting of the American Chemical Society, Washington, D.C., August 23-28, 1992.

Lumetta, G. J., M. J. Wagner, N. G. Colton, and E. 0. Jones, 1993, Underground Storage Tank Integrated Demonstration: Evaluation of Pretreatment Options for Hanford Tank Wastes, Manuscript in preparation, Pacific Northwest Laboratory, Richland, Washington.

Lımetta, G. J., D. W. Wester, J. R. Morrey, and M. J. Wagner, 1993, "Preliminary Evaluation of Chromatographic Techniques for the Separation of Radionuclides from High-Level Radioactive Waste," PNL-SA-21561, Pacific Northwest Laboratory, Richland, Washington, Submitted to the journal Solvent Extraction and Ion Exchange.

Marsh, S. F. and S. L. Yarbro, 1988, Comparative Evaluation of DHDECMP and CMPO as Extractants for Recovering Actinides from Nitric Acid Waste Streams, LA-11101, Los Alamos National Laboratory, Los Alamos, New Mexico.

National Environmental Policy Act of 1969, 42 USC 4321, et seq.

Orme, R. M., 1992, Preliminary TRU Segregation Technology Evaluation, WHC-SD-WM-TI-538, Rev. 0, Westinghouse Hanford Company, Richland, Washington.

Orth, R. J. and D. E. Kurath, 1993, Review and Assessment of Technologies for the Separation of Strontium from Alkaline and Acidic Media, TWRSPP-93-018, Pacific Northwest Laboratory, Richland, Washington. 
Ozawa, M., S. Nemoto, A. Togashi, T. Kawata, and K. Onishi, 1992, "Partitioning of Actinides and Fission Products in Highly-Active Raffinate From PUREX Process By Mixer-Settlers," Solvent Extraction and Ion Exchange, 10:829-846.

Resource Conservation and Recovery Act of 1976, 42 USC 6901, et seq.

Schulz, W. W. and E. P. Horwitz, 1988, "The TRUEX Process and the Management of Liquid TRU Waste," Separation Science and Technology, 23:1191-1210.

Schulz, W. W., and M. J. Kupfer, 1991, Candidate Reagents and Procedures for Dissolution of Hanford Site Single-Shell Tank Sludges, WHC-EP-0451, Westinghouse Hanford Company, Richland, Washington.

Silva, L. J., A. R. Felmy, E. R. Ding, 1993, Sludge Treatment Evaluation: 1992 Technical Progress, PNL-8403, Pacific Northwest Laboratory, Richland, Washington.

Straalsund, J. L., E. G. Baker, J. J. Holmes, E. O. Jones, and W. L. Kuhn, 1992, CLEAN Option: An Alternative Strategy for Hanford Tank Waste Remediation, PNL-8388, Vol. 1, Pacific Northwest Laboratory, Richl and, Washington.

Swanson, J. L., 1991a, Initial Studies of Pretreatment Methods for Neutralized Cladding Removal Waste (NCRW) Sludge, PNL-7716, Pacific Northwest Laboratory, Richland, Washington.

Swanson, J. L., 1991b, Use of the TRUEX Process for the Pretreatment of Neutralized Cladding Removal Waste (NCRW) Sludge - Results of a Design Basis Experiment, PNL-7734, Pacific Northwest Laboratory, Richland, Washington.

Swanson, J. L., 1991c, Use of the TRUEX Process for the Pretreatment of Neutralized Cladding Removal Waste (NCRW) Sludge - Results of FY 1990 Studies, PNL-7780, Pacific Northwest Laboratory, Richland, Washington.

WHC, 1992, Pretreatment Technology Development FY 93, Project Work Plan, TWRSPP-93-005, Westinghouse Hanford Company, Richland, Washington. 
WHC-EP-0629

This page intentionally left blank. 
WHC-EP-0629

APPENDIX A

PRETREATMENT MASTER SCHEDULE

APP A-1 
WHC-EP-0629

This page intentionally left blank. 
WHC-EP-0629

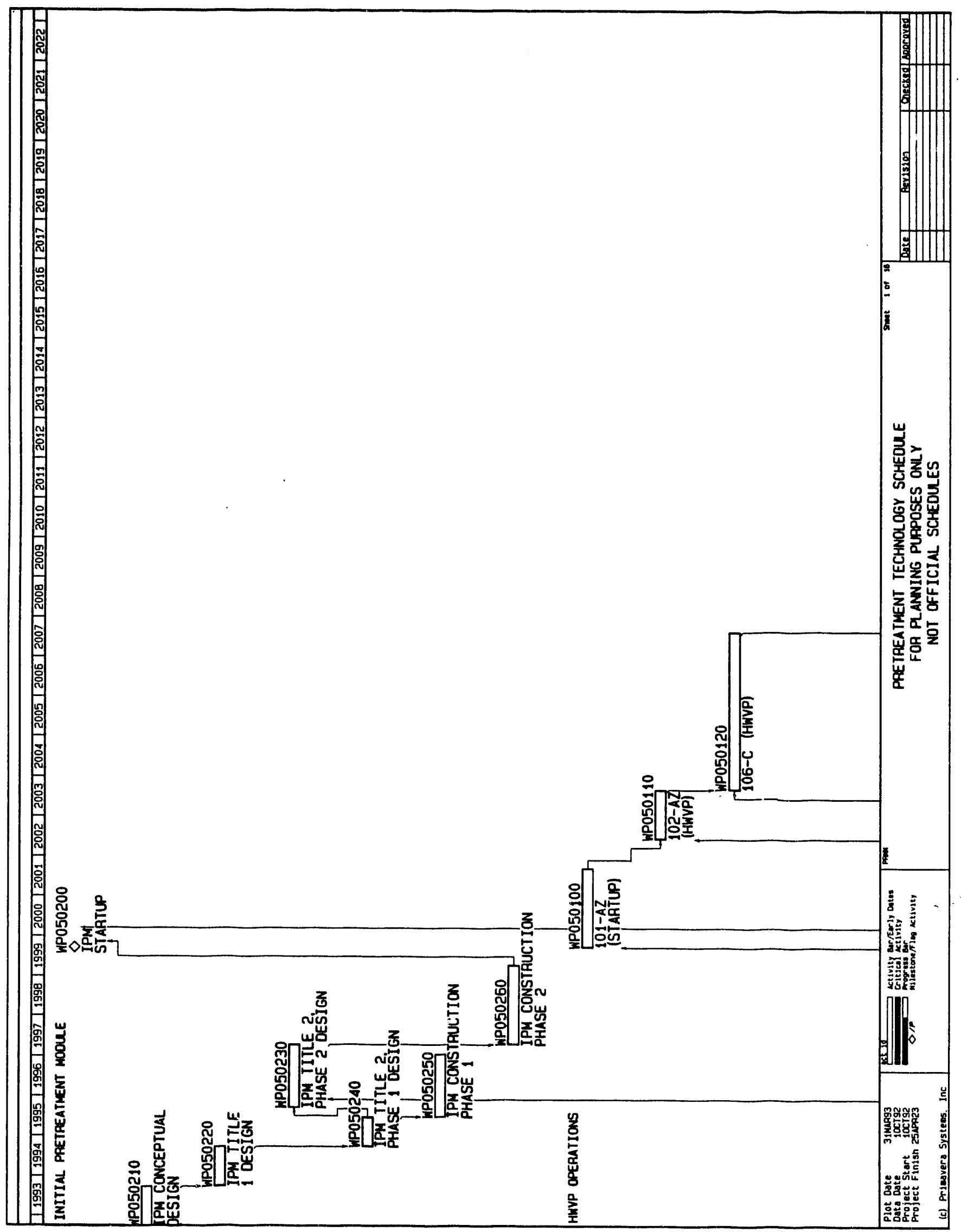

APP A-3 
WHC-EP-0629

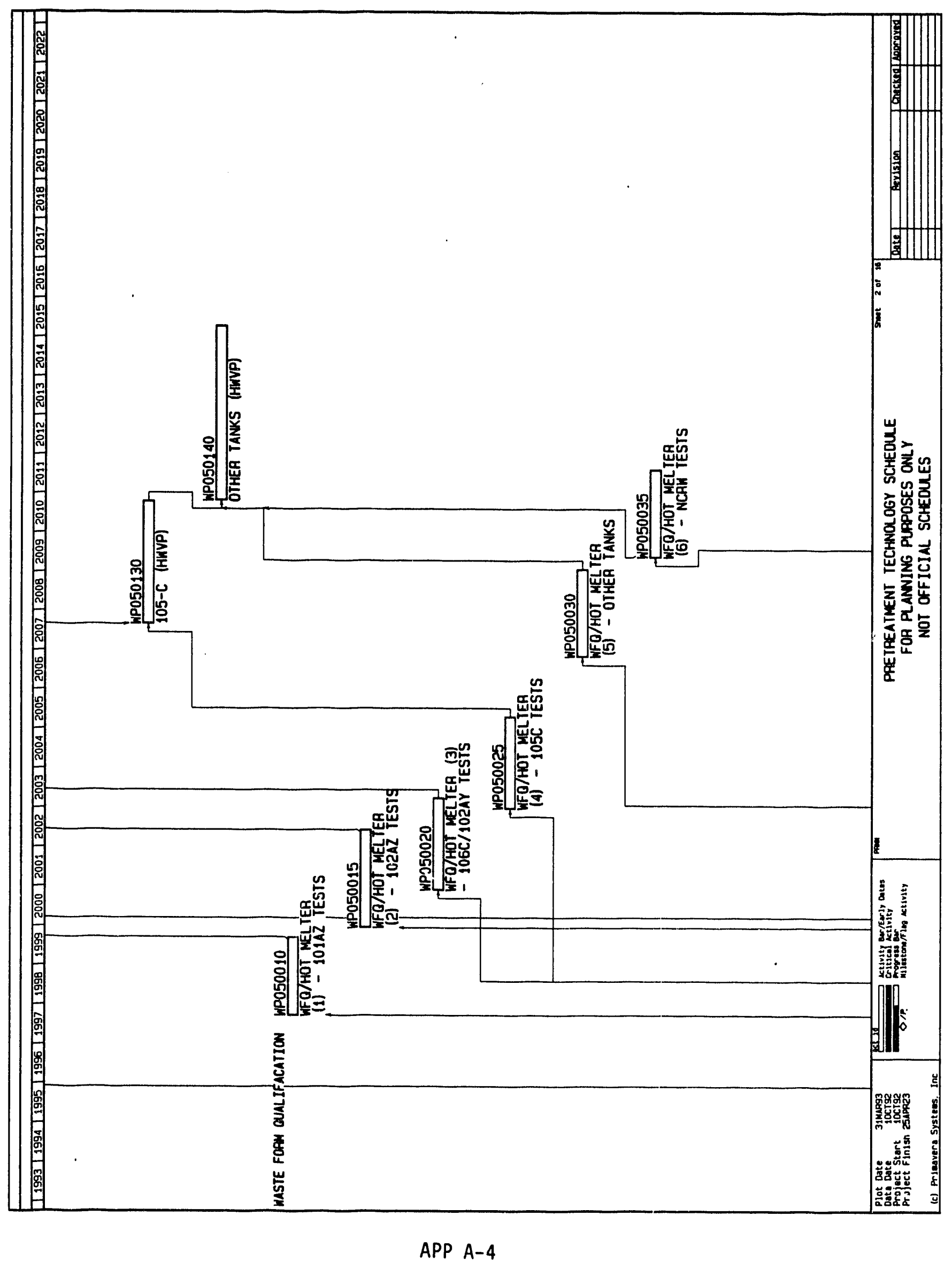


WHC-EP-0629






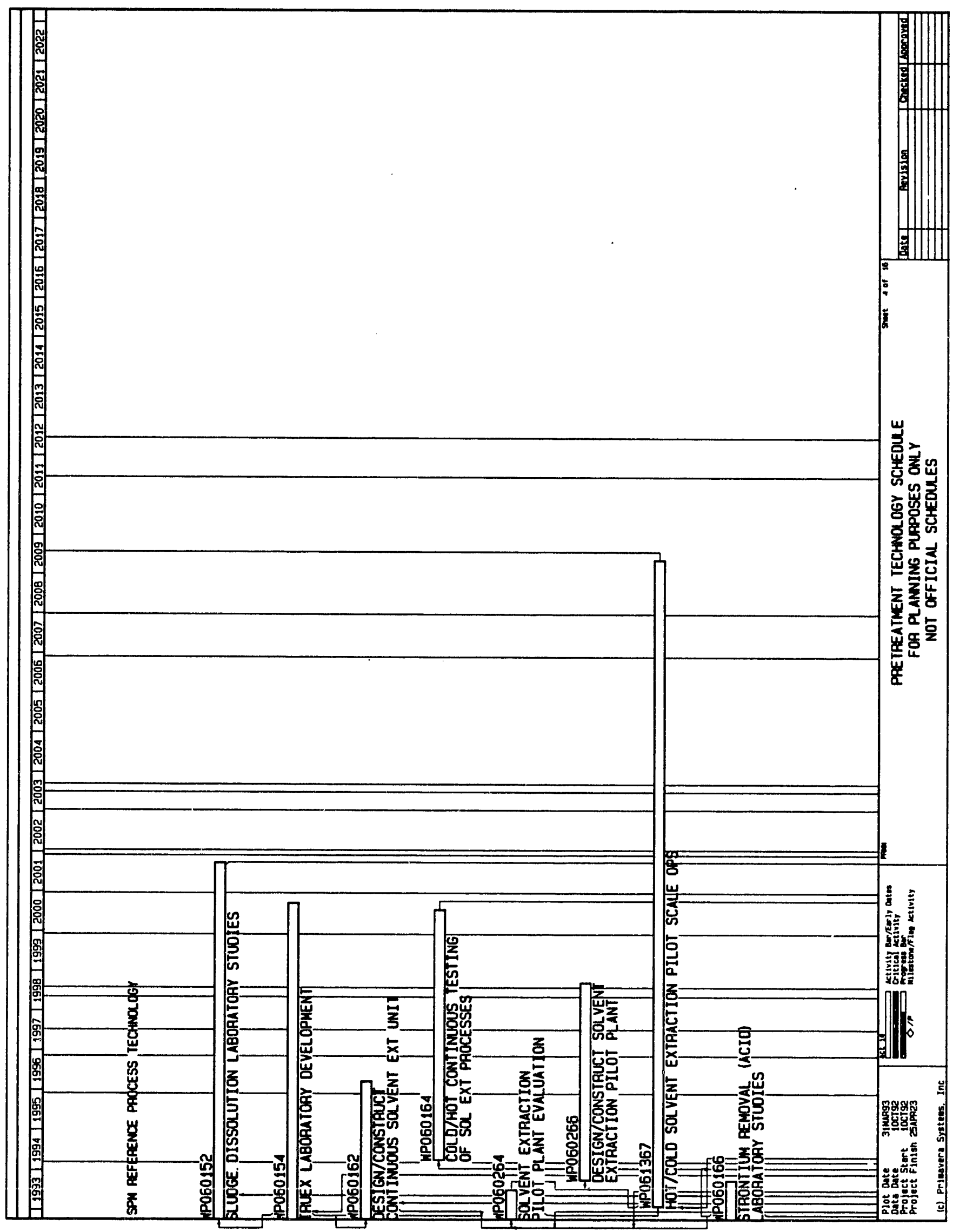

APP A-6 


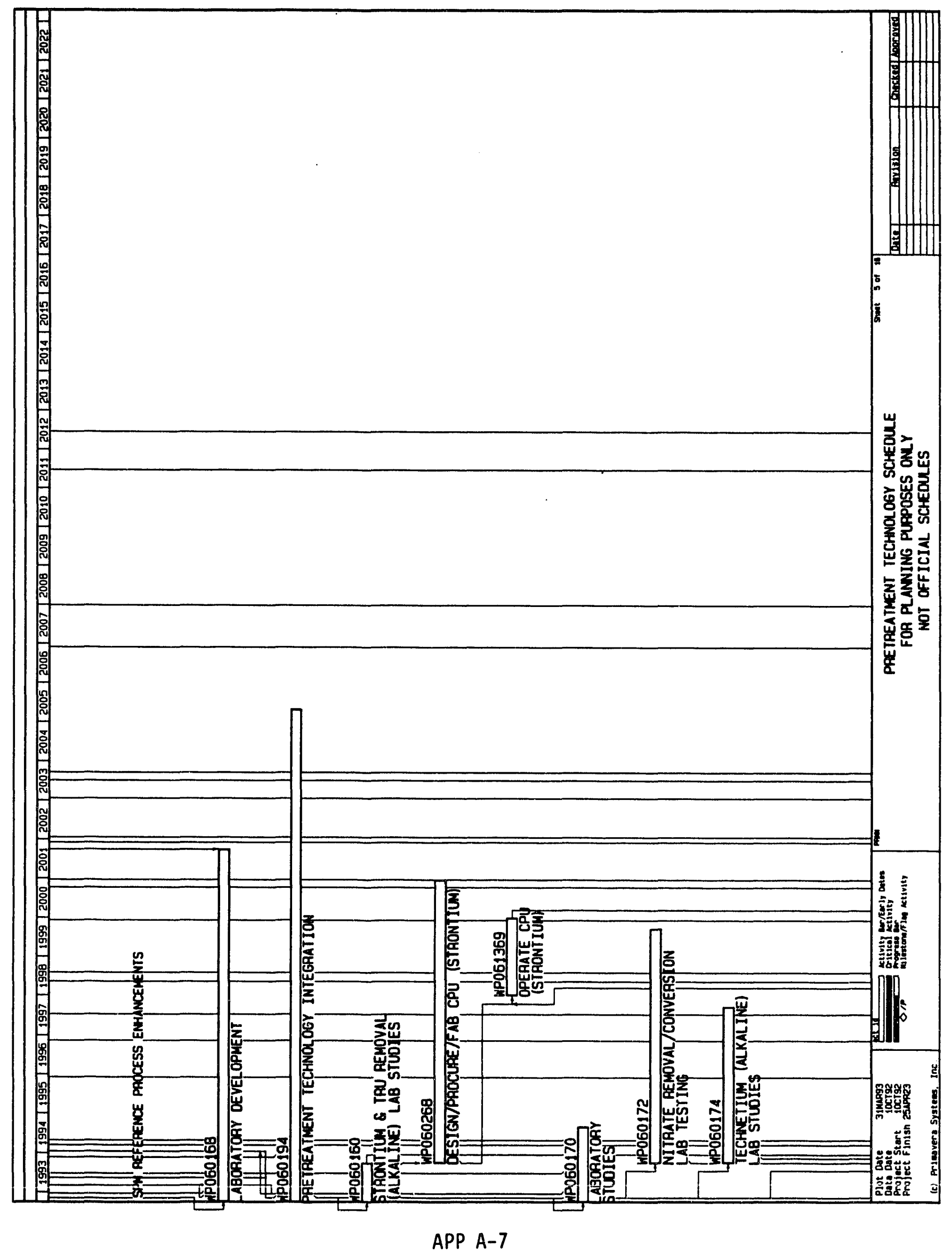


WHC-EP-0629

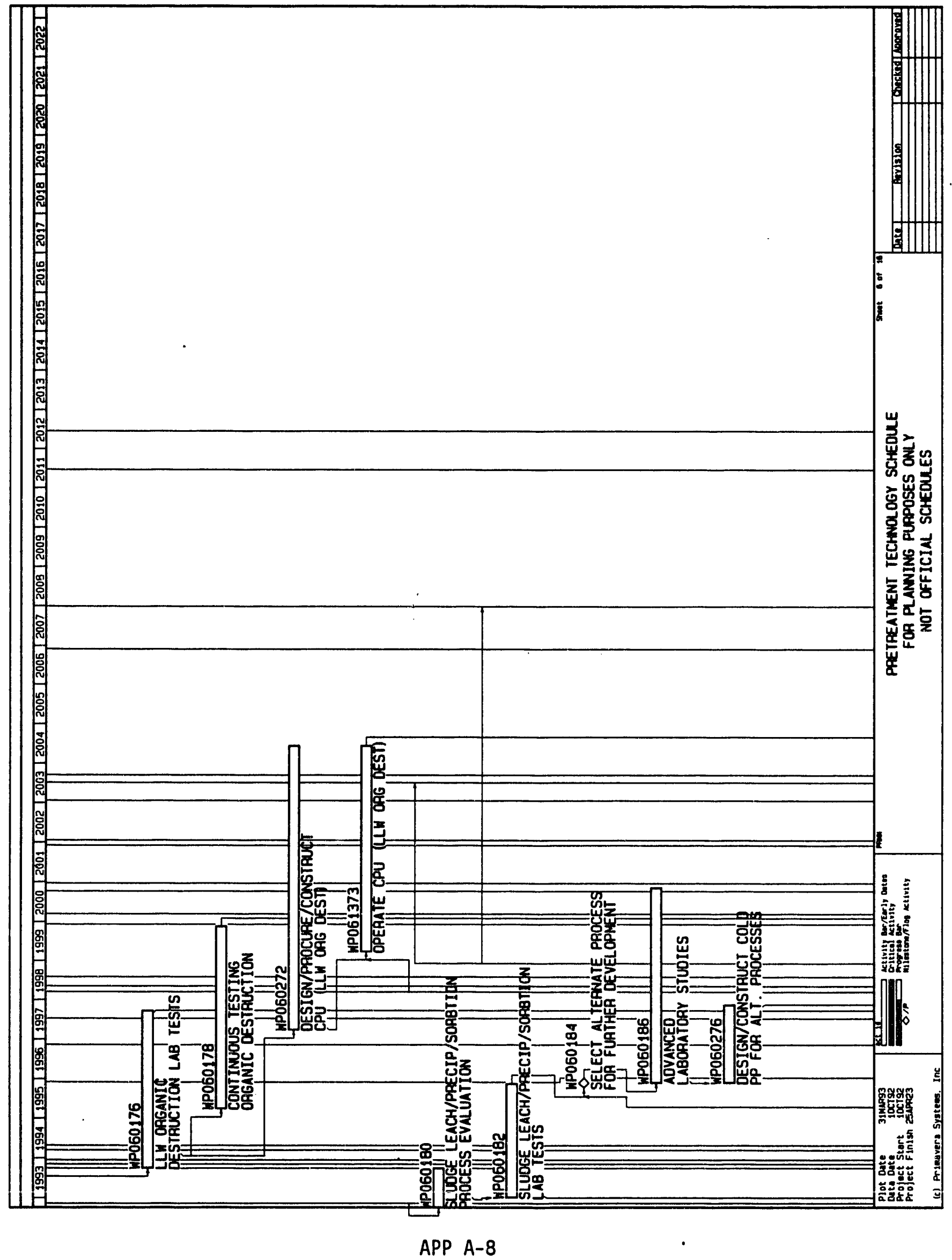


WHC-EP-0629

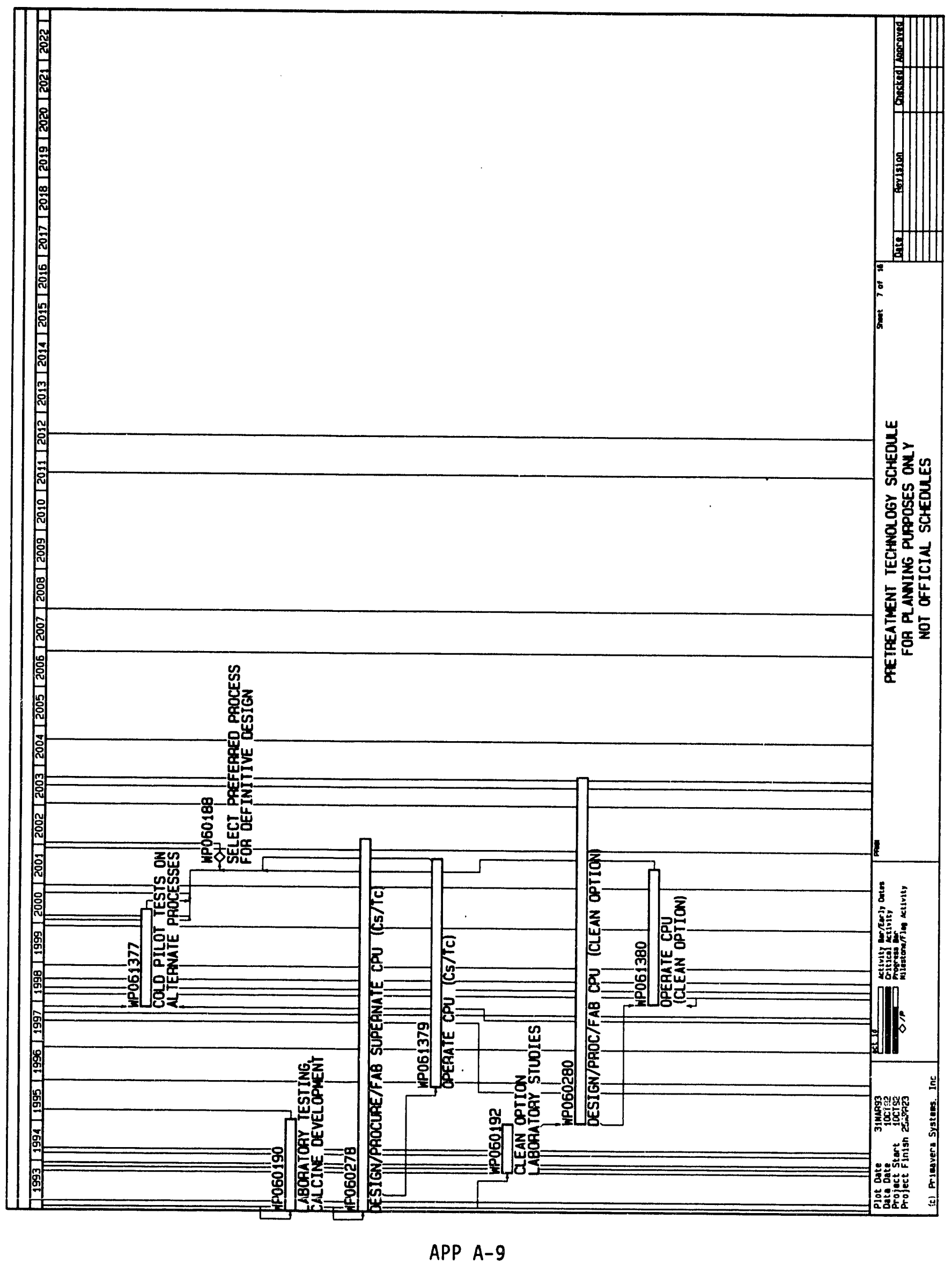


WHC-EP-0629




WHC-EP-0629

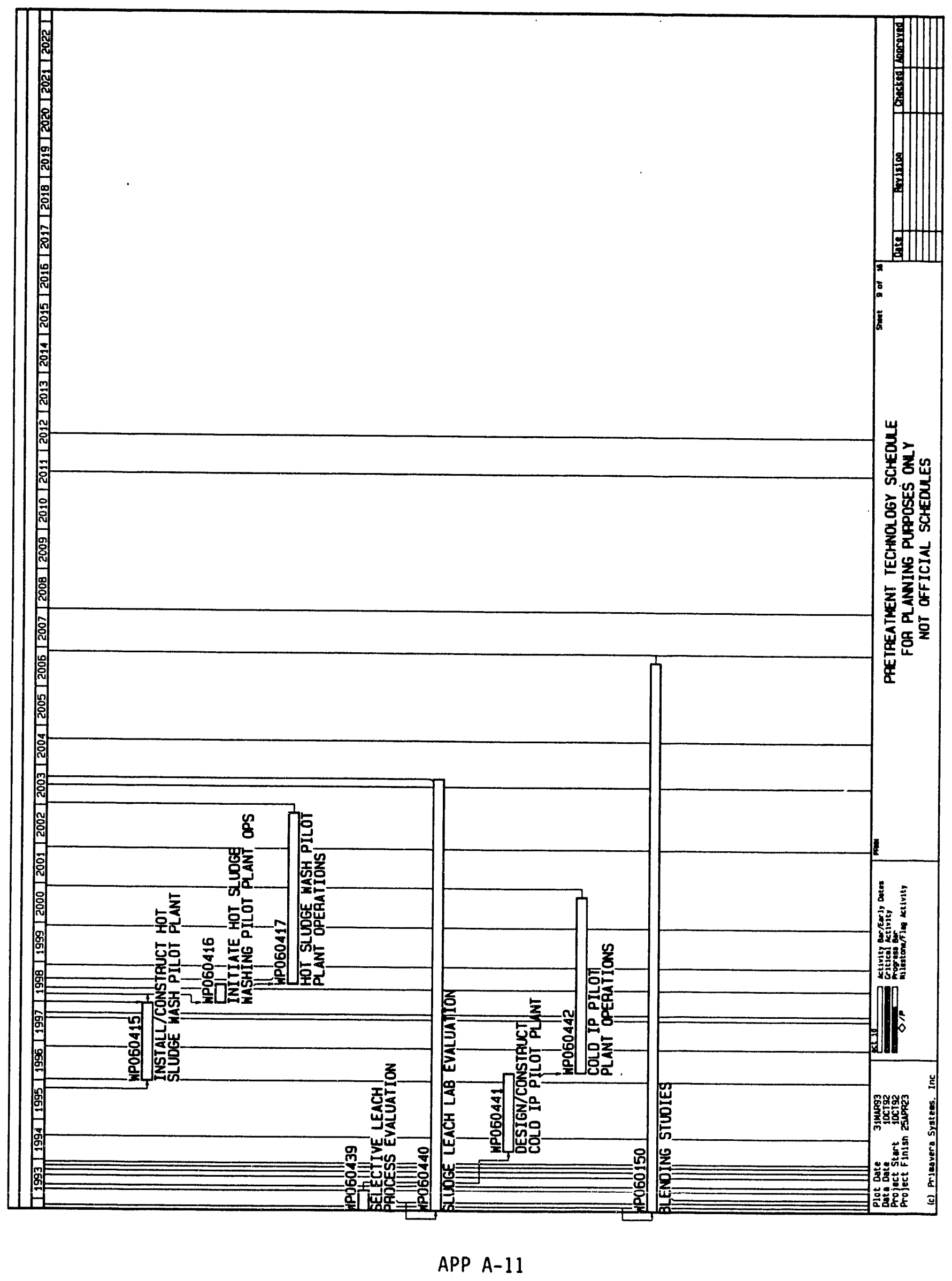


WHC-EP-0629

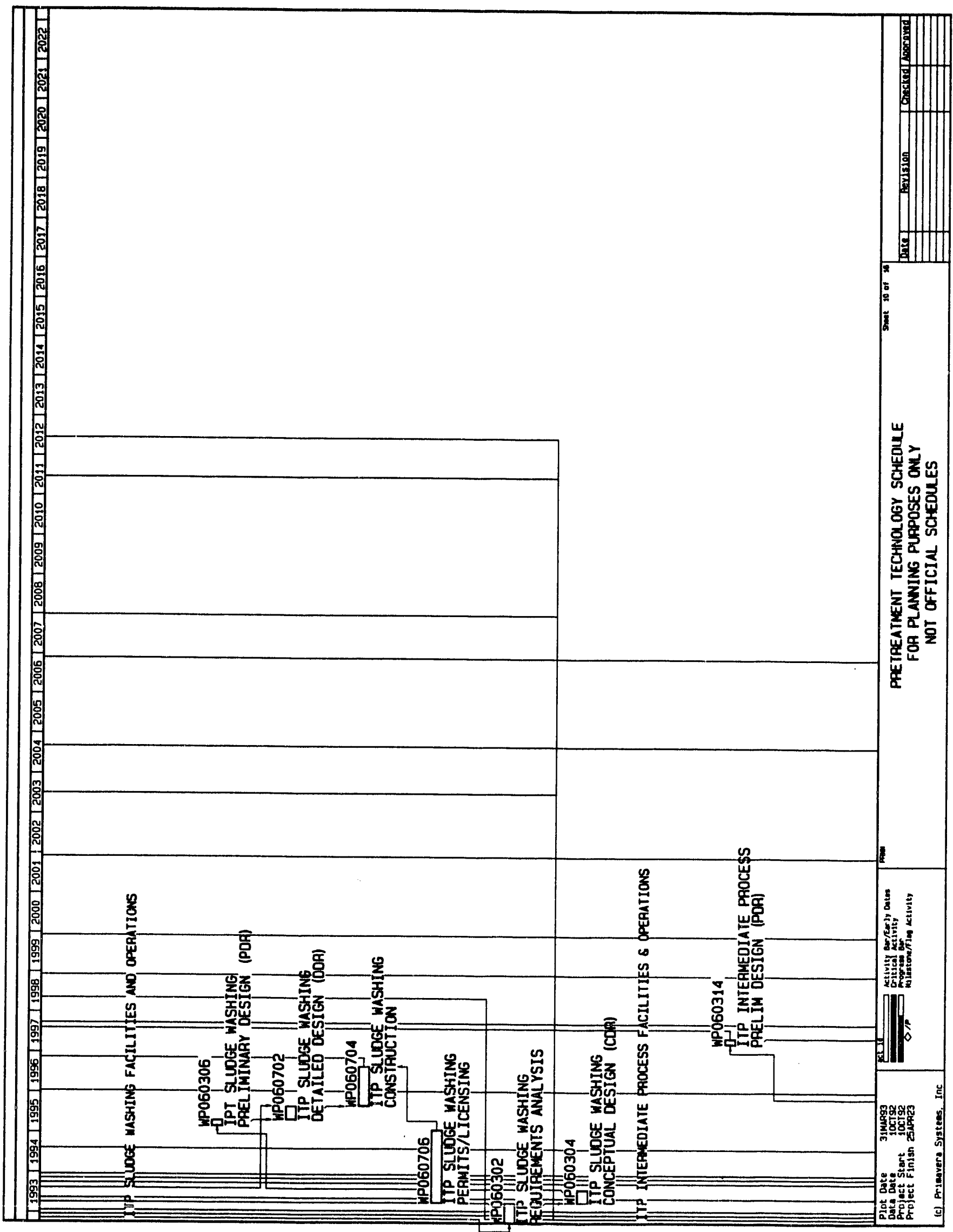


WHC-EP-0629

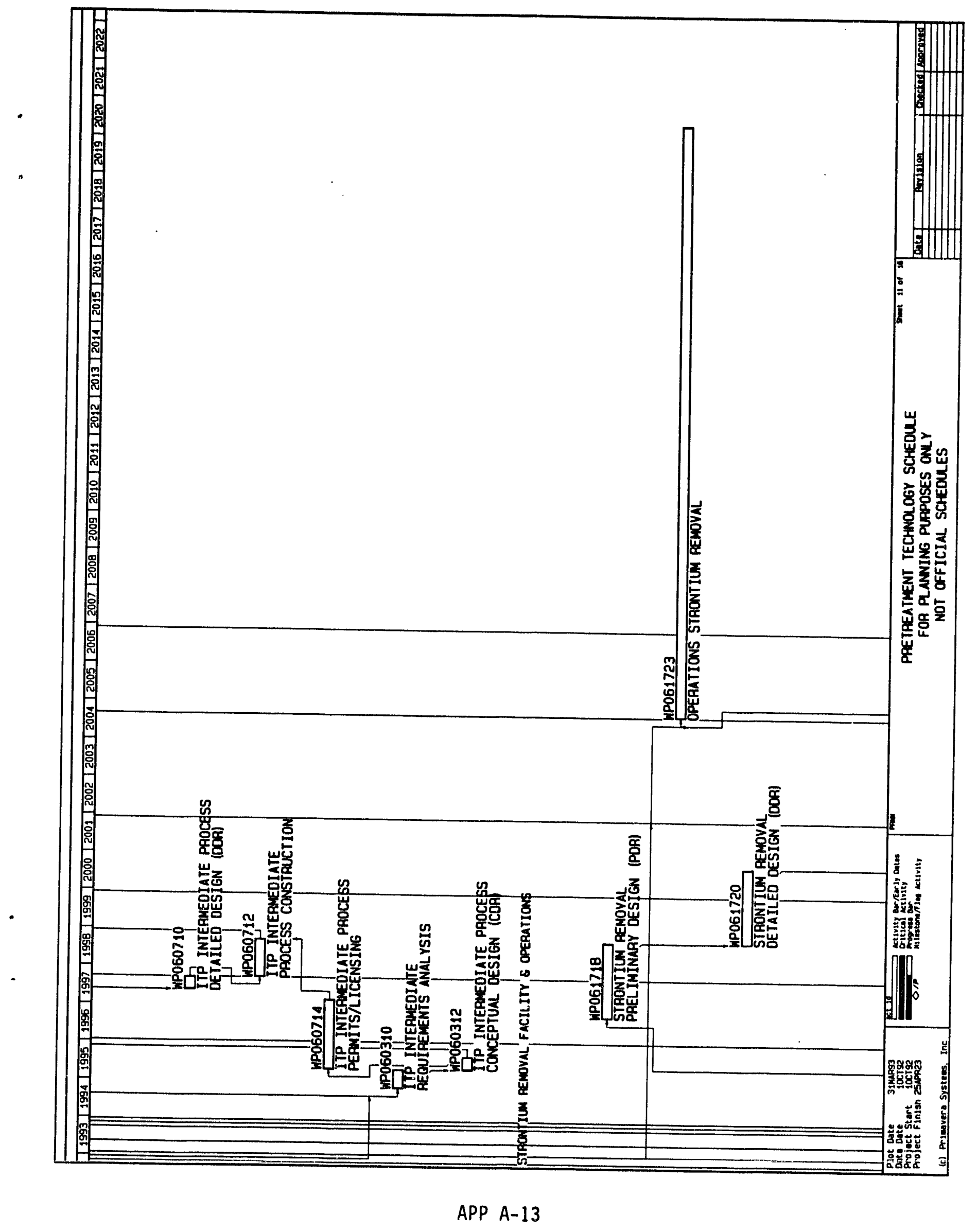


WHC-EP-0629

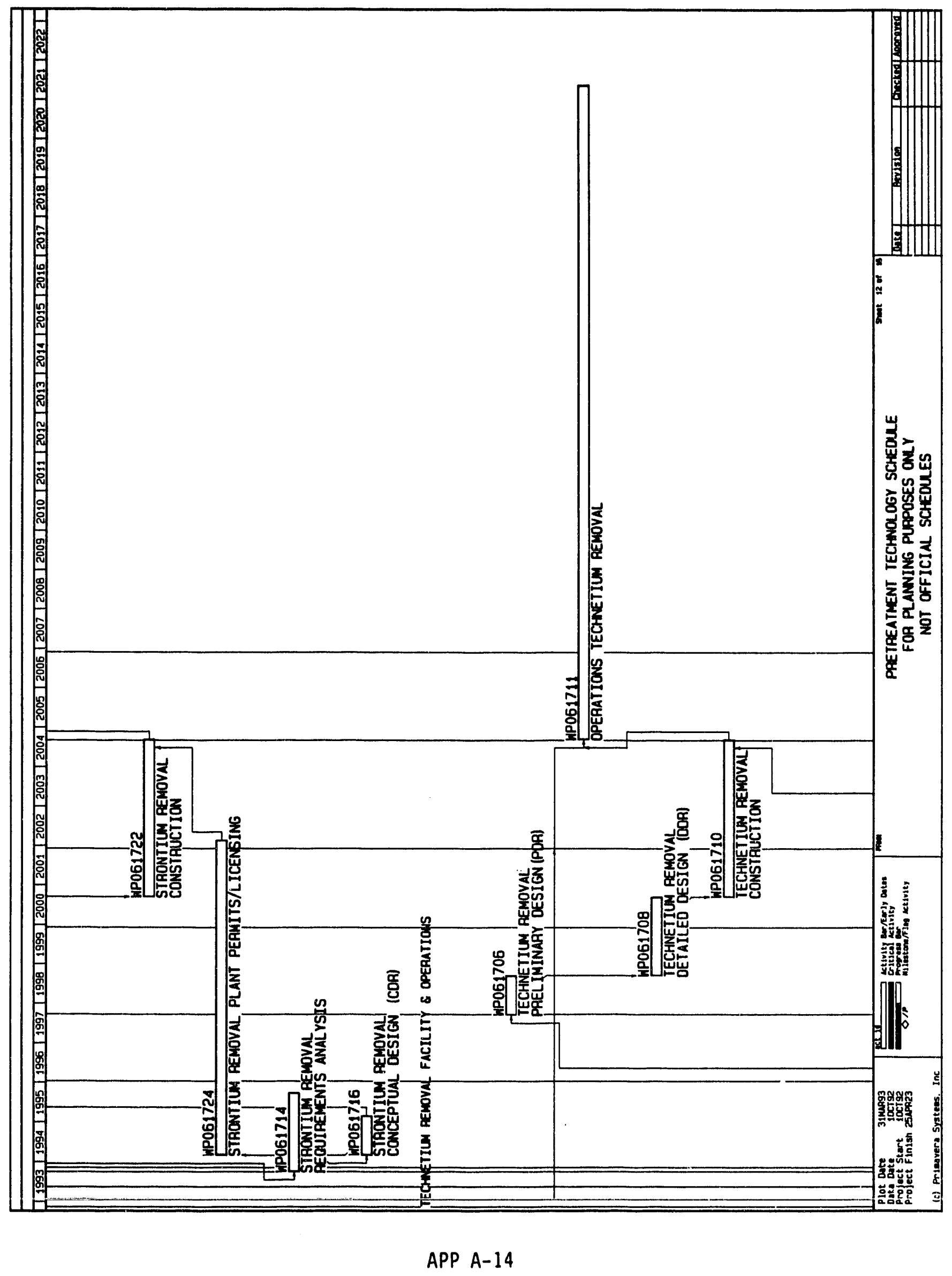


WHC-EP-0629




WHC-EP-0629

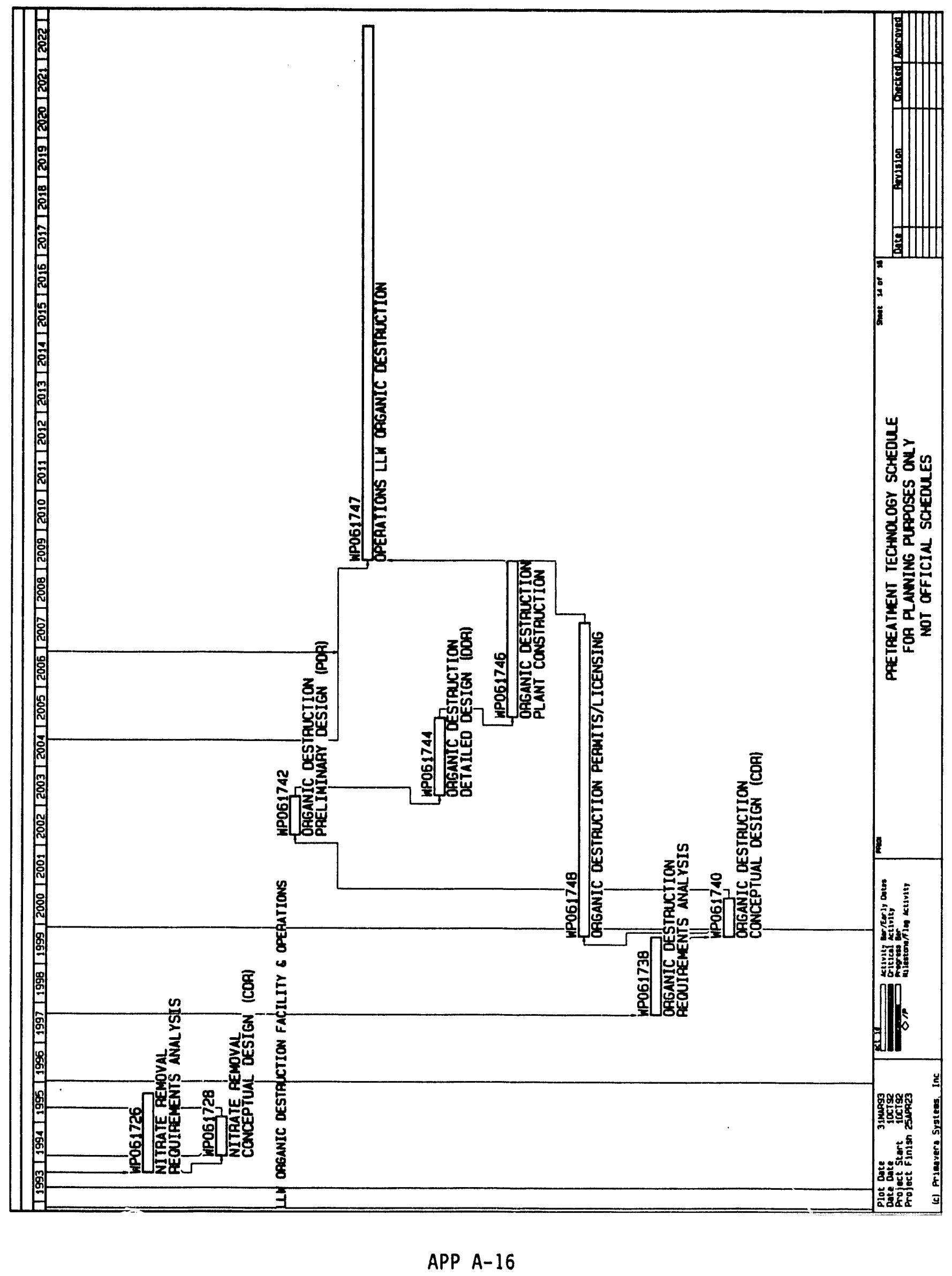


WHC-EP-0629

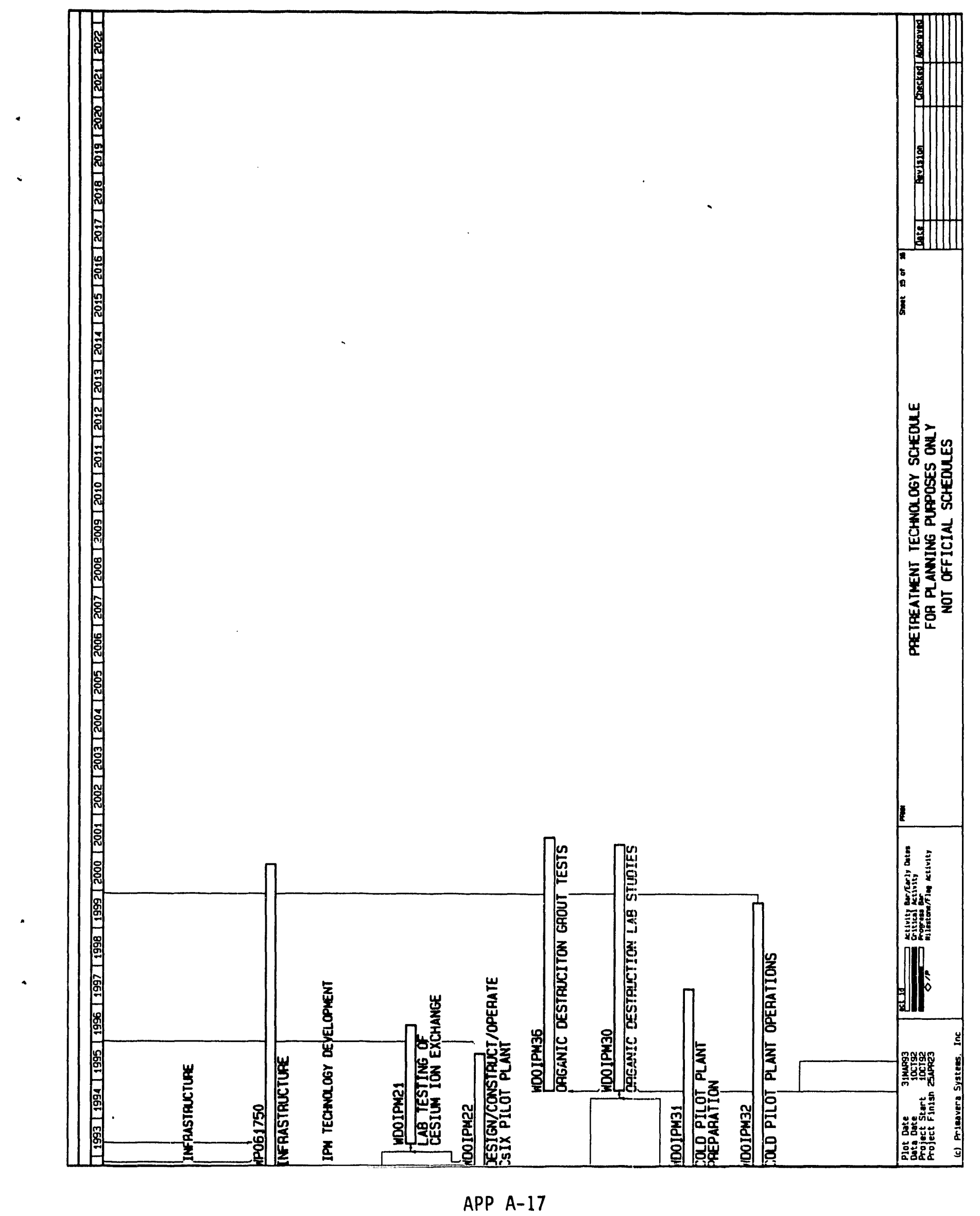


WHC-EP-0629

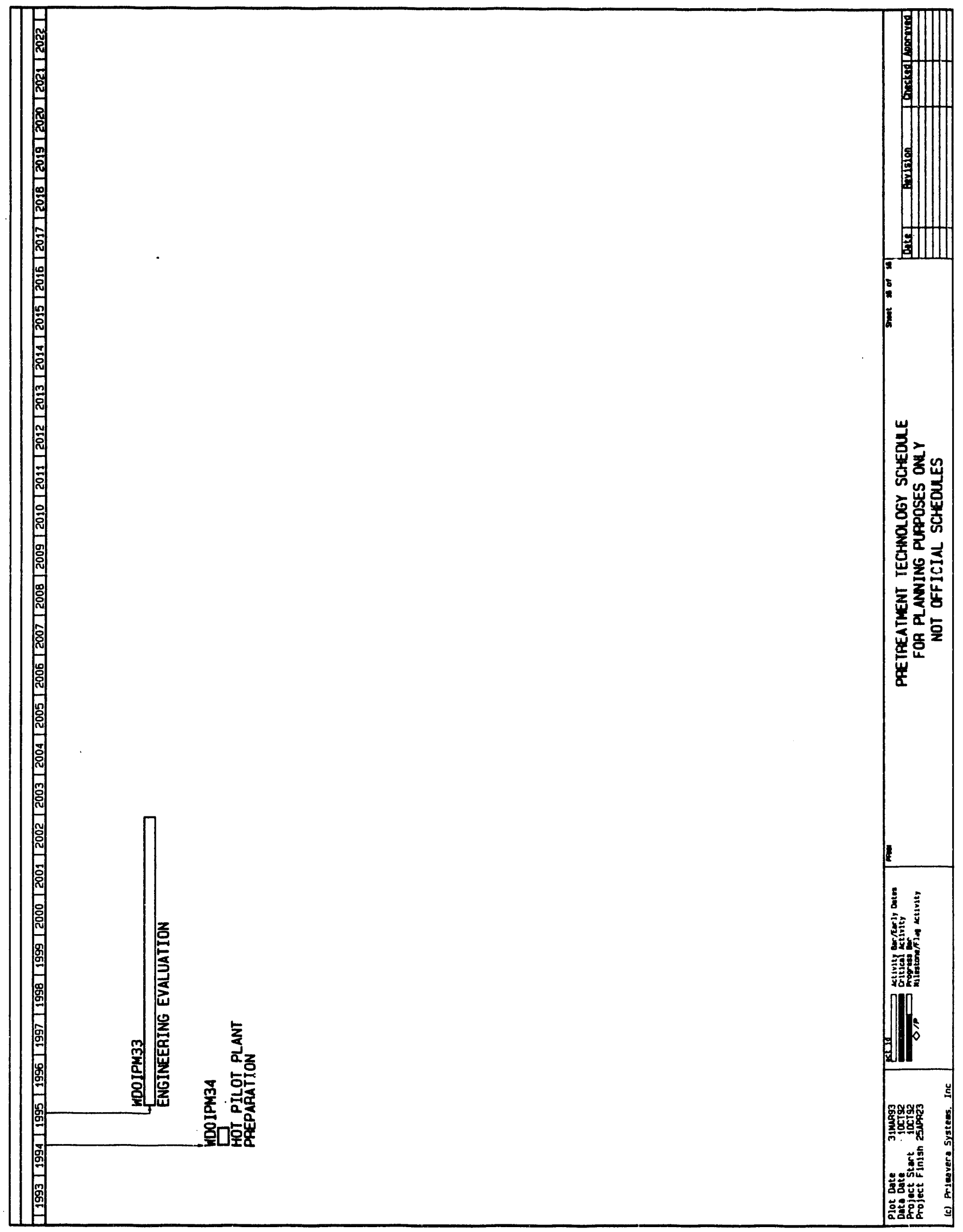


WHC-EP-0629

\section{DISTRIBUTION}

\section{Number of Copies}

\section{OFFSITE}

M. Attrep, Jr. (LANL)

Los Alamos National Laboratory

P.0. Box 1663

Los Alamos, NM 87545

J. T. Bell (ORNL)

Martin Marietta Energy Systems

P. 0. Box 2008

Oak Ridge, TN 37831-6223

1

L. Bustard (SNL)

Sandia National Lab

Dept. 6624

P.0 Box 5800

Albuquerque, NM 87185-5800

1

P. McGinnis (ORNL)

Martin Marietta Energy Systems

P. 0. Box 2008

Oak Ridge, TN 37831-6223

1

R. Nebeker (INEL)

Westinghouse Idaho Nuclear Company, Inc.

1955 Fremont Ave.

P.0. Box 4000, MS-5219

Idaho Falls, Idaho 83403-4000

1

K. Thomas (LANL)

Los Alamos National Laboratory

P.0. Box 1663

Los Alames, NM 87545

1

M. C. Thompson (SRS)

Westinghouse Savannah River Co.

Savannah River Technology Center

Building 773A, Room C140

Aiken, SC 29808

1

G. F. Vandegrift (ANL)

Argonne National Laboratory

Building 205

9700 South Cass Avenue

Argonne, IL 60439 
WHC-EP-0629

DISTRIBUTION (continued)

Number of Copies

OFFSITE

1

J. S. Watson (ORNL)

Mart in Marietta Energy Systems

P. 0. Box 2008

Oak Ridge, TN 37831-7298

1

H. Dewey (LANL)

Los Alamos National Laboratory

P.0. Box 1663

Los Alamos, NM 87545

ONSITE

19

U.S. Department of Energy Richland Field office

S. T. Burnum

A5-16

P. E. Lamont

A5-16

L. Erickson

J. C. Peschong (15)

$R$ L Public Reading Room

A5-16

A5-16

Al-65

27

Pacific Northwest Laboratory

R. M. Bean

P8-08

G. H. Beeman

K6-24

L. R. Bunnell

P8-44

C. D. Carlson

P7-25

J. A. Christensen

$\mathrm{K} 6-43$

J. M. rmeer

M. J. anielson

G6-01

L. L. Fassbender

P8-44

L. K. Holton (5)

K6-61

B. M. Johnson

P7 -43

E. 0 . Jones

$\mathrm{K} 1-78$

D. E. Kurath

P8-38

G. J. Lumetta

P7 -43

J. E. Rodriguez

P7 -25

P. A. Scott

K $7-73$

J. L. Straalsund

P7-19

D. M. Strachen

$\mathrm{K} 1-79$

J. E. Surma

C. K. Thornhill (3)

J. H. Westsick

K2-38

P7 -43

P7 -43

P7-19

PNL Technical Files

P8-55 
WHC-EP-0629

\section{DISTRIBUTION}

Number of Copies

41

Westinghouse Hanford Company

J. N. Appel

S4-58

S. A. Barker (10)

S4-55

W. B. Barton

L4-75

G. D. Bazinet

D. R. Bratzel

ᄂ4-71

E. A. Fredenburg

L5-31

R. L. Gilchrist

S4-55

G. Hansrote

J. M. Henderson

L5-63

J. J. Holmes

G6-12

S4-55

G. F. Howden

L5-55

L. L. Humphreys

S4 -57

R. A. Kirkbride

R2 -50

M. J. Klem

D. W. Lindsey

S4 -58

G. T. Maclean

S4-58

W. C. Miller

B2 -35

S4 -58

A. F. Noonan

BI -58

R. M. Orme

J. G. Propson

R2 -12

S4 -58

D. C. Richardson

$\mathrm{R} 2-18$

R2-31

P. S. Schaus

B1-59

M. J. Schliebe

S4 -25

E. J. Shen

J. P. Sloughter

$54-58$

J. A. Voogd

T6-07

E. T. Weber

R4-03

D. D. Wodrich

G6-08

Central Files

Bl-59

Information Release

Adminstration (3)

L8-04

RI -08 
WHC-EP-0629

This page intentionally left blank. 


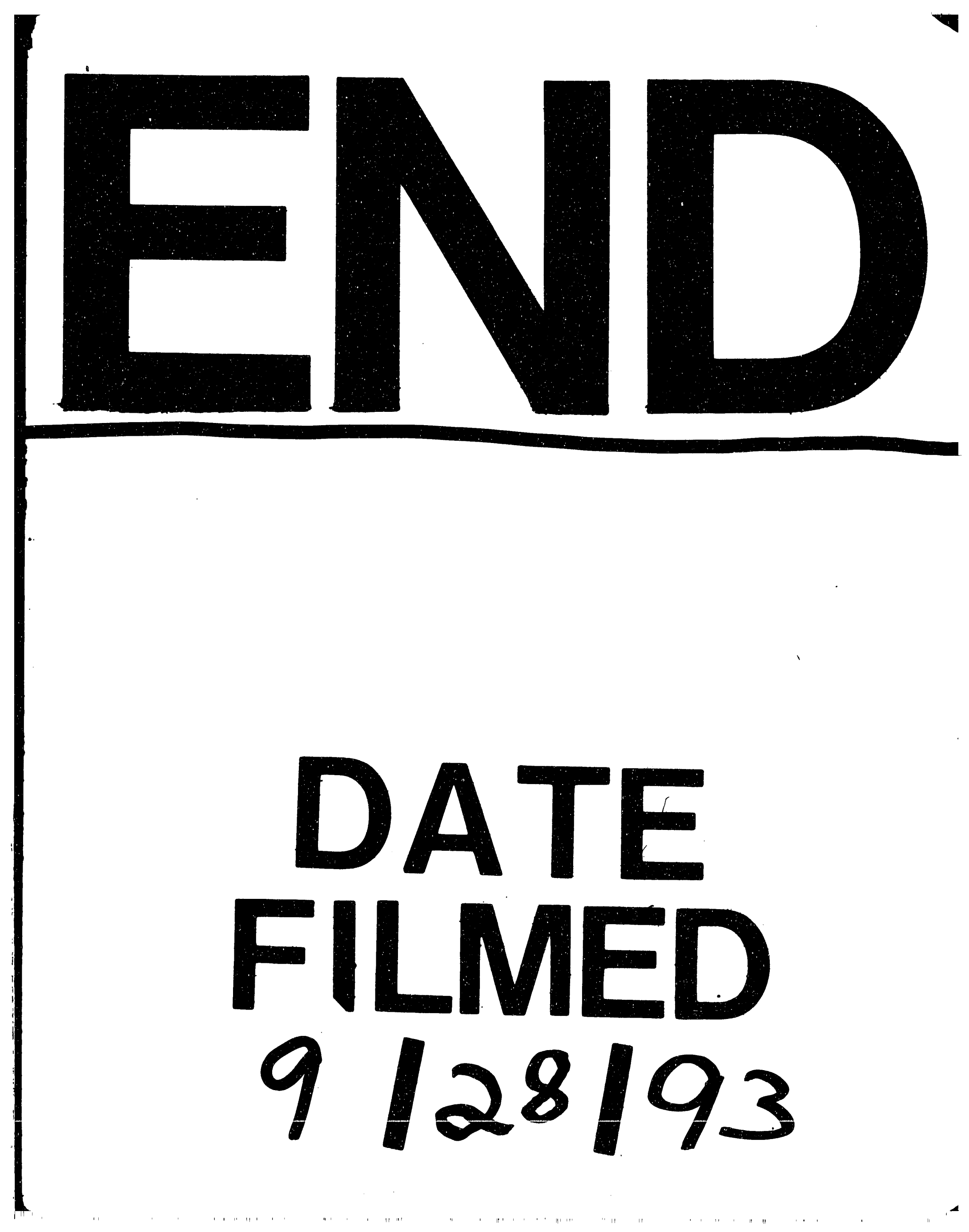


$+$ 